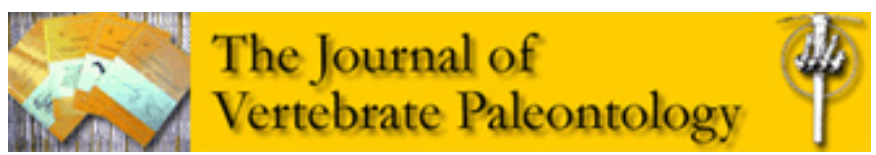

\title{
Osteology of the wide-hipped titanosaurian sauropod dinosaur Savannasaurus elliottorum from the Upper Cretaceous Winton Formation of Queensland, Australia
}

\begin{tabular}{|r|l|}
\hline Journal: & Journal of Vertebrate Paleontology \\
\hline Manuscript ID & JVP-2019-0164.R1 \\
\hline Danuscript Type: & Article \\
\hline Author: & $17-$ Apr-2020 \\
\hline Complete List of Authors: & $\begin{array}{l}\text { Poropat, Stephen; Swinburne University of Technology, Faculty of } \\
\text { Science, Engineering and Technology; Australian Age of Dinosaurs } \\
\text { Natural History Museum, } \\
\text { Mannion, Philip; University College London, Earth Sciences } \\
\text { Upchurch, Paul; University College London, Earth Sciences; } \\
\text { Tischler, Travis; Australian Age of Dinosaurs Natural History Museum, } \\
\text { Sloan, Trish; Australian Age of Dinosaurs Natural History Museum, } \\
\text { Sinapius, George; Australian Age of Dinosaurs Natural History Museum, } \\
\text { Elliott, Judy; Australian Age of Dinosaurs Natural History Museum, } \\
\text { Elliott, David; Australian Age of Dinosaurs Museum of Natural History, } \\
\text { Palaeontology }\end{array}$ \\
\hline Key Words: & $\begin{array}{l}\text { Gondwana, Somphospondyli, Titanosauriformes, Macronaria, Eromanga } \\
\text { Basin, Mesozoic }\end{array}$ \\
\hline
\end{tabular}

\section{SCHOLARONE" Manuscripts}


1 Osteology of the wide-hipped titanosaurian sauropod dinosaur Savannasaurus elliottorum from the Upper Cretaceous Winton Formation of Queensland, Australia

3

4

STEPHEN F. POROPAT $,{ }^{*}, 1,2$ PHILIP D. MANNION, ${ }^{3}$ PAUL UPCHURCH,${ }^{3}$ TRAVIS R.

5 TISCHLER, ${ }^{2}$ TRISH SLOAN, ${ }^{2}$ GEORGE H. K. SINAPIUS, ${ }^{2}$ JUDY A. ELLIOTT, ${ }^{2}$ and 6 DAVID A. ELLIOTT ${ }^{2}$

7

$8 \quad{ }^{1}$ Faculty of Science, Engineering and Technology, Swinburne University of Technology, John Street, Hawthorn, Victoria 3122, Australia; sporopat@swin.edu.au

${ }^{2}$ Australian Age of Dinosaurs Museum of Natural History, The Jump-Up, Winton, 11 Queensland 4735, Australia; stephenfporopat@gmail.com; travisr.tischler@outlook.com; trish.sloan@aaod.com.au; laboratory@aaod.com.au; judy.elliott@aaod.com.au; david.elliott@aaod.com.au

14 3epartment of Earth Sciences, University College London, Gower Street, London WC1E 15 6BT, United Kingdom; philipdmannion@gmail.com; p.upchurch@ucl.ac.uk

17 RH: POROPAT ET AL.-SAVANNASAURUS ELLIOTTORUM OSTEOLOGY

18

*Corresponding author 
19 ABSTRACT - The titanosaurian sauropod dinosaur Savannasaurus elliottorum is represented by a partial postcranial skeleton from the lower Upper Cretaceous (Cenomanian-

21 lowermost Turonian) Winton Formation of Queensland, northeast Australia. Here, we present 22 a detailed description of this specimen, as well as an emended diagnosis of Savannasaurus 23 elliottorum. Savannasaurus displays numerous character states that are generally regarded as 24 plesiomorphic for Titanosauria, as well as several traits that are often regarded as apomorphic 25 of that clade or a less inclusive subset thereof. Several features of Savannasaurus support a 26 close relationship with the coeval Diamantinasaurus matildae, and this clade appears to 27 occupy an early-branching position within Titanosauria. Relative to body size, the thoracic 28 and abdominal breadth of Savannasaurus is greater than that seen in giant titanosaurs such as 29 the contemporaneous South American lognkosaurians; however, this relative breadth is not 30 quite as extreme as that of the small-bodied latest Cretaceous saltasaurines, or 31 Opisthocoelicaudia skarzynskii. The possible advantages engendered by the barrel-shaped 32 thorax, robust limbs, wide-gauge gait, and lack of hyposphene-hypantrum articulations are 33 explored, and it is hypothesised that these traits were positively selected by the wet, 34 temperate floodplain environment in which Savannasaurus lived. Greater stability and 35 flexibility might have reduced the risk of bogging, and/or facilitated more expedient self36 extraction from muddy waterholes. Similar environmental pressures acting upon other 37 titanosaurian taxa or clades elsewhere might have led to the repeated independent 38 development, or accentuation, of the bauplan regarded as 'typical' for the clade Titanosauria.

39 This would explain the many observed convergences between Savannasaurus and 40 Diamantinasaurus, and Saltasauridae. 
43 Cretaceous sedimentary sequences in Australia have mostly provided only limited

44 evidence of sauropod dinosaurs. The Western Australian Cretaceous record is restricted to

45 footprints from the Valanginian-Barremian Broome Sandstone (Thulborn et al., 1994;

46 Thulborn, 2012; Salisbury et al., 2017), whereas the Victorian Cretaceous sauropod record is

47 non-existent: both the upper Strzelecki Group (upper Barremian-lower Aptian) and the

48 Eumeralla Formation (upper Aptian-lower Albian) entirely lack sauropods, despite

49 preserving abundant remains of ornithopods, ankylosaurs, and theropods (Poropat et al.,

50 2018). The upper Albian Toolebuc Formation of Queensland has produced several

51 fragmentary sauropod specimens (Molnar and Salisbury, 2005), whereas the upper Albian

52 Allaru Mudstone has yielded only one: the holotype of the somphospondylan titanosauriform

53 Austrosaurus mckillopi (Longman, 1933; Poropat et al., 2017). The Cenomanian Griman

54 Creek Formation in New South Wales has produced sauropod teeth (Molnar and Salisbury,

55 2005), whereas the same unit in Queensland has yielded only fragmentary postcranial

56 elements (Molnar, 2011b).

57 By far the most productive Australian Cretaceous stratum in terms of sauropods is the 58 Cenomanian-lowermost Turonian 'upper' Winton Formation of Queensland (Coombs and 59 Molnar, 1981; Molnar, 2001, 2010, 2011a; Molnar and Salisbury, 2005), which is also the 60 stratigraphically youngest sauropod-bearing unit in Australia. To date, three 61 somphospondylan titanosauriforms have been named from this unit: the non-titanosaurian 62 Wintonotitan wattsi (Hocknull et al., 2009; Poropat et al., 2015a), and the titanosaurs 63 Diamantinasaurus matildae (Hocknull et al., 2009; Poropat et al., 2015b, 2016; Klinkhamer 64 et al., 2018, 2019) and Savannasaurus elliottorum (Poropat et al., 2016). The osteology of 65 both Wintonotitan and Diamantinasaurus has recently been described in detail (Poropat et al., $662015 \mathrm{a}, \mathrm{b}$ ), whereas that of Savannasaurus has only been addressed briefly (Poropat et al., 
67 2016). In this paper, we fully describe the osteology of the holotype and only known

68

69 specimen of Savannasaurus elliottorum.

Institutional Abbreviations-AAOD, Australian Age of Dinosaurs Museum of Natural History (Winton, Queensland, Australia); AODF, Australian Age of Dinosaurs Fossil; 41H III, Henan Geological Museum, Zhengzhou, Henan Province, China; MACN, Museo Argentino de Ciencias Naturales 'Bernardino Rivadavia', Buenos Aires, Argentina; MAUPV, Museo Municipal “Argentino Urquiza” (Rincón de los Sauces, Neuquén, Argentina); MCT, Museu de Ciências da Terra, Rio de Janeiro, Brazil; MPEF, Museo Paleontológico Egidio Feruglio, Trelew, Argentina; QM, Queensland Museum (Brisbane, Queensland, Australia); UNPSJB-PV, Universidad Nacional de la Patagonia ‘San Juan Bosco’ — Paleovertebrados, Comodoro Rivadavia, Argentina.

Anatomical Abbreviations-ACDL, anterior centrodiapophyseal lamina; ACPL, anterior centroparapophyseal lamina; aSPDL, anterior spinodiapophyseal lamina; CDF, centrodiapophyseal fossa; CPAF, centroparapophyseal fossa; CPOF, centropostzygapophyseal fossa; CPOL, centropostzygapophyseal lamina; CPRF, centroprezygapophyseal fossa; CPRL, centroprezygapophyseal lamina; dp, diapophysis; dPCPL, dorsal posterior centroparapophyseal lamina; ICPRL, lateral centroprezygapophyseal lamina; mCPRL, medial centroprezygapophyseal lamina; PACDF, parapophyseal centrodiapophyseal fossa; PACPRF, parapophyseal centroprezygapophyseal fossa; PCDL, posterior centrodiapophyseal lamina; PCPL, posterior centroparapophyseal lamina; POCDF, postzygapophyseal centrodiapophyseal fossa; PODL, postzygodiapophyseal lamina; POSDF, postzygapophyseal spinodiapophyseal fossa; POSL, postspinal lamina; poz, postzygapophysis; pp, parapophysis; PPDL, parapodiapophyseal 
91 lamina; PRDL, prezygodiapophyseal lamina; PRPADF, prezygapophyseal

92 parapodiapophyseal fossa; PRPL, prezygoparapophyseal lamina; PRSDF, prezygapophyseal

93 spinodiapophyseal fossa; PRSL, prespinal lamina; pSPDL, posterior spinodiapophyseal

94 lamina; SDF, spinodiapophyseal fossa; SPDL, spinodiapophyseal lamina; SPDL-F,

95 spinodiapophyseal lamina fossa; SPOF, spinopostzygapophyseal fossa; SPOL,

96 spinopostzygapophyseal lamina; SPRF, spinoprezygapophyseal fossa; SPRL,

97 spinoprezygapophyseal lamina; TPOL, interpostzygapophyseal lamina; TPRL,

98 interprezygapophyseal lamina; vPCPL, ventral posterior centroparapophyseal lamina.

GEOLOGICAL SETTING AND ASSOCIATED PALEOBIOTA

101

102

The holotype specimen of Savannasaurus elliottorum was preserved in the Cenomanian-

103 lowermost Turonian (Tucker et al., 2013) 'upper’ Winton Formation (Fig. 1), the

104 stratigraphically youngest Mesozoic unit in the Eromanga Basin (Dunstan, 1916;

105 Whitehouse, 1954; Vine and Day, 1965; Exon and Senior, 1976). The sedimentology of the

106 Winton Formation is variable, consisting of interbedded mudstones, siltstones, and

107 sandstones, with rare intraformational conglomerates (Exon and Senior, 1976; Senior and

108 Mabbutt, 1979; Gray et al., 2002; Tucker et al., 2017). Mica, pyrite, gypsum, coal, other

109 carbonaceous material, and wood fragments are all present in varying quantities (Gray et al.,

110 2002). On the basis of its geology, flora and fauna, the 'upper' Winton Formation has been

111 interpreted to have been deposited in a freshwater setting, likely a floodplain dominated by

112 meandering river systems (Fletcher et al., 2018). The climate was seasonal, with high annual

113 rainfall (Fletcher et al., 2014b). 
114 In addition to the aforementioned sauropods (Fig. 2), other dinosaurs represented in the

115 'upper' Winton Formation by body fossils are the megaraptorid theropod Australovenator

116 wintonensis (Hocknull et al., 2009; White et al., 2012, 2013, 2015), an indeterminate

117 ankylosaur (Leahey and Salisbury, 2013), and a small, indeterminate ornithopod (Hocknull

118 and Cook, 2008). Fossil footprints from Dinosaur Stampede National Monument at Lark

119 Quarry Conservation Park site have been interpreted as representing both ornithopods and

120 theropods (Thulborn and Wade, 1979, 1984; Thulborn, 2013, 2017), or ornithopods only

121 (Romilio and Salisbury, 2011, 2014; Romilio et al., 2013).

122 Non-dinosaurian archosaurs from the 'upper' Winton Formation include the ornithocheirid

123 pterosaur Ferrodraco lentoni (Pentland et al., 2019) and undescribed pterosaur and

124 crocodyliform specimens (Hocknull et al., 2009), whereas the 'lower' Winton Formation has

125 yielded the neosuchian crocodyliform Isisfordia duncani (Salisbury et al., 2006; Turner and

126 Pritchard, 2015; Leite and Fortier, 2018). Although a turtle steinkern has been reported from

127 the Winton Formation (Molnar, 1991; Kear, 2016), this specimen might in fact derive from

128 the underlying Mackunda Formation (B. P. Kear, pers. comm.); regardless, turtles are

129 represented in the 'upper' Winton Formation by undescribed skeletal remains that might be

130 referable to Chelidae (Hocknull et al., 2009). A solitary vertebra from the 'upper' Winton

131 Formation, originally tentatively assigned to cf. Coniasaurus, within Dolichosauridae

132 (Scanlon and Hocknull, 2008), was more recently regarded as Varanoidea indet. (Kear,

133 2016). Metaceratodus wollastoni and Metaceratodus ellioti are the only two dipnoan species

134 known from the 'upper' Winton Formation, and tooth plates from both species have been

135 recovered from multiple localities (Kemp and Molnar, 1981; Kemp, 1997). The

136 actinopterygian Cladocyclus geddesi is represented by a single partial skeleton from the

137 'lower' Winton Formation (Berrell et al., 2014); an actinopterygian skeleton has also been

138 found in the 'upper' Winton Formation, but this remains undescribed (S.F.P., pers. obs.). 
139 Invertebrate fossils are relatively rare in the 'upper' Winton Formation, with only the

140 freshwater bivalves Megalovirgus wintonensis, Hyridella macmichaeli (designated Prohyria

141 macmichaeli by Hocknull et al. (2009)), Hyridella goondiwindiensis, and Alathyria jaqueti

142 represented by large numbers of specimens in Queensland (Hocknull, 1997, 2000). Rare

143 gastropods (Melanoides sp.) have also been reported (Cook, 2005). Insect body fossils

144 pertaining to Odonata (dragonflies) and Mecoptera (scorpionflies) have been reported but not

145 described (Jell, 2004), and trace fossils attributed to oribatid mites have been identified in

146 silicified wood (Fletcher and Salisbury, 2014).

147 The fossil flora of the 'upper' Winton Formation is co-dominated by conifers (Peters and

148 Christophel, 1978; Dettmann et al., 2012) and angiosperms (McLoughlin et al., 1995;

149 Dettmann et al., 2009). Conifers include the cupressacean Austrosequoia wintonensis (Peters

150 and Christophel, 1978), the araucariaceans Araucaria cf. mesozoica (McLoughlin et al.,

151 1995) and Emwadea microcarpa (Dettmann et al., 2012), and the podocarpacean

152 Protophyllocladoxylon owensii (Fletcher et al., 2014a), whereas the angiosperms comprise

153 Lovellea wintonensis (Dettmann et al., 2009) and nine magnoliophyte forms left in open

154 nomenclature (McLoughlin et al., 1995, 2010). Ferns are also abundant and diverse in the

155 Winton Formation (McLoughlin et al., 2010), with Phyllopteroides macclymontae

156 (Osmundaceae; McLoughlin et al., 1995) and Tempskya judithae (Tempskyaceae; Clifford

157 and Dettmann, 2005) among the most notable. The liverwort Marchantites marguerita

158 (Dettmann and Clifford, 2000), the horsetail Equisetites sp. (McLoughlin et al., 2010), the

159 cycadalean Pterostoma hirsutus (Pole \& Douglas 1999), the bennettitaleans Otozamites cf.

160 bengalensis and Ptilophyllum sp. (McLoughlin et al., 2010), and the ginkgoalean Ginkgo

161 wintonensis (McLoughlin et al., 1995) round out the Winton Formation flora (Fletcher et al., 162 2018). 

EXCAVATION, POST-HOC SITE RECONSTRUCTION AND TAPHONOMY

The Savannasaurus elliottorum type site was discovered by one of the authors (D.A.E.) in

167 March 2005, and excavated in July and September of that year. Most of the specimen was

168 preserved within a large siltstone concretion, which was broken up with jackhammers and

169 chisels along naturally occurring, gypsum-filled fractures. Prior to extraction from the site,

170 each siltstone fragment was assigned a number so that broken specimens could be easily put

171 back together after preparation. Although a third excavation in September 2006 yielded no

172 additional specimens, surface collection of the site in 2013 produced a partial caudal centrum

173 and other fragments.

174 Mechanical preparation of the Savannasaurus elliottorum type specimen (Fig. 3A) was

175 conducted using tungsten carbide-tipped pneumatic air scribes and micro-jacks. Once

176 prepared, joining surfaces between fragments were marked with paint pens, and superglue

177 and araldite were used to piece individual elements back together. The markings made on

178 each specimen were also used to determine their relative positions in the site. Post hoc

179 reconstruction of the site involved physical reassembly of various sections. Photogrammetric

180 models of the upper and lower surfaces of each site section were generated in AgiSoft

181 PhotoScan, and these were stitched together in Rhinoceros 4.0 to form complete three-

182 dimensional models of each site component. These were then arranged (using field notes and

183 known points of inter-specimen contact) to produce a three-dimensional digital site map (Fig.

$1843 \mathrm{~B}-\mathrm{C})$.

185 The dorsal vertebrae of Savannasaurus were not articulated, but were in association

186 immediately in front of the pelvic girdle. The posteriormost dorsal vertebrae were situated

187 closer to the pelvic girdle than the more anterior dorsal vertebrae, which expedited 
188 determination of the vertebral sequence. Ribs were present on both sides of the dorsal series,

189 although all were fragmented (mostly post-fossilisation), and those on the left side were

190 crushed prior to fossilisation. The sacrum was situated above, but rotated relative to, the

191 fused pubes and ischia. The sternal plates and coracoid were found in association with the

192 radius, dorsal ribs and the fragmentary (presumed) scapula. Left metacarpals III-V were

193 positioned above dorsal vertebra III, whereas the left humerus was found to the left side of

194 the dorsal series. Other remains were not found in contact, but all were restricted to an area of 195 less than $20 \mathrm{~m}^{2}$.

196 Although no bite marks have been identified on the Savannasaurus elliottorum holotype, a 197 single tooth (AODF 819) referable to Australovenator wintonensis was recovered from the 198 site (White et al., 2015). It is likely, therefore, that the disarticulation of the Savannasaurus 199 elliottorum type specimen was partly a result of feeding by megaraptorid theropods. Some 200 elements (e.g. dorsal vertebra V, both humeri) appear to have been trampled post mortem; 201 this implies that other dinosaurs (most likely sauropods) traversed the site after at least partial 202 burial of the carcass (pre-fossilisation), and that they also contributed to the scattering of the 203 bones.

204 The Savannasaurus elliottorum holotype specimen was significantly less scattered than 205 most other dinosaur specimens recovered from the 'upper' Winton Formation, including the 206 type specimens of Wintonotitan wattsi (Poropat et al., 2015a: fig. 3), and Diamantinasaurus 207 matildae and Australovenator wintonensis (Hocknull et al., 2009; Poropat et al., 2015b: fig.

208 3). The only articulated vertebrate specimens reported from the Winton Formation to date are 209 those of the crocodyliform Isisfordia duncani (Salisbury et al., 2006: fig. 2) and the 210 actinopterygian fish Cladocyclus geddesi (Berrell et al., 2014: fig. 3), both of which were 211 preserved in ex situ sandstone concretions (Syme et al., 2016; Syme and Salisbury, 2018) in 212 the 'lower' Winton Formation (Tucker et al., 2017). 
SYSTEMATIC PALEONTOLOGY

215

216

SAUROPODA Marsh, 1878

MACRONARIA Wilson and Sereno, 1998

218

TITANOSAURIFORMES Salgado, Coria and Calvo, 1997

219

SOMPHOSPONDYLI Wilson and Sereno, 1998

220

TITANOSAURIA Bonaparte and Coria, 1993

221

SAVANNASAURUS ELLIOTTORUM Poropat et al., 2016

222

223 Holotype-AODF 660 - one posterior cervical vertebra; several cervical ribs; dorsal

224 vertebrae III-X; several fragmentary dorsal ribs; at least four coalesced sacral vertebrae with

225 processes; at least five partial caudal vertebrae; fragmentary scapula; left coracoid; left and

226 right sternal plates; incomplete left and right humeri; fragmentary ulna; left radius; left

227 metacarpals I-V; right metacarpal IV; two manual phalanges; iliac fragments; co-ossified left

228 and right pubes and ischia; left astragalus; right metatarsal III; and associated fragments.

229 Type Locality-AODL 82 (the 'Ho-Hum' Site), Belmont Station, $\sim 60 \mathrm{~km}$ northeast of 230 Winton, Queensland, Australia.

231 Type Stratum - Winton Formation; Cenomanian-lowermost Turonian, Upper

232 Cretaceous. 
233 Diagnosis - The following characters are considered to be autapomorphies of

234 Savannasaurus elliottorum: 1) undulating anterior articular surface of anterior caudal

235 vertebral centra (concave dorsally and convex ventrally); 2) anterior-most caudal centra with

236 shallow lateral pneumatic fossae (local autapomorphy within Somphospondyli); 3) sternal

237 plate with straight lateral margin (reversal); 4) sternal plate lacking anteroposteriorly elongate

238 ridge along the anterior portion of the ventral surface (local autapomorphy within

239 Titanosauria); 5) metacarpal IV distal end hourglass-shaped; 6) pubis with ridge extending

240 anteroventrally from ventral margin of obturator foramen on lateral surface; 7) ischium with

241 proximal plate anteroposterior length $>40 \%$ the overall proximodistal length of the element;

242 8) astragalus taller proximodistally than wide mediolaterally or long anteroposteriorly; 9)

243 astragalus mediolateral width and anteroposterior length essentially equal.

\section{DESCRIPTION AND COMPARISONS}

The terminology used to describe the vertebral laminae largely follows Wilson (1999) and

248 Wilson (2012), whereas the terminology employed for the fossae follows Wilson et al.

249 (2011). The internal texture of all preserved presacral vertebrae is camellate, following Wedel

250 (2003). The fragments identified as pertaining to the scapula, ulna and ilia have been so

251 heavily affected by post mortem distortion and/or fracturing that they are anatomically

252 uninformative; consequently, they are not described herein.

254 Cervical Vertebra 
255 The only preserved cervical vertebra is represented by the majority of the centrum

256 (excluding the anterior condyle and the right parapophysis) and a minor portion of the firmly

257 coalesced neural arch (Fig. 4; Table S1). It is herein interpreted as a posterior cervical

258 vertebra because of the relatively low average elongation index (aEI) of the centrum $(\sim 1.86$,

259 based on the preserved portion; it is unlikely to have been higher than 2.0), and the broad

260 transverse width across the parapophyses relative to the anteroposteriorly short length of the

261 centrum. The anterior portion of the non-condylar centrum is not preserved. However, based

262 on the position of the remaining portion of the left parapophysis, which would have occupied

263 the anteroventral corner of the lateral surface of the centrum, and the morphology of the

264 lateral pneumatic fossa and foramen, the vertebra would not have been substantially longer

265 than preserved (Fig. 4A, B). The fact that the posterior articular surface (Fig. 4C) is concave

266 suggests that the vertebra was opisthocoelous, as are the cervical vertebrae of all eusauropods

267 (Upchurch, 1998). The dorsal margin of the posterior articular surface is shallowly concave,

268 in line with the posterior neural canal opening (Fig. 4C). Although incompletely preserved,

269 the posterior cotyle was clearly wider transversely than dorsoventrally tall (ratio $\sim 1.25$ ); this

270 distinguishes Savannasaurus from several Asian somphospondylans (Mannion et al., 2013,

271 2019a), including the euhelopodids Euhelopus (Wiman, 1929; Wilson and Upchurch, 2009)

272 and Erketu (Ksepka and Norell, 2006, 2010), and the possible titanosaur Daxiatitan (You et

273 al., 2008). The anterior portion of the ventral surface of the centrum is concave transversely

274 and, to a lesser degree, concave anteroposteriorly (Fig. 4D). This concavity is exaggerated by

275 (or might simply be a consequence of) the slight ventral projection of the parapophyses.

276 There are no sharp-lipped excavations on the ventral surface, contrasting with the paired

277 fossae that characterise the anterior portion of the middle-posterior cervical centra of some

278 titanosaurs, including Muyelensaurus (MAU-PV-LL-391: P.D.M. pers. obs. 2014),

279 Overosaurus (Coria et al., 2013), and Rukwatitan (Gorscak et al., 2014). A subtle, slightly 
280 off-centre, anteroposteriorly-oriented, and rather weak ventral keel is present (Fig. 4D).

281 Whereas the presence of a ventral keel is plesiomorphic for sauropod cervical vertebrae

282 (Upchurch, 1998), and also characterises some somphospondylans (e.g. Euhelopus; Wilson

283 and Upchurch, 2009), most titanosaurs lack ventral keels (Mannion et al., 2013). However, a

284 midline crest is present in at least one posterior cervical vertebra of Mendozasaurus

285 (González Riga, 2005; González Riga et al., 2018), Overosaurus (Coria et al., 2013), and

286 probably Austroposeidon (Bandeira et al., 2016), and is present throughout the cervical series

287 in Rapetosaurus (Curry Rogers, 2009). Towards the posterior cotyle, the ventral surface of

288 the centrum becomes transversely convex. The lateral surface of the centrum is dominated by

289 an anteroposteriorly elongate pneumatic foramen, which is divided by several bony struts.

290 This is set within the anterior half of an anteroposteriorly elongate, posteriorly acuminate,

291 pneumatic fossa, which extends almost the full length of the centrum (Fig. 4A). The presence

292 of a well-developed lateral excavation contrasts with the cervical centra of many

293 somphospondylans, especially titanosaurs (e.g. Futalognkosaurus, Rapetosaurus), which are

294 often characterised by a shallow fossa, or lack an excavation altogether (Upchurch, 1998;

295 Wilson, 2002; Curry Rogers, 2005). The ventral margin of the pneumatic fossa is defined by

296 a thickened PCPL which, when viewed dorsally (Fig. 4B) or ventrally (Fig. 4D), runs parallel

297 to the long axis of the centrum before sweeping laterally towards the parapophysis. The

298 PCPL becomes thicker dorsoventrally towards the parapophysis and is well defined along its

299 length, almost to the margin of the posterior cotyle. The posterior portion of the lateral

300 pneumatic fossa is bounded dorsally by the PCDL, which runs anterodorsally-

301 posteroventrally. A horizontal lamina, extending from the posterior end of the PCDL to the

302 anteriormost preserved portion of the vertebra, constitutes the rest of the dorsal margin of the

303 lateral pneumatic fossa. The robust parapophysis projects laterally and slightly ventrally from

304 the anteroventral corner of the centrum, lacking the strong ventral deflection that 
305 characterises the middle-posterior cervical vertebrae of several somphospondylans (D'Emic,

306 2012; Mannion et al., 2013), including the titanosaurs Isisaurus (Jain and Bandyopadhyay,

307 1997) and Overosaurus (Coria et al., 2013), as well as some members of Lognkosauria

308 (González Riga et al., 2018). Unlike the elongate parapophyses of the middle-posterior

309 cervical vertebrae of several derived titanosaurs (e.g. saltasaurids; D'Emic, 2012), those of

310 Savannasaurus are restricted to the anterior half of the centrum. The dorsal surface of the

311 parapophysis is convex along its length, lacking any pneumatic excavation or extension of the

312 lateral pneumatic fossa, whereas its ventral surface is flat. The articular surface of the

313 parapophysis was firmly sutured to the cervical rib, but breakage of this specimen during

314 excavation has resulted in their separation (the connection point is labelled in Fig. 4A and E).

315 At the anterior margin of the dorsal surface of the parapophysis, an anteroposteriorly thin

316 ridge is present, separating anterior and posterior fossae on the internal surface of the

317 mediolaterally thin plate connecting the capitular and tubercular heads of the cervical rib. The

318 anterior fossa continues onto the anterior margin of the parapophysis as a dorsoventrally and

319 somewhat mediolaterally concave surface, whereas the posterior surface of the base of the

320 parapophysis is dorsoventrally convex. The cervical rib is poorly preserved and incomplete;

321 nevertheless, there are indications that both anterior and posterior projections were present

322 (Fig. 4A-B, D). Immediately below the ventral margin of the cervical rib, portions of the

323 distal shafts of two additional parallel cervical ribs are present (Fig. 4E-G). This suggests that

324 at least some of the cervical ribs of Savannasaurus were elongate, extending along the length

325 of at least three centra (including the one to which they were adhered).

327 Dorsal Vertebrae 
328 A total of eight dorsal vertebrae from Savannasaurus have been recovered (Figs. 5-12;

329 Table S1). Assuming that the entire dorsal series comprised ten vertebrae, as in most other

330 titanosaurs with complete sequences (e.g. Trigonosaurus (Campos et al., 2005),

331 Futalognkosaurus (Calvo et al., 2007), Overosaurus (Coria et al., 2013), Rapetosaurus

332 (Curry Rogers, 2009)), and based on the position of the parapophysis on the preserved

333 vertebrae, we infer that the anterior two dorsal vertebrae are missing. Therefore, we describe

334 the preserved elements as dorsal vertebrae III-X.

335 All of the dorsal centra are strongly opisthocoelous, as in most macronarians (Salgado et 336 al., 1997; Wilson and Sereno, 1998), with no decrease in the degree of development of the 337 anterior condyle along the series. Virtually all preserved centrum articular surfaces are 338 notably shorter dorsoventrally than they are wide transversely, which is consistent with the 339 condition in titanosaurs (Mannion et al., 2013, 2019b), especially in the anterior part of the 340 dorsal series. The anterior condyles of dorsal vertebrae IV (Fig. 6A), VII (Fig. 9A), and VIII 341 (Fig. 10A) each bear a dorsoventrally elongate groove, which is less than half the height of

342 the condyle and located approximately centrally. The lateral and ventral margins of the 343 anterior condyles and posterior cotyles are convex. By contrast, the dorsal margin of each

344 anterior condyle is flat, whereas that of each posterior cotyle is concave. All preserved dorsal

345 centra are transversely constricted at their mid-lengths and flared both anteriorly and

346 posteriorly. The ventral surfaces of the centra are (generally) transversely and

347 anteroposteriorly concave, and lack midline ridges. Thus, the midline keel that is present in

348 the middle-posterior dorsal vertebrae of a small number of titanosaurs, including

349 Diamantinasaurus (Poropat et al., 2015b), Futalognkosaurus (Calvo et al., 2007), and

350 Opisthocoelicaudia (Borsuk-Białynicka, 1977), is absent in Savannasaurus. Weakly

351 developed ventrolateral ridges are present on some of the dorsal centra of Savannasaurus.

352 Similar, albeit better-developed, ridges characterise the middle-posterior dorsal centra of 
353 Diamantinasaurus (Poropat et al., 2015b) and Opisthocoelicaudia (Borsuk-Białynicka,

354 1977). All dorsal centra have dorsoventrally short, posteriorly acuminate pneumatic foramina

355 set within fossae on their lateral surfaces, as in most somphospondylans (Upchurch et al.,

356 2004). Ventral to the pneumatic fossa, the lateral surface of each centrum is dorsoventrally

357 convex and anteroposteriorly concave.

358 In each dorsal vertebra, the prezygapophysis is supported ventrally by a CPRL; two left

359 CPRLs (designated the mCPRL and ICPRL) are present in dorsal vertebrae III-IV and VIII

360 (Fig. 5A, 6A, 10A). The TPRL, CPRLs, and the dorsal margin of the anterior condyle define

361 the CPRF, within which the anterior neural canal opening lies. This contrasts with the

362 middle-posterior dorsal vertebrae of several titanosaurs (e.g. Tapuiasaurus, Epachthosaurus,

363 Rapetosaurus, Alamosaurus, and saltasaurines), in which the anterior neural canal opening is

364 entirely surrounded by the neural arch (Carballido et al., 2012; Poropat et al., 2016). In dorsal

365 vertebrae III-IV and VI-VIII, the CPRF is bisected by a vertical lamina running from the

366 centre of the TPRL to the dorsal margin of the anterior neural canal opening (Fig. 5A, 6A,

367 8A, 9A, 10A). The CPRL (1CPRL when two left CPRLs are present) shares its base with the

368 ACPL, and a PACPRF is delineated by these laminae and the stout PRPL in dorsal vertebrae

369 III-IV and VI-IX at least (its presence in dorsal vertebrae $\mathrm{V}$ and $\mathrm{X}$ cannot be determined).

370 The PACPRF is visible only in anterior view in dorsal vertebrae III-IV and VI-VII (Fig. 5A,

$3716 \mathrm{~A}, 8 \mathrm{~A}, 9 \mathrm{~A}$ ), whereas it is visible in lateral view in dorsal vertebrae VIII-IX (Fig. 10B, 11B).

372 A hyposphene and hypantrum structure is absent in all dorsal vertebrae, as is the case in

373 nearly all derived titanosaurs (Salgado et al., 1997; Apesteguía, 2005). The prezygapophyseal

374 facets tend to be wider mediolaterally than they are long anteroposteriorly, and are connected

375 to each other via a TPRL in all preserved dorsal vertebrae. In the anteriormost preserved

376 dorsal vertebrae, the prezygapophyses are widely spaced and are strongly dorsomedially

377 oriented $\left(>40^{\circ}\right)$; consequently, the TPRL in these vertebrae is V-shaped, as is the case in most 
378 titanosaurs (Carballido et al., 2012). Further along the dorsal series, the prezygapophyses

379 successively face more dorsally than medially, such that by dorsal X the articular facets and 380 the associated TPRL are essentially horizontal (Fig. 12C). This differs from nearly all other 381 titanosaurs, in which the zygapophyseal table remains strongly tilted in posterior dorsal 382 vertebrae (Carballido et al., 2012; Poropat et al., 2016).

383 As in all other sauropods, the positions of the parapophyses and diapophyses in

384 Savannasaurus shift relative to one another, and to the centrum, along the sequence. This

385 leads to changes in the orientation of their associated laminae, and affects which laminae are 386 present along the sequence. All preserved parapophyseal articular facets are oval, taller

387 dorsoventrally than long anteroposteriorly, and often concave. In all preserved dorsal 388 vertebrae, the parapophysis is situated anteroventral to the diapophysis. The parapophysis is 389 supported ventrally by a sub-vertical ACPL, and at least one PCPL; however, as is common 390 in many titanosauriforms (D’Emic, 2012), including Austrosaurus (Poropat et al., 2017) and 391 Diamantinasaurus (Poropat et al., 2015b, 2016), two parallel PCPLs are present on several 392 dorsal vertebrae - especially on the left side. In dorsal III, wherein the parapophysis is 393 located near the dorsal margin of the centrum (Fig. 5B), the vPCPL is sub-horizontal and

394 forms the dorsal margin of the lateral pneumatic fossa, whereas the dPCPL is weakly

395 developed and crosscut by the ACDL. In dorsal vertebrae IV and VI-X, where the 396 parapophysis is situated further dorsally, both the vPCPL and dPCPL are anterodorsally397 posteroventrally inclined. The vPCPL tends to brace the ACPL, rather than reaching the 398 parapophysis, and often forms the dorsal margin of the pneumatic fossa. The ACPL, dPCPL 399 and the dorsal margin of the centrum invariably define a CPAF; in instances where two 400 PCPLs are present on the same side, the CPAF is split by the vPCPL, and in several cases 401 (e.g. dorsal vertebrae IV and IX) a truncated ACDL also interrupts the CPAF. The PCPL 402 (dPCPL, where relevant) and the PCDL invariably project from the same point as each other 
403 on the centrum. In more anterior dorsal vertebrae (IV, VI, VIII), the dPCPL generally merges

404 smoothly with the base of the PCDL (or coalesced ACDL+PCDL), whereas in more posterior

405 dorsal vertebrae (VII, IX, X) the dPCPL simply projects from the same point on the centrum

406 as the PCDL. In dorsal vertebrae IV-X, a slightly posterodorsally-anteroventrally inclined

407 PPDL connects the parapophysis with the diapophysis. The PPDL bifurcates at its

408 parapophyseal end in dorsal vertebra IV (Fig. 6C). This is an unusual feature but, given its

409 presence on only one dorsal vertebra, we do not include it as an autapomorphy of

410 Savannasaurus.

411 When complete, the diapophyseal facets are invariably longer anteroposteriorly than they

412 are tall dorsoventrally, have a smoothly convex dorsal margin and an undulating ventral one,

413 and are often convex, lacking a distinct distal end surface. Although there is a subtle shift in

414 the orientation of the diapophyses relative to the centra along the series, they are never

415 strongly deflected dorsally: they project mostly laterally and somewhat dorsally in the

416 anteriormost preserved dorsal vertebrae, and more strongly dorsally but still mostly laterally

417 in more posterior dorsal vertebrae. In all dorsal vertebrae, the diapophysis is supported from

418 below by a single, ventrally unexpanded PCDL that projects dorsolaterally and tends to be

419 the most robust lamina on each vertebra. Although an ACDL can be tentatively identified on

420 most of the preserved dorsal vertebrae, this structure is more often than not truncated by the

421 PCPL (or vPCPL where present; e.g. dorsal IV (Fig. 6C), VIII (Fig. 10B)). In dorsal vertebra

422 VII, the ACDL appears to brace the shared base of the PCPL and PCDL (Fig. 9B). A PACDF

423 is present in all preserved dorsal vertebrae. In dorsal vertebra III, the PACDF is bordered by

424 the PRDL, PRPL, PCPL and PCDL, and interrupted by a weak ACDL (Fig. 5B). By contrast,

425 in dorsal vertebrae IV-X — which lack a PRDL — the PACDF is bordered by the PPDL,

426 PCPL (dPCPL, where relevant) and PCDL (coalesced ACDL+PCDL, where relevant). In 
427 dorsal vertebra VIII, accessory laminae are present within the PACDF, dorsal to the junction 428 of the dPCPL and the PCDL (Fig. 10B).

429 The postzygapophyseal articular facets are generally wider mediolaterally than they are 430 long anteroposteriorly. In the anteriormost preserved dorsal vertebrae they face

431 ventrolaterally, whereas further posteriorly in the sequence they face progressively less 432 laterally and more ventrally; in dorsal vertebrae IX and X, they face almost entirely ventrally 433 (Fig. 11C, 12A). Each postzygapophysis is supported ventrally by a CPOL, at or near its 434 medial margin. This lamina extends dorsally from approximately the same point on the 435 centrum as the PCDL. The ventral end of the left CPOL is bifurcated in dorsal vertebra III, 436 whereas the right one is undivided (Fig. 5D). In all dorsal vertebrae, the paired CPOLs form 437 the lateral margins of the CPOF, the ventral half of which is penetrated by the posterior 438 neural canal opening. The dorsal margin of the CPOF is formed by the TPOL in dorsal 439 vertebrae III-IV (Fig. 5D, 6D), but no TPOL is present in subsequent dorsal vertebrae; thus, 440 the CPOF and SPOF are effectively confluent. A confluent SPOF+CPOF is also seen in an 441 anterior dorsal vertebra of Choconsaurus (Simón et al., 2018), in middle dorsal vertebrae of 442 both Yongjinglong (Li et al., 2014) and Sonidosaurus (Xu et al., 2006), in dorsal vertebra VI 443 of Epachthosaurus (UNPSJB-PV 920; S.F.P., pers. obs. 2013), in a posterior dorsal vertebra 444 of Mnyamawamtuka (Gorscak and O'Connor, 2019), and in at least some dorsal vertebrae of 445 Ampelosaurus (Le Loeuff, 2005) and Isisaurus (Jain and Bandyopadhyay, 1997). Similarly, 446 some middle-posterior dorsal vertebrae of saltasaurines have either extremely reduced 447 TPOLs or appear to lack them altogether (Zurriaguz and Powell, 2015). Although the SPOF 448 and CPOF appeared to be confluent in one dorsal vertebra of Dreadnoughtus, the presence of 449 a TPOL in most other exemplars suggests that it was present throughout the dorsal series, and 450 that the SPOF and CPOF were separate (Voegele et al., 2017). In dorsal vertebrae IX-X, the 451 postzygapophyses of Savannasaurus almost meet on the midline (Fig. 11C, 12A). This is also 
452 evident in some dorsal vertebrae of Chubutisaurus (Carballido et al., 2011), Patagotitan

453 (Carballido et al., 2017), and Opisthocoelicaudia (Borsuk-Białynicka, 1977). The CPOL and

454 PCDL form the ventrolateral corner of a posterolaterally-facing fossa. In dorsal vertebrae III-

455 VI, in which no PODL is present, this fossa is bordered dorsally by the SPDL (pSPDL, where

456 relevant; see below), making it a POCDF+POSDF. In dorsal vertebrae VII-X, which do

457 possess a PODL, this fossa is a POCDF. The left POCDF+POSDF is interrupted by a vertical

458 accessory lamina in dorsal vertebrae IV and VI, as is the left POCDF of dorsal vertebrae VII

459 and VIII, and the right POCDF of dorsal vertebra VII and IX.

460 As preserved, dorsal neural spine height increases posteriorly along the sequence. This is

461 consistent with the condition in most sauropods, but the reverse is true in some titanosaurs

462 (Mannion et al., 2013), including Opisthocoelicaudia (Borsuk-Białynicka, 1977),

463 Rapetosaurus (Curry Rogers, 2009), and some members of Lognkosauria (Carballido et al.,

464 2017). We caveat this with the possibility that the unpreserved anteriormost dorsal vertebrae

465 of Savannasaurus might be unusually dorsoventrally tall, but consider this unlikely. In

466 general, the dorsal neural spines have a consistent anteroposterior thickness along their

467 length. As is the case in most sauropods (Upchurch, 1995), the neural spines of the posterior

468 dorsal vertebrae are taller than the posterior articular surfaces of their respective centra.

469 However, this is not the case in a small number of derived somphospondylans, with taxa such

470 as Dongyangosaurus and Opisthocoelicaudia characterised by dorsoventrally short posterior

471 dorsal neural spines (Mannion et al., 2013).

472 None of the preserved dorsal neural spines of Savannasaurus are bifurcated, which

473 contrasts with Opisthocoelicaudia (Borsuk-Białynicka, 1977), as well as the putative

474 titanosaurs Daxiatitan (You et al., 2008) and Dongyangosaurus (Lü et al., 2008). In the

475 anteriormost preserved dorsal vertebrae of Savannasaurus, the neural spine is strongly

476 inclined posterodorsally. Further posteriorly, the inclination of the neural spine decreases, 
477 such that in dorsal $\mathrm{X}$ it is sub-vertical. These shifts in the orientation of the neural spines

478 result in serial changes in lamina configuration (see below). A similar transition from

479 posterodorsally-inclined to sub-vertical neural spines is observed in the dorsal series of

480 several titanosaurs, including Epachthosaurus (Martínez et al., 2004), Trigonosaurus

481 (Campos et al., 2005), Overosaurus (Coria et al., 2013), Rapetosaurus (Curry Rogers, 2009),

482 Alamosaurus (Lehman and Coulson, 2002), and Neuquensaurus (Salgado et al., 2005); by

483 contrast, the neural spines appear to be vertical throughout the dorsal series in Isisaurus (Jain 484 and Bandyopadhyay, 1997). On the lateral sides of each neural spine of Savannasaurus, an 485 aliform process is present; in the anteriormost preserved dorsal vertebrae, these processes are 486 small, whereas they are more prominent further along the sequence.

487 The PRSL fails to reach the apex of the neural spine in all preserved dorsal vertebrae of 488 Savannasaurus. It is most extensive in dorsal vertebrae IX-X, wherein it runs for two-thirds 489 of the neural spine height; by contrast, in dorsal vertebrae III-VIII, it fades out before the 490 spine mid-height. In dorsal vertebrae III-IV, there is a weak SPRL that extends from each 491 prezygapophysis to a point where it terminates one-quarter of the way along the neural spine. 492 The SPRL is more strongly developed in dorsal vertebrae VI and VII, reaching one-third and 493 two-thirds of the height of the neural spine, respectively. In dorsal vertebra VIII, the SPRL 494 reaches even further up the neural spine, but not as far as the SPDL. In dorsal vertebra IX, an 495 mSPRL and a 1SPRL are present on the right side, whereas the left SPRL is undivided and 496 seemingly equivalent to the right mSPRL. The right $1 S P R L$ is prevented from ascending more 497 than one-quarter the height of the neural spine by the mSPRL, which appears to reach the 498 same height as the SPDL. In dorsal X, the SPRLs fade out at the point that the SPDL reaches 499 the neural spine. A shallow SPRF separates each SPRL (mSPRL, where relevant) from the 500 PRSL, whereas a small PRSDF separates the SPRL (1SPRL, where relevant) from the SPDL 501 (mSPDL, where relevant). 
502 In dorsal vertebrae III and IV, the posterodorsal corner of the diapophysis is connected to

503 the neural spine by a near-horizontal, sheet-like SPDL. Two SPDLs are present on each side

504 in dorsal vertebrae VI-VII: an aSPDL, which runs medially across the face of the neural

505 spine towards the midline; and a pSPDL, which forms the lateral margin of the neural spine.

506 In dorsal VII, the pSPDL reaches the level of the aliform process. Where present, the aSPDL

507 and pSPDL are invariably separated by a fossa. Only one SPDL, equivalent to the pSPDL, is

508 present in dorsal vertebrae VIII-IX: in dorsal vertebra VIII, it diminishes at the level of the

509 aliform process, whereas in dorsal vertebra IX it connects to the neural spine anterior to the

510 aliform process. In dorsal vertebra X, the SPDL bifurcates as it approaches the apex of the

511 neural spine, with the posterior projection of the SPDL extending to the aliform process and

512 the anterior one projecting towards the midline. The bifurcated SPDL and aliform process

513 define a small, yet deep, dorsally facing fossa. A small number of titanosaurs also have two

514 SPDLs on either side, as well as a bifid pSPDL, in their middle-posterior dorsal vertebrae,

515 including Epachthosaurus, Rapetosaurus, and Saltasaurus (Poropat et al., 2016), although in

516 those taxa these laminae tend to be more consistently present along the sequence.

517 The orientation of the neural spine directly impacts upon the SPOLs, which connect the

518 postzygapophyses to the posteroventral surface of the neural spine. In the anterior dorsal

519 vertebrae, each postzygapophysis is connected to the posterodorsally inclined neural spine by

520 a short, stout SPOL, and no PODL is present. As the posterior inclination of the neural spine

521 decreases, the length of the SPOL increases. Evidently, the postzygapophyses and SPOLs in

522 the posterior dorsal vertebrae required additional bracing: in dorsal vertebrae VII-X, a PODL

523 provides such support. A PODL is present only in the posteriormost two dorsal vertebrae of

524 Trigonosaurus (Campos et al., 2005; MCT 1488-R: PDM pers. obs. 2019), contra Salgado et

525 al. (2006) and Salgado and Powell (2010). By contrast, a PODL is absent in all of the

526 posterior dorsal vertebrae of Alamosaurus and Opisthocoelicaudia (Salgado et al., 1997). In 
527 dorsal vertebra VI, horizontal accessory laminae connect each SPOL to the POSL; these

528 might have accommodated some of the stresses borne by the PODL in the more posterior

529 dorsal vertebrae. In dorsal vertebrae VII-X, a dorsolaterally facing POSDF is present,

530 separated from the POCDF by the PODL, and otherwise bounded by the SPDL (pSPDL,

531 where relevant) and SPOL. A POSL is present in all preserved dorsal vertebrae, separated

532 from each SPOL by a SPOF. In dorsal vertebrae V-VIII, the wide spacing of the

533 postzygapophyses and the absence of a TPOL means that the POSL enters the CPOF and

534 approaches the dorsal margin of the posterior neural canal opening. This morphology is

535 otherwise known only in Diamantinasaurus (Poropat et al., 2016). The POSL is less

536 pronounced in dorsal vertebrae VIII-X than in dorsal vertebrae III-VII.

537 A notable feature of the dorsal series of the Savannasaurus elliottorum type specimen is

538 the bilateral directional asymmetry in the lamina system of the dorsal vertebrae. This is by no

539 means novel to the vertebrae of Savannasaurus: Osborn (1899) identified asymmetry in a

540 specimen of Diplodocus; Gilmore (1936) in the holotype of Apatosaurus louisae and in other

541 diplodocid specimens; Santucci and Bertini (2006) in several titanosaur vertebrae from the

542 Bauru Group of Brazil; Csiki et al. (2010) in the holotype of the titanosaur Paludititan

543 nalatzensis; and Wilson (2012) and Wedel and Taylor (2013) in numerous sauropod

544 specimens. In Savannasaurus specifically, the left side of each dorsal vertebra appears to

545 have been more strongly reinforced by split and/or accessory laminae than the right.

546 Although the asymmetry in the dorsal vertebral lamina system is most likely a consequence

547 of the independent pneumatisation of each side of the vertebral column (Hogg, 1984; Wedel,

548 2003), it is also possible that the spinal column of the Savannasaurus elliottorum type

549 individual was subjected to asymmetric loading, and that the extra laminae on the left side

550 developed in response to this. 


\section{Dorsal Ribs}

553 Several portions of dorsal ribs of Savannasaurus are preserved, although the majority were

554 fragmented post mortem, such that in most cases the rib heads are poorly preserved or 555 missing. One exception is a left dorsal rib (Fig. 13), in which the tuberculum and capitulum 556 are well preserved. The incomplete capitular articular surface is taller dorsoventrally (58 $\mathrm{mm})$

557 than it is long anteroposteriorly $(41 \mathrm{~mm})$. By contrast, the complete tubercular articular

558 surface is longer anteroposteriorly $(70 \mathrm{~mm})$ than it is tall dorsoventrally $(35 \mathrm{~mm})$. The rib

559 heads are separated by $80 \mathrm{~mm}$. A thin (and incompletely preserved) lip of bone is present 560 between the tuberculum and capitulum; on both its external and internal surfaces, an opening 561 is present which would have facilitated the intrusion of pneumatic diverticula. All dorsal ribs 562 in titanosauriforms tend to show pneumatisation (Wilson and Sereno, 1998); however, some 563 non-titanosauriforms preserve rare evidence for pneumatised dorsal ribs as well (e.g.

564 Apatosaurus (Gilmore, 1936; Mannion et al., 2012)). The shaft of the rib is teardrop-shaped 565 in cross-section, with the anterior surface broadly convex and the posterior end tapered. The

566 lateral surface is anteroposteriorly convex; by contrast, the medial surface varies from

567 slightly concave at the proximal end to flat further distally, and concave again at the

568 distalmost preserved portion. At the distal end, the cross-section through this rib is triangular.

569 The remaining dorsal ribs are incompletely preserved. The longest preserved exemplar,

570 which is lacking the proximal end but appears to derive from the right side, is $1680 \mathrm{~mm}$ long 571 (measured along the outside surface using a cloth tape measure); when complete it probably 572 exceeded $1800 \mathrm{~mm}$ in overall length. The proximalmost preserved portion of this rib is bell573 shaped in cross-section: the lateral surface is essentially flat, the medial surface is strongly 574 convex, and the junction between these two surfaces (which occurs in line with the lateral 575 margin) is slightly concave both anteriorly and posteriorly. The anterior surface remains 576 tapered along its length, whereas the flange that runs along the posterior surface varies in 
577 extent. On the posterior surface, a prominent flange is present along the proximalmost 578 preserved $400 \mathrm{~mm}$ of the rib; along the same length of rib, the expression of the medial bulge 579 decreases towards the distal end. At the proximal end, the junction between these two 580 features was shallowly mediolaterally concave; $400 \mathrm{~mm}$ further distally, the concavity 581 between these two features is a deep trench. The rib is triangular in cross-section at this point, 582 with a concave posterior face. This concavity shallows over the succeeding $300 \mathrm{~mm}$, 583 disappearing slightly proximal to the mid-length of the preserved rib. At the distal end, this 584 rib is clearly 'plank'-like (49 mm long anteroposteriorly; $12 \mathrm{~mm}$ wide mediolaterally).

585 One other dorsal rib (130 mm long proximodistally, missing the proximal end) is bell586 shaped in cross-section at its proximalmost preserved point but becomes strongly 'plank'-like 587 along its distal half (91 mm long anteroposteriorly; $13 \mathrm{~mm}$ wide mediolaterally). This rib also 588 preserves a complete distal end, with an undulating texture typical of a surface covered with 589 cartilage in life.

\section{Sacrum}

The entire dorsal surface of the sacrum of Savannasaurus, including the neural spines and the upper row of sacral processes, has been obliterated, as has the anteriormost centrum (or centra). Thus, all that remains are the ventral portions of four sacral vertebrae (anterior to which at least one additional sacral would have been sutured), and six of the eight ventral 596 sacral processes (only five of which are shown in Fig. 14) that would have projected from 597 these centra. As is the case with the pubes and ischia (see below), the preserved portion of the 598 sacrum is extremely broad (1070 $\mathrm{mm}$ transversely) although, based on the preserved length of 599 the sacral centra ( $720 \mathrm{~mm}$ anteroposteriorly), it is probable that the complete sacrum was as 600 long or longer anteroposteriorly than it was wide transversely at the acetabulum. The 
601 sacricostal yoke is preserved on both sides of the sacrum, although neither ilium is present;

602 presuming that, as in other titanosauriforms, the ilia flared anterolaterally, the pelvis of

603 Savannasaurus would have been even wider at its anterior margin than the preserved sacrum

604 suggests. It appears unlikely that the middle sacral centra of Savannasaurus were notably

605 narrower than the anteriormost and posteriormost ones, contrasting with derived titanosaurs

606 (Salgado et al., 2005; D’Emic and Wilson, 2011; Poropat et al., 2016). The lateral surfaces of

607 the centra lack openings. The sutures between the sacral centra are generally indistinct.

608 However, the suture between the ultimate and penultimate preserved sacral vertebrae is

609 pronounced as a consequence of the flared nature of the articular surfaces. This suture might

610 have occurred relatively late in the life of the holotype individual of Savannasaurus. The only

611 articular surface observable, the posterior surface of the posteriormost preserved sacral

612 vertebra, is slightly concave.

613

614 Caudal Vertebrae

615 Portions of at least five caudal vertebrae are preserved, although only four of these are

616 sufficiently complete to provide anatomical information (Fig. 15; Table S2). All preserved

617 caudal centra are amphicoelous, distinguishing Savannasaurus from most titanosaurs

618 (Salgado et al., 1997). However, other titanosauriforms that are sometimes classified within

619 Titanosauria, such as Traukutitan (Salgado and Calvo, 1993; Juárez Valieri and Calvo, 2011)

620 and Malarguesaurus (González Riga et al., 2009), also have at least some anterior caudal

621 centra that are non-procoelous (i.e. that lack a posterior condyle). The only preserved caudal

622 vertebrae in the putative titanosaurs Baotianmansaurus and Dongyangosaurus, which are

623 from the anteriormost section of the tail, have shallowly amphicoelous centra (Lü et al., 2008;

624 Zhang et al., 2009; Mannion et al., 2019a). Nevertheless, perhaps the most relevant taxa for 
625

626

628

629

630

631

632

633

634

635

636

637

638

639

640

641

642

643

644

645

646

647

648

649

comparison with Savannasaurus are the approximately coeval Gondwanan taxa Andesaurus, in which only the anteriormost caudal centra are gently procoelous (Calvo and Bonaparte, 1991; Mannion and Calvo, 2011), Mnyamawamtuka, in which the anteriormost caudal centra are either mildly procoelous or lack a posterior condyle entirely (Gorscak and O’Connor, 2019), and Chubutisaurus, in which the anterior caudal centra have shallowly concave anterior articular surfaces and flat posterior articular surfaces (Del Corro, 1975; Salgado, 1993; Carballido et al., 2011).

All of the preserved caudal centra are anteroposteriorly short relative to the dimensions of their articular surfaces. In all exemplars, the anterior margin of the centrum is perpendicular to the anteroposterior axis of the centrum, differentiating Savannasaurus from aeolosaurines (Santucci and Arruda-Campos, 2011). All caudal vertebrae of Savannasaurus lack hyposphene-hypantrum articulations. This distinguishes Savannasaurus from brachiosaurids and euhelopodids, in which these articulations are usually present in the anteriormost caudal vertebrae, but unites it with most other titanosauriforms (Upchurch, 1998; Mannion et al., 2013).

\section{Proximal-Middle Anterior Caudal Vertebrae - Two proximal-middle anterior caudal} vertebrae are preserved in Savannasaurus (Fig. 15A-J); herein, these are designated caudal vertebra A and B. Caudal vertebra A is represented by most of the centrum, the left transverse process, the bases of the prezygapophyses, and a fragmentary neural spine that includes the postzygapophyses; the right lateral surface is poorly preserved, and the ventral surface is mostly missing. The preserved portion of caudal vertebra B comprises an incomplete centrum (missing most of the ventral half), the left transverse process, all four zygapophyses and a complete neural spine. Caudal vertebra A was presumably situated more anteriorly in the tail than caudal vertebra B, based on its larger size and more developed transverse processes. However, it was probably not one of the anteriormost vertebrae in the tail. 
650 The internal bone of caudal vertebra B can only be observed on the broken centrum and

651 postzygapophyses, and in both cases it is cancellous (fine and spongy), with only very small

652 coels present. In the centrum, these become anteroposteriorly elongate near the lateral

653 margin. By contrast, in caudal vertebra A the internal texture can be observed on many

654 broken surfaces (Fig. 15C, E). Along the rim of the posterior articular surface of the centrum,

655 the internal texture is cancellous, with only minuscule spaces $(<5 \mathrm{~mm}$ across $)$ present. For

656 the most part, the internal texture of the broken transverse process is similarly cancellous;

657 however, along the posterior margin, the coels become dorsoventrally elongate (thereby

658 paralleling the posterior margin of the transverse process) and increase in size such that they

659 are almost $10 \mathrm{~mm}$ tall dorsoventrally, yet only $2 \mathrm{~mm}$ long anteroposteriorly. Further dorsally,

660 the portion of the transverse process situated upon the neural arch is filled with larger spaces,

$661 \sim 30 \mathrm{~mm}$ across, separated by relatively thin $(\sim 5 \mathrm{~mm})$ bony struts; thus, the internal texture is

662 camellate. The internal structure of the left prezygapophysis comprises a single large coel

663 with a thickened ventral rim; otherwise, the internal texture is similar to that of the neural

664 arch portion of the transverse process. The restriction of pneumaticity in the caudal vertebrae

665 of Savannasaurus to the neural arch is similar to that seen in an unnamed Early Cretaceous

666 titanosaur from China (PMU 24709 [formerly PMU R 263]; Whitlock et al., 2011; Poropat,

667 2013), Xianshanosaurus (Lü et al., 2009; although it is possible that the pneumaticity in this

668 taxon might extend into the centra as well), Malawisaurus (Wedel, 2009), and Alamosaurus

669 (Fronimos, 2011). By contrast, the centrum (and possibly the neural arch) in Volgatitan is

670 pneumatic (Averianov and Efimov, 2018), whereas in saltasaurine titanosaurs the

671 pneumaticity in the anterior (and middle) caudal vertebrae extends into the centrum as well

672 (Cerda et al., 2012).

673 The preserved portion of the anterior articular surface of the centrum of caudal vertebra A

674 shows a distinct undulation, with the dorsal half concave and the ventral half flat (Fig. 15C). 
675 This unusual morphology might represent an autapomorphy of Savannasaurus. Only the

676 dorsal half of the anterior articular surface of the centrum of caudal vertebra B is preserved,

677 and it too is concave (Fig. 15F); however, the depth of this concavity has been exaggerated

678 by post mortem crushing based on the fractured left lateral margin. The posterior articular

679 surface of caudal vertebra A is more strongly concave than the anterior articular surface (Fig.

680 15D). This morphology is otherwise primarily known in the anterior-middle caudal centra of

681 a number of East Asian somphospondylans, including euhelopodids and Huabeisaurus

682 (D’Emic et al., 2013; Poropat et al., 2016), although it is also variably present in Wintonotitan

683 (Poropat et al., 2015a). The posterior articular surface of the centrum of caudal vertebra B is

684 more shallowly concave than the anterior articular surface; however, the aforementioned post

685 mortem crushing to which this centrum was subjected might have impacted this. The lateral

686 margins of the anterior and posterior articular surfaces of both anterior caudal vertebrae are

687 broadly convex. In both anterior caudal vertebrae, the dorsal margin of the anterior articular

688 surface is flat, whereas that of the posterior articular surface is broadly convex. When

689 complete, the anterior and posterior articular surfaces of both anterior caudal vertebrae would

690 have been wider transversely than they were tall dorsoventrally.

691 The preserved left lateral surfaces each bear a transverse process. In caudal vertebra A,

692 only the base of the transverse process is present (Fig. 15C); although broken, it clearly

693 extended from the base of the neural arch (immediately posteroventral to the

694 prezygapophysis) to the dorsal one-third of the centrum. The anterior surface of the

695 transverse process is concave, whereas the posterior one is convex. The base of the transverse

696 process tapers ventrally, and when complete it presumably would have projected

697 posterolaterally. In caudal vertebra B, the left transverse process is complete, and projects

698 laterally before sweeping posteriorly (Fig. 15G). The ventral surface of the base of the

699 transverse process is mediolaterally concave and anteroposteriorly convex, and tapers to a 
700 ridge both anteriorly (possibly representing a vestigial ACPL or ACDL) and posteriorly

701 (possibly representing a vestigial PCPL or PCDL). Another ridge separates the ventral

702 surface of the transverse process from the ventrolateral surface, which is mediolaterally

703 concave and forms a somewhat compressed parallelogram; the acute corners are located

704 anteroventrally and posterodorsally, whereas the obtuse corners are positioned anterodorsally

705 and posteroventrally (Fig. 15H). A thin ridge separates the ventrolateral surface from the

706 dorsal surface, which is mostly anteroposteriorly convex but slightly flattened laterally and

707 slightly concave anteriorly. A mild bulge on the anterodorsal margin of the transverse process

708 (Fig. 15I), nearer the centrum than the lateral tip, is similar to that observed in an array of

709 eusauropods (Kellner et al., 2005; D’Emic et al., 2013; Poropat et al., 2016; Mannion et al.,

710 2019b). It is usually only prominent in the anteriormost caudal vertebrae. Although the

711 transverse process curves strongly posterolaterally, it does not extend beyond the posterior

712 margin of the centrum (Fig. 15G).

713 Immediately ventral to the base of the transverse process in each anterior caudal centrum,

714 the lateral surface is strongly concave, with the maximum depth of this pneumatic concavity

715 in line with the posterolateral projection of the transverse process and the margin gradational

716 with the rest of the centrum, rather than being sharp-lipped. The presence of lateral pneumatic

717 fossae distinguishes the anterior caudal centra of Savannasaurus from those of most

718 somphospondylans, which tend to lack them (Mannion et al., 2013), although the non-

719 titanosaurian somphospondylan Padillasaurus possesses similar blind fossae (Carballido et

720 al., 2015). In both anterior caudal vertebrae, a small foramen is set within the pneumatic fossa

721 (Fig. 15C, H). Similar structures are present in the non-titanosaurian somphospondylan

722 Chubutisaurus (MACN 18222: S.F.P., pers. obs. 2018); by contrast, titanosaurs tend to

723 possess foramina only, Gobititan has small, shallow excavations, and brachiosaurids lack

724 foramina but possess fossae (D’Emic, 2012; Mannion et al., 2013). 
725

726

727

728

729

730

731

732

733

734

735

736

737

738

739

740

741

742

743

744

745

746

747

748

749

The prezygapophyses of caudal vertebra B are almost complete, whereas those of caudal vertebra A are represented only by their ventral bases. The lateral margin of the prezygapophysis in each anterior caudal vertebra is contiguous with the dorsal margin of the transverse process. In caudal vertebra B, the prezygapophyses project $62 \mathrm{~mm}$ anterodorsally from the dorsal margin of the articular surface (Fig. 15H, J), and their posteromedial margins are $32 \mathrm{~mm}$ apart. The flattened articular surfaces face dorsomedially and are anteroposteriorly longer $(61 \mathrm{~mm})$ than they are mediolaterally broad $(39 \mathrm{~mm})$. The ventral surfaces of the prezygapophyses are strongly and smoothly mediolaterally convex.

Both postzygapophyseal articular facets are preserved in each anterior caudal vertebra, and their concave surfaces face mostly laterally and slightly ventrally. CPOLs are not present. In caudal vertebra $\mathrm{A}$, the ventromedial margins of the postzygapophyses meet on the midline; by contrast, in caudal vertebra B they are connected by a TPOL (17 mm wide transversely $\times$ $50 \mathrm{~mm}$ long anteroposteriorly; Fig. 15I). In both caudal vertebrae, a narrow yet deep SPOF is present between the postzygapophyses. In caudal vertebra A, the postzygapophyses project posteriorly beyond the level of the posterior articular surface of the centrum, whereas in caudal vertebra B the posterior margins of the postzygapophyses and the centrum are approximately level. There is no gap between the junction of the bases of the postzygapophyses and the dorsal margin of the neural spine. As is the case in the anterior caudal vertebrae of most derived somphospondylans (Mannion et al., 2013), there is no hyposphene.

The neural spine of caudal vertebra $\mathrm{A}$ is incomplete and poorly preserved; all that can be stated about it with certainty is that its base was transversely wider than anteroposteriorly long (Fig. 15B). By contrast, the neural spine of caudal vertebra B is complete, and forms the basis for the following description. The neural spine projects mostly vertically and slightly posteriorly (Fig. 15H, J), and becomes slightly thickened transversely towards its apex (Fig. 
$75015 \mathrm{~F}, \mathrm{I})$. A thick PRSL is present on the anterior surface, flanked on either side by what

751 appears to be a rudimentary SPRL. The posterior surface shows a similar morphology to the

752 anterior one, with a thickened POSL projecting dorsally from near the floor of the SPOF,

753 flanked on either side by a poorly developed SPOL. The lateral surfaces are essentially flat,

754 and the dorsal surface is smoothly convex anteroposteriorly and transversely.

755 Distal Anterior Caudal Vertebrae - The two preserved distal anterior caudal vertebrae

756 are herein designated caudal vertebra $\mathrm{C}$ and $\mathrm{D}$ (Fig. 15K-S). Each is represented by an

757 incomplete centrum, solidly sutured with the ventralmost vestige of the neural arch. The

758 internal texture of both centra is cancellous. The centrum of caudal vertebra $\mathrm{C}$ is

759 amphicoelous, with the posterior articular surface more deeply concave than the anterior one.

760 Within both concavities (Fig. 15K, N), a small bulge is present centrally, slightly above the

761 mid-height; a similar feature has also been described in Tastavinsaurus sanzi (Canudo et al.,

762 2008). The posterior articular surface of the centrum is not preserved in caudal vertebra $D$;

763 however, the anterior articular surface is shallowly concave. Both caudal vertebrae C and D

764 are approximately the same length as caudal vertebra B, implying that the anteroposterior

765 length of the distal anterior caudal vertebrae did not vary greatly along the series. This is

766 further implied by differences in the proportions of the centra: in caudal vertebra $\mathrm{C}$, both

767 articular surfaces are transversely broader than they are dorsoventrally tall, whereas in caudal

768 vertebra $\mathrm{D}$ the anterior articular surface is substantially taller dorsoventrally than it is wider

769 transversely. This proportional disparity indicates that these two vertebrae were situated some

770 distance from one another in the caudal series (with caudal vertebra $\mathrm{C}$ situated more

771 anteriorly), and that the relative proportions of the caudal centra changed along the length of

772 the tail.

773 The posterior end of the ventral surface of caudal vertebra $\mathrm{C}$ bears chevron facets.

774 Otherwise, this surface is smooth, shallowly concave anteroposteriorly (Fig. 15O), and 
775 separated from each lateral surface by a ventrolateral ridge. This ridge is well preserved on 776 the left side of the centrum (Fig. 15L), but is not evident on the right side (Fig. 15P), which is

777 more heavily eroded despite being otherwise more complete. The right lateral surface of 778 caudal vertebra $\mathrm{C}$ potentially preserves evidence of a pneumatic fossa, although erosion 779 appears to have exaggerated the depth and size of this feature (Fig. 15P). The right lateral 780 surface of the centrum of caudal vertebra D is almost complete (Fig. 15R), and preserves a 781 very small fossa immediately dorsal to an anteroposteriorly oriented lateral ridge, which sits 782 two-thirds of the way up from the ventral margin. Dorsal and ventral to this ridge, the lateral 783 surface of the centrum of caudal vertebra $\mathrm{D}$ is shallowly concave. No indication of the 784 transverse process has been identified on either side of caudal vertebra $\mathrm{C}$, although this is 785 probably because of non-preservation rather than genuine absence. By contrast, a very subtle 786 bulge is present at the base of the right neural arch on caudal vertebra $\mathrm{D}$, which possibly 787 represents a reduced transverse process; if correct, then it is likely that a better developed 788 transverse process was present in caudal vertebra $\mathrm{C}$ as well.

789 Part of the neural canal is preserved on the dorsal surface of caudal vertebrae C (Fig. 15M) 790 and D (Fig. 15Q), flanked on either side by the base of the neural arch. In both vertebrae,

791 these neural arch pedicels are two-thirds the length of the centrum and are positioned anterior 792 to the mid-length of the centrum, as in all members of Titanosauriformes (Salgado et al., 793 1997).

\section{Coracoid}

796 The coracoid of Savannasaurus (Fig. 16; Table S3) is described as if the long axis of the 797 scapulocoracoid were held horizontally. The coracoid is taller dorsoventrally than long 798 anteroposteriorly, and is ovate in lateral (Fig. 16A) and medial (Fig. 16D) views, with a 
799 broadly curved ventral margin and a more acutely curved dorsal margin. Thus,

800 Savannasaurus lacks the quadrangular coracoid characteristic of saltasaurids (Salgado et al.,

801 1997; Upchurch, 1998). Of all the margins of the coracoid, the dorsal one is mediolaterally

802 thinnest (Fig. 16C). The anterior margin of the coracoid varies greatly in mediolateral

803 thickness (Fig. 16F), from $\sim 10 \mathrm{~mm}$ dorsally to $65 \mathrm{~mm}$ ventrally, whereas the glenoid region

804 is the mediolaterally broadest part (Fig. 16E). The glenoid fossa is surrounded by a subtle

805 ridge. Its articular surface is slightly bevelled, such that it is visible in lateral view. In this

806 regard, Savannasaurus differs from several derived titanosaurs (Poropat et al., 2016), such as

807 Lirainosaurus (Díez Díaz et al., 2013), saltasaurines (Powell, 1992, 2003; Otero, 2010), and

808 some members of Colossosauria (González Riga et al., 2018, 2019), in which there is little

809 lateral expansion of the glenoid. The glenoid fossa is significantly broader in both

810 anteroposterior and transverse dimensions (Table S3) than that of Diamantinasaurus (Poropat

811 et al., 2015b). There is a notch anterior to the glenoid in Savannasaurus, but whether or not

812 an infraglenoid lip was present is unclear. Despite the fact that the articulation point for the

813 sternal plate is incompletely preserved, it is presumed that very little of it is missing based on

814 its curvature.

815 In posterior view (Fig. 16B), the scapular articulation is sub-triangular (narrowing

816 dorsally), whereas it is essentially straight in lateral (Fig. 16A) and medial (Fig. 16D) views.

817 The scapular articular surface is slightly taller dorsoventrally than the coracoid as a whole is

818 long anteroposteriorly; this is uncommon among titanosauriforms (Wilson, 2002; Mannion et

819 al., 2013), but is observed in the early-diverging somphospondylans Daxiatitan (You et al.,

820 2008), Ligabuesaurus (Bonaparte et al., 2006), and Sauroposeidon (Rose, 2007).

821 Immediately anterior to the scapular articular surface lies the oval-shaped coracoid foramen,

822 the long axis of which runs anteroposteriorly. The posterior third of the coracoid, which hosts 
823 the coracoid foramen, is medially convex and correspondingly laterally concave; by contrast,

824 the anterior two-thirds are medially concave and laterally convex (Fig. 16C).

826 Sternal Plate

827 The sternal plates were found adjacent to one another, and were associated with the left

828 coracoid. The left element is the more complete and better preserved of the pair (Fig. 17;

829 Table S4), and the description herein is based exclusively on it. It was incorrectly labelled as

830 the right sternal plate in Poropat et al. (2016: fig. 4j). The transverse width of the paired

831 sternal plates would have been approximately $850 \mathrm{~mm}$; this corresponds well with the

832 dimensions of the sacrum and pelvis of Savannasaurus, and supports a wide-gauge stance for

833 this sauropod. The ratio of the maximum length of the sternal plate to proximodistal length of

834 the (incompletely preserved) humerus was somewhat less than 0.71 in Savannasaurus, but

835 almost certainly exceeded 0.65, as in most other titanosaurs (McIntosh, 1990; Upchurch,

836 1998; Mannion et al., 2013). The sternal plate is D-shaped in ventral view (Fig. 17A), with

837 the lateral margin straight and all others convex. This distinguishes the sternal plate of

838 Savannasaurus from those of most titanosauriforms, which have concave lateral margins

839 (such that the overall morphology is kidney-shaped in most titanosaurs (McIntosh, 1990;

840 Upchurch, 1998)), and constitutes a local autapomorphy of Savannasaurus. The medial two-

841 thirds of the ventral surface are mediolaterally convex, whereas the lateral third (marked with

842 a dashed line in Fig. 17A) is concave. The coracoid articulation forms a thickened process at

843 the anterolateral margin of the sternal plate. The dorsoventral thickness of the anterior margin

844 decreases medially. Much of the coracoid articulation surface is roughened by grooves and

845 pits that would have supported a cartilaginous cap. However, the ventral surface of the sternal

846 plate lacks similar furrows or ridges, both medially and posteriorly. There is also no 
847 anteroposteriorly elongate ridge along the anterior portion of the ventral surface, contrasting

848 with most neosauropods (Sanz et al., 1999; Upchurch et al., 2004), and representing a local

849 autapomorphy of Savannasaurus within Neosauropoda (Mannion et al., 2019b). The coracoid

850 articulation merges smoothly with the external surface both medially and ventrally, although

851 the intersection of these two surfaces forms a ventromedially-dorsolaterally oriented ridge.

852 Although the lateral margin of the sternal plate is exceptionally thin, the posterolateral corner

853 is thickened - presumably to accommodate cartilaginous extensions from the anterior

$854 \mathrm{dorsal} /$ sternal ribs or to provide support to the bony gastralia (if they were present; Tschopp

855 and Mateus, 2013). Further evidence for cartilaginous attachment can be seen in the grooves

856 and ridges that occur along the posterior half of the lateral margin and the posterior margin

857 (even medially, where it is extremely thin). In dorsal and ventral views, the posterior margin

858 is convex, differing from the straight margin that characterises some titanosaurs, including

859 Alamosaurus, Malawisaurus, and Mendozasaurus (González Riga, 2003; González Riga et

860 al., 2009). The medial margin appears to have been thicker than the lateral margin

861 (presumably for articulation with the other sternal plate), and was clearly convex, despite

862 having sustained some damage. The dorsal surface is almost entirely shallowly convex, with

863 the exception of the anterolateral and posterolateral regions, which are shallowly concave

864 (Fig. 17B). Based on the lack of correspondence between the undulations of the ventral and

865 dorsal surfaces, it is clear that the sternal plate thickened towards its centre.

\section{Humerus}

868 Both humeri are incomplete; the description herein is based primarily on the more

869 complete right humerus (Fig. 18; Table S5). Although neither the proximal nor distal end is

870 preserved (Fig. 18A), it is clear that the humerus of Savannasaurus was robust (sensu Wilson 
871 \& Upchurch, 2003), as in Diamantinasaurus (Hocknull et al., 2009; Poropat et al., 2015b),

872 Opisthocoelicaudia (Borsuk-Białynicka, 1977), and saltasaurines (Powell, 1992, 2003;

873 Salgado et al., 2005; Otero, 2010). Based only on the preserved portions of the proximal and

874 distal ends, the Robusticity Index (Wilson and Upchurch, 2003) of this element was 0.31.

875 Evidently, the base of the deltopectoral crest did not extend as far as the mid-length of the

876 shaft (Fig. 18B-C); this differentiates Savannasaurus from some titanosaurs (Curry Rogers,

877 2005), such as Neuquensaurus (Salgado et al., 2005; Otero, 2010). The proximal half of the

878 posterior surface is shallowly convex mediolaterally, with the apex of this convexity running

879 approximately centrally down the shaft until it merges with a similarly subtle convexity much

880 nearer the medial margin than the lateral one (Fig. 18A). Although the posterior surface is too

881 poorly preserved to enable the identification of the attachment points of the triceps, towards

882 the proximal end it becomes distinctly roughened. A similarly distinct rugose patch on the

883 posterolateral surface, at about the same level as the distal extent of the deltopectoral crest,

884 represents the point of attachment of the M. latissimus dorsi. Unlike several derived

885 titanosaurs, including saltasaurids (Borsuk-Białynicka, 1977; Otero, 2010), this does not form

886 a prominent process. In anterior view, the lateral margin of the shaft is straight. The posterior

887 and anterior surfaces of the humerus are separated by subtle ridges at the mid-shaft: the

888 lateral ridge is more sharply defined than the medial one. On the posterior surface, the mid-

889 shaft is smoothly convex mediolaterally; further distally, the dorsal margin of what was

890 clearly a deep supracondylar fossa is present between the preserved portions of the distal

891 condyles. As preserved, the medial condyle is angular, with a distinct corner between a

892 posteriorly facing, shallowly concave surface and a posteromedially facing, shallowly

893 convex-flat surface. By contrast, the preserved base of the lateral condyle is smoothly

894 convex. Evidently, the distal end was trampled prior to fossilisation; extensive disintegration

895 of the internal bone is evident. 


\section{Radius}

898 The left radius (Fig. 19; Table S5) was found with its anterior surface contacting the

899 ventral surface of the left sternal plate. Although it is essentially complete, only the posterior

900 surface and the proximal and distal ends are well preserved. The radius of Savannasaurus is

9010.75 times the length of the incomplete humerus, but whether or not the ratio was 0.65 or less

902 when the humerus was complete (as in most titanosauriforms (Mannion et al., 2013)) cannot

903 be ascertained. The anteroposterior lengths of the proximal and distal ends are almost equal.

904 The long axes of the proximal and distal ends are not oriented in the same plane; thus, the

905 radius shows a distinct axial twist, as in Huabeisaurus (D'Emic et al., 2013) and a small

906 number of titanosaurs, including Epachthosaurus and Rapetosaurus (Mannion et al., 2013;

907 Poropat et al., 2016). The proximal surface of the radius (Fig. 19B) is broadly wedge-shaped,

908 as in most titanosauriforms (Upchurch et al., 2015). It is also essentially flat, and covered

909 with grooves and ridges that would have supported a cartilaginous cap. The maximum

910 diameter of the proximal end of the radius is 0.33 times the overall proximodistal length of

911 the radius, similar to most titanosaurs (Upchurch et al., 2004). The anteromedial surface is

912 convex and forms the external surface of the wedge, whereas the concave posteromedial

913 surface and straight posterolateral surface meet at the posterior apex of the wedge. The

914 preserved portion of the medial surface is strongly convex anteroposteriorly, but is

915 incomplete in the region in which the ridge for the insertion of the tendon from the combined

916 M. biceps brachii and M. brachialis inferior would be expected (Upchurch et al., 2015). The

917 preserved proximal portion of the lateral surface of the shaft is anteroposteriorly concave

918 between two ridges that parallel the long axis of the shaft. This concave surface appears to

919 have become convex at the mid-shaft and continues to the distal end; it is separated from the

920 posterior surface by a strong interosseous ridge, which extends almost three-quarters of the 
921 way down the shaft, as in most titanosaurs (Curry Rogers, 2005). The posterior surface of the 922 radius is essentially flat at the proximal end, but becomes proximodistally concave from one923 fifth the length of the shaft to the distal end (Fig. 19A). A marked extension of this concavity 924 is present at the distal end, forming the articulation point for the ulna. Medial to this 925 concavity, a slight protuberance is present that extends towards the medial margin. Little else 926 can be ascertained about the morphology of the radial shaft because of its poor preservation.

927 The distal end of the radius (Fig. 19C) has an essentially straight anterior margin, a broadly 928 convex medial surface, a more acutely convex lateral margin, and an undulating posterior 929 surface. Only the lateral half of the distal end is bevelled proximolaterally relative to the long 930 axis of the shaft (distinguishing Savannasaurus from saltasaurines, wherein the entire distal 931 end is bevelled (Poropat et al., 2016)); although the angle of bevelling appears to be relatively 932 low $\left(10^{\circ}\right)$, the true degree of bevelling might have been affected by deformation of the 933 element. The transverse diameter of the distal end is $\sim 1.7$ times that of the radius at the mid934 shaft; this differs from many somphospondylans, in which this ratio is closer to 2.0 (Wilson 935 and Sereno, 1998; Mannion et al., 2013). The lateral half of the posterior margin is strongly 936 concave, whereas the medial half is strongly convex. Consequently, the medial half of the 937 distal end is almost twice as wide anteroposteriorly as the lateral half.

938

939 Metacarpals

$940 \quad$ Poropat et al. (2016: p. 3) reported that right metacarpals I-V and left metacarpal IV were 941 present in the holotype specimen of Savannasaurus; however, the preserved metacarpals are 942 in fact left I-V (Fig. 20A-AF) and right IV (Fig. 20AG-AK). The described metacarpals and 943 phalanges of Diamantinasaurus, although correctly placed within the manus by Hocknull et 944 al. (2009) and Poropat et al. (2015b), are all from the left side as well; this was revealed when 
945 the associated right manus of the Diamantinasaurus type individual was prepared. The

946 metacarpals of Savannasaurus were arranged in a horseshoe shape when observed in

947 proximal (Fig. 20A) and distal views (Fig. 20B), as in all neosauropods (Upchurch, 1998;

948 Wilson and Sereno, 1998). Description of the elements in vivo (i.e. in articulation) has the

949 potential to cause confusion (see Mannion and Otero, 2012); consequently, here they are all

950 described with their internal (palmar) surfaces facing posteriorly. In life, the external surfaces

951 of the metacarpals would have faced in the following directions: I, posteromedially; II,

952 anteromedially; III, anteriorly; IV, anterolaterally; and V, posterolaterally.

953 The proximodistal lengths of the metacarpals of Savannasaurus vary (Table S6). From

954 longest to shortest, the metacarpals of Savannasaurus are III-II-I-IV-V, as in both

955 Diamantinasaurus (Poropat et al., 2015b) and Wintonotitan (Poropat et al., 2015a). Given

956 that metacarpal I is incomplete, it is probable that its proximodistal length has been

957 underestimated. However, it is clear that it was shorter than metacarpal II, differentiating

958 Savannasaurus from those titanosaurs in which metacarpal I is longest (e.g. Epachthosaurus

959 (Martínez et al., 2004), Alamosaurus (Gilmore, 1946), and Opisthocoelicaudia (Borsuk-

960 Białynicka, 1977)). Although metacarpal IV is shorter than I in most titanosaurs (including

961 Savannasaurus), Aeolosaurus (Powell, 2003) and Rapetosaurus (Curry Rogers, 2009) are

962 exceptions. The variation in length of the metacarpals in Savannasaurus implies that they

963 would have been tightly bound proximally and splayed distally, such that each was inclined

964 relative to the vertical. The flattened proximal surface produced by the articulated metacarpus

965 suggests that no ossified carpal elements were present, as in nearly all titanosaurs (e.g.

966 Epachthosaurus (Martínez et al., 2004), Diamantinasaurus (Poropat et al., 2015b),

967 Alamosaurus (Gilmore, 1946), Opisthocoelicaudia (Borsuk-Białynicka, 1977; D’Emic,

968 2012)). The proximodistal length of the longest metacarpal (III) is 0.49 times that of the

969 radius; thus, this ratio exceeds 0.45, as in most macronarians (McIntosh, 1990; Upchurch, 
970 1998; Wilson and Sereno, 1998; Upchurch et al., 2004), although this is at the low end of the 971 spectrum amongst titanosaurs, with ratios exceeding 0.6 in some taxa (Mannion and Otero,

972 2012; Poropat et al., 2015a). The distal articular surfaces of the metacarpals do not extend on 973 to the anterior surfaces, as is also the case in most titanosaurs (Salgado et al., 1997; D’Emic, 974 2012), other than Alamosaurus (Gilmore, 1946) and Diamantinasaurus (Poropat et al., 975 2015b). This is unusual, given that at least some manual digits possessed phalanges in 976 Savannasaurus (see below).

977 Metacarpal I-The left metacarpal I is almost complete (Fig. 20C-H), missing only a 978 section of the lateral margin of the shaft and a portion of the proximal end. However, it 979 appears to have suffered from significant post mortem distortion, such that the mid-shaft is 980 significantly shorter anteroposteriorly than it would have been in life. The distal end of 981 metacarpal I was found in contact with the proximal end of left metacarpal II. The 982 incompletely preserved proximal surface is horseshoe-shaped (Fig. 20F) and, when viewed 983 posteriorly (Fig. 20G), it is distinctly stepped, with the medial half slightly taller than the 984 lateral. As in both Wintonotitan (Poropat et al., 2015a) and Diamantinasaurus (Poropat et al., 985 2015b), the proximal end is longer anteroposteriorly than it is wide mediolaterally; however, 986 this feature might have been exaggerated by deformation, and is in any case highly variable 987 among neosauropods (Apesteguía, 2005; Mannion and Calvo, 2011). The posterolateral 988 surface of the proximal end of metacarpal I is distinctly concave, whereas the other margins 989 are all convex; this gives the proximal end its distinctive horseshoe-shape. The proximal 990 articular surface for metacarpal II is located posterolaterally, whereas the distal one is situated 991 laterally. The anterior surface of the shaft is strongly convex mediolaterally at the proximal 992 end, and weakly so at the distal end, terminating as a distal lip (Fig. 20C). A strong lateral 993 ridge marks the junction of the anterior and posterior surfaces, and is most prominent at mid994 shaft (Fig. 20E). Proximal to the mid-shaft, the posterior surface is strongly concave between 
995 the prominently expressed lateral ridge and the less developed medial ridge (Fig. 20G). This

996 concavity might have been exaggerated by post mortem deformation, but appears to be a

997 genuine morphological feature. Distal to mid-shaft, the posterior surface is essentially flat,

998 but becomes slightly concave again at the distal end. The posterior surface forms a distal lip,

999 albeit less prominently expressed than the anterior distal lip. The medial surface of

1000 metacarpal I is incompletely preserved (Fig. 20H), although it was clearly less strongly

1001 convex than the lateral surface. The distal end of metacarpal I is blocky, massive, and broadly

1002 parallelogram-shaped (Fig. 20D). The grooves and bulges on the distal end would have

1003 supported a cartilaginous cap. The distal articular surface is undivided and slopes relative to

1004 the shaft, such that it is visible in anterior view and forms a pronounced rim. It is likely that

1005 this feature has been exaggerated by post mortem deformation, since in most titanosauriforms

1006 the distal end of metacarpal I lies perpendicular to the long axis of the shaft (Wilson, 2002).

1007 In Savannasaurus, the surface area of the distal end of metacarpal I is greater than that of any

1008 of the other metacarpals (Fig. 20B); although this was almost certainly the case in life, the

1009 degree to which this has been exaggerated by post mortem deformation is unclear.

1010 Metacarpal II-Like metacarpal I, the left metacarpal II (Fig. 20I-N) was subjected to

1011 significant post mortem deformation - the proximal and distal ends have become flattened

1012 and expanded anteroposteriorly and mediolaterally, and the medial and lateral flare of the

1013 proximal end has been exaggerated (see Fig. 20K, N). The proximal end is wedge-shaped,

1014 with a flattened anterior margin, a shallowly convex medial margin, and a gently concave

1015 lateral margin (Fig. 20L). Posteriorly, the junction between the medial and lateral surfaces is

1016 rounded. The distal end is mediolaterally broader than the proximal end. The medial margin

1017 is effectively straight, whereas the lateral one is shallowly concave. The anterior surface is

1018 more or less flat along its length, although it becomes shallowly convex mediolaterally

1019 towards the distal end. The proximal articular surfaces for metacarpals I (on the medial 
1020 surface) and III (on the lateral surface) are shallowly convex, whereas the distal articular 1021 surfaces are shallowly concave. In both anterior and posterior views, the distal end is strongly 1022 concave (Fig. 20I, M); however, this might have been caused (or at least exaggerated) by post 1023 mortem deformation. In distal view, the metacarpal is weakly arched (Fig. 20J), with a 1024 convex anterior margin, a concave posterior margin, and generally straight medial and lateral 1025 margins.

1026 Metacarpal III-The left metacarpal III of Savannasaurus (Fig. 20O-T), the longest of 1027 the metacarpals, is effectively complete, missing only a small portion of the proximal end. 1028 This metacarpal appears to have suffered relatively little post mortem deformation, except at 1029 the poorly preserved proximal end. In overall morphology, it is similar to the corresponding 1030 element in Diamantinasaurus (Poropat et al., 2015b). In proximal view (Fig. 20R), 1031 metacarpal III is triangular, with the margins facing anteriorly, posteromedially and 1032 posterolaterally and the corners pointing anteromedially, anterolaterally and posteriorly. The 1033 proximal end is not expanded mediolaterally relative to its anteroposterior length, 1034 distinguishing Savannasaurus from brachiosaurids (Mannion et al., 2017). In anterior view 1035 (Fig. 200), the lateral margin is distinctly concave and bowed inwards, whereas the medial 1036 margin is only slightly concave; the same is true of metacarpal III in Diamantinasaurus 1037 (Poropat et al., 2015b). The anterior surface of metacarpal III is relatively flat at the proximal 1038 end, but very shallowly mediolaterally concave along the midline at the mid-shaft. This 1039 shallow depression is bound by lateral and medial ridges that extend distally towards the 1040 articular surface for the manual phalanx. The medial condyle is more strongly developed than 1041 its lateral counterpart, and the same is true of the ridges on each condyle. In lateral view (Fig. 1042 20Q), the dorsal margin is dominated by a pronounced ridge that marks the union between 1043 the anterior and posterolateral surfaces. The posterolateral surface is markedly concave, with 1044 a slight bulge at three-quarters the length of the shaft; below this, the surface again becomes 
1045 shallowly concave. Both proximally and distally, articulation points for metacarpal IV are 1046 present. The proximal articulation is poorly preserved, but would have been convex; the 1047 distal articulation for metacarpal IV is far better preserved. In posterior view (Fig. 20S), 1048 metacarpal III is dominated by a ridge that is somewhat closer to the medial margin than the 1049 lateral one. This ridge extends from the proximal end to three-quarters of the length of the 1050 shaft, merging smoothly with the posterior surface of the medial condyle at the distal end. 1051 The posterior ridge is broadest at its proximal end, narrowing as it descends the shaft, and is 1052 flanked on both sides by concave surfaces. The posteromedial surface is incompletely 1053 preserved along the proximal third, although the more distal two-thirds demonstrate that this 1054 surface was less concave than the posterolateral one. In medial view, the anterior margin is 1055 defined by a medial ridge (Fig. 20T); like the posterior ridge, this medial ridge is strongly 1056 pronounced proximally and tapered distally. The medial surface of the distal condyle is 1057 essentially flat. In distal view (Fig. 20P), the metacarpal is wedge-shaped, as a result of the 1058 medial condyle being notably anteroposteriorly longer than the lateral one. Roughened pits 1059 and grooves again indicate the presence of a cartilaginous cap and, presumably, a manual 1060 phalanx on this digit.

1061 Metacarpal IV - The left metacarpal IV is essentially complete, missing only a small 1062 section of the medial margin (Fig. 20U-Z). By contrast, only the proximal half of the right 1063 metacarpal IV is preserved (Fig. 20AG-AK); despite this, it is slightly less distorted than left 1064 metacarpal IV. In proximal view, the left (Fig. 20X) and right (Fig. 20AI) fourth metacarpals 1065 are virtually mirror images of one another, despite the distortion suffered by left metacarpal 1066 IV; however, the proximal surface of the right is much flatter than that of the left. Because it 1067 is more complete, left metacarpal IV will serve as the basis for much of the following 1068 description. Its proximal end is broad on its anterior margin but tapers to a point posteriorly 1069 (Fig. 20X). The medial and lateral margins are concave for articulation with metacarpals III 
1070 and V respectively. The concavity for metacarpal III is shallower but slightly more extensive 1071 than that for metacarpal V: the latter is exacerbated by an anterolateral projection that would 1072 have wrapped around the dorsal face of metacarpal V (Fig. 20A), similar to that present in the 1073 fourth metacarpals of brachiosaurids (D’Emic, 2012) and some somphospondylans (Mannion 1074 et al., 2013). The proximal two-thirds of metacarpal IV can be divided into three surfaces: 1075 anterior, posteromedial, and posterolateral. A true posterior surface is only present along the 1076 distal third of the shaft (see below). The anterior surface of metacarpal IV is shallowly 1077 proximodistally concave at the proximal end, and very shallowly mediolaterally convex along 1078 the distal three-quarters of the shaft (Fig. 20U). At the distal end, a concavity separates the 1079 paired, evenly developed distal condyles. In posterior view (Fig. 20Y), a ridge extends down 1080 the midline along the proximal three-quarters of the shaft. This ridge is strongly bulbous at 1081 the proximal end but decreases slightly in thickness as it descends the shaft. At its base, the 1082 posterior surface of the metacarpal is shallowly concave between the paired distal condyles. 1083 In posterior view, the lateral condyle is more strongly developed than the medial one. The 1084 posterolateral surface is incompletely preserved (Fig. 20W), although it is clear that the 1085 anterolateral ridge was more robust than the anteromedial one. The proximal portion of the 1086 posterolateral surface is concave to accommodate metacarpal $\mathrm{V}$, although this concavity 1087 extends along the proximalmost three quarters of the shaft. The surface of the distal lateral 1088 condyle is incomplete, although a distinct posterolateral concavity is present for the 1089 articulation of metacarpal $\mathrm{V}$. The posteromedial surface is proximally concave to 1090 accommodate metacarpal III (Fig. 20Z). This concavity, which is bordered by thin medial and 1091 posterior ridges, extends approximately two-thirds of the way down the shaft; distal to this, a 1092 second, shallower concavity is present, which is separated from the proximal concavity by a 1093 slightly convex region. This convex region occurs at the same level as that of the 1094 disappearance of the posterior ridge. In distal view, metacarpal IV is hourglass-shaped, with 
1095 the long axis of the hourglass running transversely (Fig. 20V), unlike the trapezoidal or 1096 hexagonal fourth metacarpal distal ends seen in most titanosaurs (Poropat et al., 2016); this

1097 feature is autapomorphic for Savannasaurus. The discrepancy between the medial and lateral 1098 condyles is most marked in this view: the lateral condyle is broader mediolaterally and longer 1099 anteroposteriorly than the medial one. The morphology of the distal end implies that a 1100 manual phalanx articulated with metacarpal IV. The distal surface is covered in roughened 1101 pits and bulges that presumably supported a cartilaginous pad.

1102 Metacarpal V-The left metacarpal V is almost complete, missing only a small portion of 1103 the posterior ridge (Fig. 20AA-AF). The proximal end is roughly wedge-shaped, being 1104 broadly convex on its anterior margin, slightly concave on its medial margin, and gently 1105 convex on its lateral margin. Posteriorly, it tapers to a rounded point (Fig. 20AD). The 1106 anterior surface is slightly convex proximally, flattened at the mid-shaft, and slightly concave 1107 distally (Fig. 20AA). This distal concavity is flanked by medial and lateral ridges, which 1108 extend approximately three-quarters of the length of the shaft, but might have been 1109 exaggerated by post mortem distortion. The undulating proximal portion of the medial 1110 surface is convex near the posterior ridge but concave towards the medial one (Fig. 20AF).

1111 The medial ridge extends along the anterior margin and remains narrow for much of its 1112 length, becoming less strongly pronounced towards the distal end as it expands to form the 1113 surface of the distal medial condyle. Thus, Savannasaurus lacks the ridge present in this 1114 region in Mendozasaurus, Muyelensaurus and Petrobrasaurus (González Riga et al., 2018). 1115 In posterior view, metacarpal $\mathrm{V}$ is transversely narrow at the proximal end and expanded 1116 distally (Fig. 20AE). A strong ridge extends along the posterior surface from the proximal 1117 margin for approximately two-thirds the length of the shaft. The distal third of the posterior 1118 surface is convex towards the lateral margin and slightly concave towards the medial one; 1119 this undulation is caused by the lateral bulge, which is more strongly pronounced than the 
1120 medial one. In lateral view, metacarpal $\mathrm{V}$ bears a ridge: at the proximal end this structure is

1121 confluent with the anterior margin, whereas further distally it becomes more centrally placed

1122 (Fig. 20AC). Posterior to this ridge, the proximal half is slightly concave, becoming markedly 1123 convex distal to the mid-length as it merges with the posterior surface. In lateral view, the 1124 narrowest point of the metacarpal occurs just proximal to the distal end. In distal view, 1125 metacarpal V is essentially rectangular (Fig. 20AB), although it is slightly constricted along 1126 the midline because of the subtle division of the medial and lateral condyles. The grooves and 1127 ridges at the distal end (to which a cartilaginous cap would have adhered), and the presence 1128 of a slight midline concavity on the anterior margin, support the interpretation that this 1129 metacarpal would have articulated with a manual phalanx.

\section{Manual Phalanges}

1132 At least two manual phalanges of Savannasaurus have been identified, although only one 1133 is sufficiently complete and well preserved to warrant description (Fig. 20AL-AQ; Table S7).

1134 That manual phalanges were present at all is significant, since titanosaurs were thought to 1135 have lacked them (Wilson, 2002; Upchurch et al., 2004); Savannasaurus and

1136 Diamantinasaurus are exceptions (Poropat et al., 2015b, 2016). Based on the morphology of 1137 the better-preserved element, the dimensions of its proximal end, and attempted articulations 1138 with the various preserved metacarpals, it is probably left manual phalanx II-1. In dorsal view 1139 (Fig. 20AL), the manual phalanx is semicircular, the proximal margin being only slightly 1140 convex. The dorsal surface of the phalanx is transversely convex and proximodistally slightly 1141 concave, rising towards the proximal margin. In medial (Fig. 20AM) and lateral (Fig. 20AP) 1142 views, the proximodistally concave nature of the dorsal margin is clear. The ventral surface 1143 (Fig. 20AN) is convex in lateral view (Fig. 20AP), and expands below the level of the 
1144 boundary between the dorsal and ventral surfaces. In proximal view (Fig. 20AQ), the phalanx

1145 tapers to lateral and medial points but is broadly oval in the mid-section. The dorsal margin

1146 of the proximal end is characterised by a bony rim, which would have abutted the ventral

1147 margin of metacarpal II; this suggests that the curved dorsal surface faced anterodorsally.

1148

1149 Pelvic Girdle

1150 The paired pubes and ischia of Savannasaurus (Fig. 21; Table S8-9) have a combined 1151 transverse width in excess of 1.1 metres. Taken together, these four elements form an 1152 undulating sheet that attests to the transversely broad and dorsoventrally compressed lower 1153 pelvic region of Savannasaurus. The curvature of the lateral surfaces of the pubis and 1154 ischium (Fig. 21D) mirrors those of the medial surfaces (Fig. 21B). In most 1155 somphospondylans, the ischium is much shorter than the pubis (Calvo and Salgado, 1995; 1156 Salgado et al., 1997; Upchurch, 1998), with a proximodistal length ratio of less than 0.8 1157 (Mannion et al., 2013). This ratio is very low (0.63) in Savannasaurus (one ischium of which 1158 is slightly more complete than shown in Fig. 21C), with most other taxa characterised by 1159 ratios exceeding 0.7 (Table S10); exceptions include Rapetosaurus (0.54: Curry Rogers, 1160 2009) and Opisthocoelicaudia (0.64: Borsuk-Białynicka, 1977). The combined pubic and 1161 ischiadic acetabular rim in Savannasaurus is $520 \mathrm{~mm}$ long, measured along the curve (Fig. 1162 21C).

1163 Pubis - The paired pubes are almost completely fused along the midline, with the pubic 1164 symphysis manifesting as an irregular, dorsally raised ridge (Fig. 21E); however, a small, 1165 posteriorly situated triangular section $(80 \mathrm{~mm}$ anteroposteriorly $\times 100 \mathrm{~mm}$ transversely $)$ 1166 evidently remained unfused (Fig. 21B). Each pubis is also firmly fused with its corresponding 1167 ischium (Fig. 21B-D). The dorsoventral height of the ischiadic articulation is 0.56 times that 
1168 of the proximodistal length of the pubis - higher than in Diamantinasaurus (0.46) and most

1169 other titanosaurs (Salgado et al., 1997; Wilson and Sereno, 1998; Upchurch et al., 2004;

1170 Mannion et al., 2013; Poropat et al., 2015b). The proximal portions of both pubes are slightly

1171 incomplete, although based on the preserved margin of the acetabulum, very little of the right

1172 pubis is missing (Fig. 21E). As preserved, the incomplete iliac peduncle is almost three times

1173 longer anteroposteriorly than it is wide mediolaterally, although there is no guarantee that it

1174 was similarly proportioned at its summit. The iliac peduncle and the proximal portion of each

1175 pubis is oriented vertically. However, both pubes curve abruptly towards the midline, such

1176 that the long axes of their distal plates are parallel with each other. Consequently, the lateral

1177 surface of the distal plate of each pubis faces posteroventrally (Fig. 21D), whereas the medial 1178 surface faces anterodorsally (Fig. 21A). The lateral surface of each pubis is broadly divisible 1179 into three sections: the posterodorsal portion, including the obturator foramen (Fig. 21C); the 1180 anterodorsal portion, comprising the anterior margin; and the distal plate. The posterodorsal 1181 portion is dominated by the oval-shaped obturator foramen, which projects ventrolaterally1182 dorsomedially and is completely encircled by bone. The long axis of the lateral margin of the 1183 obturator foramen extends parallel to the long axis of the pubis. Laterally, the dorsal margin 1184 of the obturator foramen forms a thin, transversely compressed, dorsoventrally elongate lip; 1185 the same is true medially of its ventral margin. Anterior to the obturator foramen, the medial 1186 surface of the base of the iliac peduncle is anteroposteriorly convex; however, posteriorly 1187 and immediately ventral to the obturator foramen — it becomes mediolaterally and 1188 anteroposteriorly concave. The anterior and posterior margins of the obturator foramen are 1189 mediolaterally narrow. Ventral to the obturator foramen, a single anteroventrally1190 posterodorsally inclined ridge is present, somewhat similar to the multiple grooves and ridges 1191 seen in Diamantinasaurus (Poropat et al., 2015b). The incompletely preserved anterodorsal 1192 portion of the lateral surface of the pubis is essentially flat anterior to the obturator foramen, 
1193 and is the mediolaterally broadest portion of the pubis. No ambiens process is present (based

1194 on a portion of the right pubis not included in Fig. 21). The lateral surface of the pubis lacks

1195 the anteriorly positioned ridge and groove seen in several advanced titanosaurs (Powell,

1196 2003; Salgado and Carvalho, 2008; Otero, 2010; Poropat et al., 2016), including

1197 Epachthosaurus (Martínez et al., 2004). However, the anterodorsal portion of the pubis is

1198 separated from the distal plate by a subtle ventrolateral ridge (the external surface of which

1199 faces ventrally), which is an autapomorphy of Savannasaurus (Poropat et al., 2016). This

1200 ridge is approximately aligned with the ridge beneath the obturator foramen, and fades out

1201 before reaching the distal end of the pubis. Medial to this feature, the pubis is broadly

1202 dorsoventrally convex on its medial surface, becoming concave again towards the pubic

1203 symphysis. With the pubes oriented in vivo, the distal plate of each is markedly expanded

1204 mediolaterally and extremely compressed dorsoventrally (less than $20 \mathrm{~mm}$ thick on average,

1205 such that it is laminar as in most somphospondylans (Curry Rogers, 2005; Poropat et al.,

1206 2016). The anterior margin of the distal plate is strongly concave in lateral view, such that it

1207 forms a pubic 'boot' (Fig. 21C). The ventral surfaces of the distal plates are convex towards

1208 their lateral margins and shallowly mediolaterally concave towards the pubic symphysis; this

1209 concavity becomes increasingly pronounced towards the posteromedial margin. By contrast,

1210 the medial (anterodorsally-facing) surface of the distal plate is very slightly concave

1211 mediolaterally.

1212 Ischium - The paired ischia were evidently fused along almost their entire length, as in 1213 most other titanosaurs (McIntosh, 1990; Upchurch, 1998; Wilson, 2002), with only a slight 1214 separation at the distal end (Fig. 21A-B). The pubic articulation is dorsoventrally taller than 1215 the proximal plate is anteroposteriorly long, as in most titanosauriforms (Salgado et al., 1997;

1216 Carballido et al., 2012; Mannion et al., 2019b). The long axis of the ischiadic shaft is

1217 approximately $60^{\circ}$ to the horizontal in lateral view, as in most sauropods (Upchurch, 1995, 
1218 1998; Wilson and Sereno, 1998), and is inclined at approximately $90^{\circ}$ relative to the

1219 acetabular line, as in most macronarians (Carballido et al., 2012; Mannion et al., 2019b),

1220 other than Opisthocoelicaudia (Borsuk-Białynicka, 1977) and Isisaurus (Jain and

1221 Bandyopadhyay, 1997). The iliac peduncle of each ischium is essentially complete and is 1222 convex on all faces except for the acetabular and medial margins. The mediolateral width of 1223 the iliac articular surface is less than half the anteroposterior length of the same (ratio $=0.47)$, 1224 contrasting with Wintonotitan (1.43: Poropat et al., 2015a) and Diamantinasaurus (0.80: 1225 Poropat et al., 2015b). In lateral view, the iliac peduncle is essentially straight. The ratio of 1226 the anteroposterior length of the iliac peduncle to that of the proximal plate is 0.32 , 1227 significantly lower than that of most other sauropods (Wilson, 2002; D'Emic, 2012; Mannion 1228 et al., 2013), including Wintonotitan (0.63: Poropat et al., 2015a) and Diamantinasaurus 1229 (0.53: Poropat et al., 2015b), and indicating that the ischium in Savannasaurus contributed 1230 significantly to the acetabulum. The acetabular margin is well preserved in both ischia. It has 1231 an essentially uniform mediolateral thickness along its length, and is strongly concave in 1232 lateral view (as in titanosaurs generally (D'Emic, 2012)), tapering to a very thin, medially1233 projecting lip. Ventral to the acetabulum, the ischium is dorsoventrally convex on its lateral 1234 surface, and correspondingly dorsoventrally concave on its medial surface. The ratio of the 1235 anteroposterior length of the proximal plate to the proximodistal length of the ischium is 0.42 , 1236 higher than in any other sauropod (Mannion et al., 2013), including Wintonotitan (0.36: 1237 Poropat et al., 2015a) and Diamantinasaurus (0.31: Poropat et al., 2015b); this possibly 1238 represents an autapomorphy of Savannasaurus (Table S10). The distinct ridge at the posterior 1239 margin of the ischium is thickest at mid-height, forming the point of attachment for M. flexor 1240 tibialis internus 3 (Fig. 21C). This ridge projects further laterally than that of

1241 Diamantinasaurus (Poropat et al., 2015b), and less so than that of Wintonotitan (Poropat et 1242 al., 2015a), but is more robust anteroposteriorly in Savannasaurus than in either. As in most 
1243 titanosauriforms, there is no groove associated with this ridge in Savannasaurus (D'Emic,

1244 2012; Poropat et al., 2016). Distally, the lateral surface of the ischium becomes

1245 anteroposteriorly (and somewhat dorsoventrally) concave between three landmarks: the

1246 proximal ventral convexity, the posterior ridge, and the anteromedialmost portion of the distal

1247 plate. The medial portion of each ischium is twisted such that the medial surface faces

1248 posterodorsally, and the lateral one faces anteroventrally. Consequently, the distal ends of the

1249 ischia are nearly coplanar, as in most macronarians (Upchurch, 1998; Wilson and Sereno,

1250 1998). The mediolateral width of the distal end of the ischium is equal to almost exactly half

1251 the proximodistal length of the entire element (0.49); the only other sauropod with a similarly

1252 high value for this ratio (0.51) is Diamantinasaurus (Mannion et al., 2013; Poropat et al.,

1253 2015b). By contrast, the mediolateral width of the distal end of the ischium is only 1.26 times

1254 the minimum mediolateral width of the ischium as a whole, as in many titanosauriforms (1.1-

1255 1.7; Mannion et al., 2013), but not Diamantinasaurus (1.95: Poropat et al., 2015b).

1256

1257 Astragalus

1258 The left astragalus of Savannasaurus is virtually complete (Fig. 22A-F; Table S11). It is

1259 unusual inasmuch as its proximodistal height is greater than either the mediolateral or

1260 anteroposterior diameters, as a result of the reduction of the medial process and the

1261 accentuation of the ascending process. Presuming that the astragalus has not suffered

1262 significant post mortem distortion, the extremely low mediolateral width to proximodistal

1263 height ratio (0.87) and the low mediolateral width to anteroposterior length ratio $(0.98)$ are

1264 both autapomorphic for Savannasaurus (Poropat et al., 2016), since these values are

1265 substantially lower than those of all other titanosauriforms (Mannion et al., 2013). In

1266 proximal view (Fig. 22A), the astragalus is wedge-shaped, as in all neosauropods (Upchurch, 
1267 1998; Wilson and Sereno, 1998). The apex of the ascending process is positioned nearer to 1268 the posterior margin than the anterior one (Fig. 22C), which is typical of neosauropods 1269 (Wilson and Sereno, 1998; Wilson, 2002), and is closer to the lateral margin than the medial 1270 one (Fig. 22B, E). The tibial articular surface of the ascending process can be divided into 1271 three regions: a flat anterior surface; a concave medial surface; and a flat posterior surface. 1272 The anterior surface (Fig. 22E) is steeply inclined anterodistally and is reasonably smooth 1273 near its apex, whereas further distally it develops a series of ridges and grooves that are more 1274 elongate and shallower than those elsewhere. The concave medial surface (Fig. 22C) is 1275 separated from the anterior surface by a subtle anteromedial shelf. Although no paired 1276 foramina are visible on the medial surface, it is likely that they are present but are infilled 1277 with matrix. Both medial and posterior surfaces of the astragalus are covered in subtle ridges 1278 and shallow grooves, and they are separated from one another by a posteromedial ridge. In 1279 this regard, the astragalus of Savannasaurus differs from those of some derived titanosaurs 1280 (e.g. Neuquensaurus, Opisthocoelicaudia), in which the posterior fossa is undivided (Wilson, 1281 2002). The posterior surface of the ascending process is essentially flat (Fig. 22B). The 1282 fibular articular facet, which is situated on the lateral side of the ascending process (Fig. 22F), 1283 is shallow and has its long axis oriented posteroventrally-anterodorsally. Unlike the other 1284 surfaces of the astragalus, the bone forming the fibular articular facet is smoothly concave. 1285 The laterally-directed ventral shelf that underlies the fibula in many neosauropods is absent 1286 (Wilson and Upchurch, 2009; Mannion et al., 2013), contrasting with Diamantinasaurus 1287 (Poropat et al., 2015b). In distal view (Fig. 22D), the astragalus is broadly rhomboidal. The 1288 distal surface is shallowly convex mediolaterally, and the medial margin is more tapered than 1289 the lateral one; both of these features are typical of neosauropods (Upchurch, 1998). The 1290 posterodistal process that is present in Diamantinasaurus (Poropat et al., 2015b) and many 
1291 other titanosauriforms (D’Emic, 2012; Mannion et al., 2013) could not be identified in

1292 Savannasaurus, although the position it would have occupied (if present) is damaged.

1293

1294 Metatarsal III

1295 The right metatarsal III is essentially complete, missing only a small portion of bone along 1296 its dorsal surface (Fig. 22G-L; Table S12). In proximal view, it is wedge-shaped (Fig. 22G), 1297 with the convex medial and ventromedial margins merging smoothly into one another. The 1298 medial and ventromedial margins meet the straight dorsal and ventrolateral margins 1299 respectively at sharp angles, whereas the latter unite to form a dorsolateral point. The 1300 ventrolateral margin would have articulated with metatarsal IV, whereas the convex medial 1301 margin would have abutted against metatarsal II. The proximal surface is covered in ridges 1302 separated by deep grooves, implying the presence of a cartilaginous cap in life. The dorsal 1303 surface (Fig. 22H) is broadly concave proximodistally. This surface is transversely convex at 1304 the proximal end and along the distal third, but is flat in between. The lateral margin (Fig. 1305 22I) is expressed as a twisted ridge that is thick at the proximal end (extending from the 1306 dorsolateral corner), narrows slightly towards the mid-shaft, and thickens again as it merges 1307 with the lateral condyle at the distal end. Ventral to this ridge, the proximal end is deeply 1308 concave. This concavity fades out at approximately the mid-length of the shaft, distal to 1309 which the ventral surface becomes flat to slightly convex as it approaches the distal condyles. 1310 The distalmost section of the ventral surface (Fig. 22K) is concave between the weakly 1311 developed (and slightly incomplete) medial condyle and the more strongly developed lateral 1312 condyle. The medial surface (Fig. 22L) is relatively well preserved, and is proximodistally 1313 concave when viewed dorsally or ventrally. A small, worn, triangular facet at the proximal 1314 end was presumably the articulation site for metatarsal II; distal to this, the proximal half of 


\begin{abstract}
1315 the shaft is essentially flat and meets the dorsal and ventral surfaces at a $90^{\circ}$ angle. The
1316 corner separating the dorsal and medial margins projects distoventrally-proximodorsally

1317 because of the distal expansion of the dorsal surface. The external bone at the mid-shaft of

1318 the medial surface is missing, although it is clear that the medial surface became

1319 dorsoventrally convex at or just distal to this point; it remains dorsoventrally convex along

1320 the entire distal half. The distal end is reniform (Fig. 22J), with the dorsal margin broadly

1321 convex and the ventral one shallowly concave between the distal condyles. The medial

1322 surface of the distal end is nearly flat, whereas the lateral surface tapers ventrolaterally to a

1323 rounded point.
\end{abstract}

\title{
DISCUSSION
}

1326

\section{The Phylogenetic Affinities of Savannasaurus elliottorum}

1328 Although Savannasaurus has been included in several phylogenetic analyses since its 1329 initial description (Poropat et al., 2016), all of which ultimately derive from that of Mannion 1330 et al. (2013), its precise position within Somphospondyli remains uncertain. In several 1331 analyses it has been resolved as a non-lithostrotian titanosaur, specifically as the sister taxon 1332 to the clade comprising the Diamantinasaurus matildae holotype (AODF 603) and referred 1333 (AODF 836) specimens (Royo-Torres et al., 2017; Averianov and Efimov, 2018; González 1334 Riga et al., 2018; Mocho et al., 2019a, b); note that in Mannion et al. (2017), the resolved 1335 topology was the same, but incorrectly depicted as Diamantinasaurus + (Savannasaurus 1336 AODF 836). However, in one of these analyses (Royo-Torres et al., 2017), the exclusion of 1337 three taxa changed the topology such that Savannasaurus was situated at the base of a grade 
1338 comprising Diamantinasaurus, AODF 836, and Baotianmansaurus + Dongyangosaurus.

1339 Although Savannasaurus and Baotianmansaurus do share several features (e.g., absence of

1340 PRSL throughout dorsal vertebral series; presence of aSPDL and pSPDL in some middle

1341 dorsal vertebrae; absence of TPOL in middle dorsal vertebrae; amphicoelous caudal centra),

1342 there are other features that separate them (Zhang et al., 2009; 41H III-0200: PDM and PU

1343 pers. obs. 2012). These include the morphology of the anterior dorsal neural spines (bifid in

1344 Baotianmansaurus, undivided in Savannasaurus), number of PCPLs per side on the dorsal

1345 vertebrae (one in Baotianmansaurus, one or two in Savannasaurus), the inclination of the

1346 dorsal transverse processes (inclined dorsolaterally in Baotianmansaurus, essentially

1347 horizontal in Savannasaurus), and the presence/absence of hyposphene-hypantrum

1348 articulations in the dorsal vertebrae (present in anterior-middle dorsal vertebrae but not in the

1349 middle-posterior dorsal vertebrae of Baotianmansaurus, absent throughout the dorsal series

1350 in Savannasaurus). Similarly, there are several features that are shared between

1351 Dongyangosaurus and Savannasaurus (e.g. lack of ridges or excavations on ventral surfaces

1352 of dorsal centra; amphicoelous caudal centra; no ridge on lateral surface of pubic shaft).

1353 However, there are many other features that distinguish them: PODLs are present throughout

1354 the dorsal series of Dongyangosaurus but are only present in dorsal vertebrae VII-X of

1355 Savannasaurus; the dorsal neural spines of Dongyangosaurus are bifid, whereas those of

1356 Savannasaurus are not; and the anterior caudal centra of Dongyangosaurus lack the lateral

1357 excavations seen in (Lü et al., 2008; Mannion et al., 2019a).

1358 In another analysis (González Riga et al., 2019), the removal of eleven taxa (including

1359 AODF 836) and the addition of three characters caused Savannasaurus to fall out in a

1360 polytomy with Dongyangosaurus, Baotianmansaurus, and all titanosaurs more derived than

1361 Andesaurus + Ruyangosaurus, whereas Diamantinasaurus was resolved as the sister taxon to

1362 Lithostrotia. Another recent analysis (Silva Junior et al., 2019), which was based on that of 
1363 González Riga et al. (2018) but excluded all non-titanosauriform taxa, resolved

1364 Savannasaurus as a non-titanosaurian somphospondylan, whereas Diamantinasaurus was

1365 placed within Saltasauridae, as the sister taxon to AODF 836 + Baotianmansaurus. However,

1366 it is worth noting that this analysis also produced some unusual results that have not been

1367 recovered before, including the placement of Epachthosaurus and Colossosauria outside

1368 Titanosauria. Finally, in recent analyses of two slightly different, updated versions of the

1369 same matrix, Savannasaurus has been resolved within Saltasauridae as the sister taxon to

1370 AODF 836 + Diamantinasaurus when equal weights were used (Mannion et al., 2019a, b).

1371 However, when the analysis was run under extended implied weights, Savannasaurus was

1372 resolved outside Lithostrotia (Mannion et al., 2019a).

1373 As outlined above, Savannasaurus presents several anatomical features that argue against

1374 a placement within Saltasaurinae or Saltasauridae: cervical vertebrae with anteroposteriorly

1375 short parapophyses; dorsal vertebrae with deep pneumatic foramina; caudal vertebral centra

1376 not pneumatised; coracoid rounded; humerus lacks strong tuberosity for M. latissimus dorsi;

1377 radius distal end partially bevelled. Similarly, numerous features seem to set Savannasaurus

1378 apart from Lithostrotia, and from 'classic' members of Titanosauria as a whole: posterior

1379 dorsal vertebrae with horizontal TPRLs; middle sacral vertebral centra not constricted; caudal

1380 centra amphicoelous; anterior caudal vertebrae with pneumatic fossae; sternal plate D-

1381 shaped; manual phalanges present; pubis without lateral ridge. Nevertheless, in some respects

1382 Savannasaurus is similar to saltasaurids (e.g. humerus robust; ischium very short relative to

1383 pubis) and titanosaurs more generally (e.g. sternal plate elongate relative to humerus; ossified

1384 carpals absent; metacarpal distal articular surfaces non-extensive).

1385 One feature shared by Savannasaurus and Diamantinasaurus, that links them with

1386 'classic' titanosaurs and some basal somphospondylans, while simultaneously distinguishing

1387 them from brachiosaurids, euhelopodids and other basal somphospondylans, is the absence of 
1388 hyposphene-hypantrum articulations throughout the dorsal and caudal vertebral series. Most

1389 basal titanosauriforms, including brachiosaurids, euhelopodids, and some basal

1390 somphospondylans, possess hyposphene-hypantrum articulations in their middle-posterior

1391 dorsal vertebrae (Apesteguía, 2005). However, they are absent in the early-branching

1392 somphospondylan Jiangshanosaurus (Mannion et al., 2019a), and in many, but not all,

1393 titanosaurs (Salgado et al., 1997; Apesteguía, 2005). Some of the few titanosaurs that possess

1394 hyposphene-hypantrum articulations in (at least some of) their middle-posterior dorsal

1395 vertebrae are Andesaurus (Mannion and Calvo, 2011) — the sister taxon to all other

1396 titanosaurs by definition - and Epachthosaurus (Martínez et al., 2004). The lognkosaurian

1397 titanosaur Patagotitan has a hyposphene on dorsal vertebra III (and is presumed to have had a

1398 corresponding hypantrum on dorsal vertebra IV), and might have had a hyposphene on dorsal

1399 vertebra VI (MPEF-PV 3400: S.F.P., pers. obs. 2018); however, it lacks hyposphenes-

1400 hypantra throughout the rest of its dorsal series (Carballido et al., 2017). Although the

1401 prezygapophyses of at least one dorsal vertebra of Argentinosaurus appear to have hypantral

1402 articular facets (Bonaparte and Coria, 1993), there is no corresponding hyposphene on any of

1403 them, suggesting that this 'hypantrum' is an independently derived structure (Salgado et al.,

1404 1997; Apesteguía, 2005). Given that hyposphene-hypantrum articulations are present in

1405 brachiosaurids, euhelopodids, many (but not all) non-titanosaurian somphospondylans, some

1406 early-branching titanosaurs, and at least one lognkosaurian, the absence of these structures in

1407 Savannasaurus and Diamantinasaurus could be used to support a relatively derived position

1408 within Titanosauria. However, it is also possible that hyposphene-hypantrum articulations

1409 were independently lost or acquired multiple times within Titanosauria, since (for example)

1410 Epachthosaurus, which has prominent hyposphene-hypantrum articulations, shows more

1411 features aligned with 'classic' members of Titanosauria (e.g. strongly procoelous caudal

1412 vertebrae) than Savannasaurus and Diamantinasaurus. The absence of hyposphene- 
1413 hypantrum articulations in Savannasaurus and Diamantinasaurus, in tandem with numerous

1414 characters that are plesiomorphic for Titanosauria, might support the notion that they occupy 1415 an earlier-branching position within Titanosauria than Epachthosaurus, as resolved in many, 1416 but not all, recent phylogenetic analyses (Mannion et al., 2017, 2019a, 2019b; González Riga 1417 et al., 2018).

1418 The anterior caudal vertebrae of Savannasaurus also lack hyposphene-hypantrum 1419 articulations. This feature distinguishes Savannasaurus from brachiosaurids and 1420 euhelopodids, which tend to have narrow hyposphenal ridges on their caudal vertebrae 1421 (Mannion et al., 2013), and from Astrophocaudia (D’Emic, 2013), which has prominent, 1422 triangular hyposphenes on its caudal vertebrae. Among titanosaurs, hyposphenes are present 1423 in at least some caudal vertebrae of very few taxa; these include Volgatitan (Averianov and 1424 Efimov, 2018), Epachthosaurus (Martínez et al., 2004), Malawisaurus (Gomani, 2005) and 1425 Opisthocoelicaudia (Borsuk-Białynicka, 1977). Thus, the absence of hyposphene-hypantrum 1426 articulations in the caudal vertebrae of Savannasaurus aligns it with most, but not all, 1427 titanosaurs (Mannion et al., 2013). Caudal vertebral hyposphene-hypantrum articulations 1428 might also have been independently gained or lost multiple times within Titanosauria.

1429 Based on numerous similarities between Savannasaurus and Diamantinasaurus, we 1430 hypothesise that they form a clade (as resolved in many previous analyses (e.g., Poropat et 1431 al., 2016)) which occupies an early-branching position within Titanosauria. The anatomy of 1432 Savannasaurus (and Diamantinasaurus), as well as that of other taxa resolved in close 1433 phylogenetic proximity to them, suggests that 'classic' titanosaurs developed several features 1434 that the earliest diverging members of the clade lacked, such as procoelous (or 1435 opisthocoelous) anterior caudal vertebrae, loss of manual phalanges, and (in some cases) 1436 osteoderms. Several of the anatomical features that have led Savannasaurus (and 1437 Diamantinasaurus) to be resolved within Lithostrotia or Saltasauridae presumably represent 
1438 convergences (e.g., a robust humerus that is not much longer than the sternal plate);

1439 consequently, it is plausible that these features were linked to the wide-gauge gait adopted by

1440 Savannasaurus (and, to a lesser extent, Diamantinasaurus), which might in turn have

1441 developed (or been exaggerated) in response to the unique palaeoenvironment in which these 1442 titanosaurs lived.

1444 Savannasaurus as a 'Wide-Gauge' Sauropod: A Response to Paleoenvironmental 1445 Pressures?

1446 Even among titanosaurs, which are especially wide-bodied among sauropods,

1447 Savannasaurus elliottorum was extremely transversely broad across the thorax and pelvis

1448 relative to its body size. Given that dorsal vertebra III is $\sim 560 \mathrm{~mm}$ wide transversely across

1449 the diapophyses, that the most complete dorsal rib is $1680 \mathrm{~mm}$ long proximodistally, and that 1450 each sternal plate is $425 \mathrm{~mm}$ wide mediolaterally (total sternal breadth $=850 \mathrm{~mm}$ ), the 1451 circumference of the thorax of Savannasaurus would have exceeded 5 metres (including 1452 cartilage). Moreover, given that the sacrum is $934 \mathrm{~mm}$ across the posteriormost sacral 1453 processes, and the pelvis is $1140 \mathrm{~mm}$ wide transversely across the iliac peduncles of the 1454 pubes (and would have been broader still across the ilia, were they preserved), it was also 1455 clearly wide-hipped.

1456 Several truly gigantic sauropods appear to be less transversely broad relative to body size 1457 than Savannasaurus. The total sternal transverse breadth $(1090 \mathrm{~mm})$ of Patagotitan is 1.28 1458 times that of Savannasaurus, whereas the pubis $(1400 \mathrm{~mm})$ of Patagotitan is 1.49 times as 1459 long (Carballido et al., 2017). Similarly, the total sternal transverse breadth (at least 1160 $1460 \mathrm{~mm}$ ) of Dreadnoughtus is 1.36 times that of Savannasaurus, and the transverse breadth of the 1461 sacrum (1160 mm wide across the posteriormost sacral processes, sans ilia) is 1.24 times that 
1462 of Savannasaurus, despite the fact that the pubis $(1400 \mathrm{~mm})$ of Dreadnoughtus is 1.49 times

1463 as long. The sacrum of Futalognkosaurus (1170 mm wide transversely across the

1464 posteriormost sacral processes, sans ilia) is 1.25 times as broad as that of Savannasaurus,

1465 despite the pubis $(1370 \mathrm{~mm})$ of Futalognkosaurus being 1.46 times as long. By these metrics, 1466 these titanosaurs, which were substantially larger than Savannasaurus, were not as wide1467 bodied relative to body size.

1468 By contrast, Opisthocoelicaudia appears to exceed Savannasaurus in terms of transverse 1469 breadth relative to body size (Borsuk-Białynicka, 1977). Each appendicular element 1470 preserved in Savannasaurus is proximodistally longer than its counterpart in 1471 Opisthocoelicaudia (even the humerus, which is incomplete in Savannasaurus). Despite this, 1472 in Opisthocoelicaudia the left and right sternal plates have mediolateral widths of $480 \mathrm{~mm}$ 1473 and $500 \mathrm{~mm}$ respectively (giving a total sternal breadth of at least $980 \mathrm{~mm}, 1.15$ times that of 1474 Savannasaurus), whereas the sacrum measures approximately $1060 \mathrm{~mm}$ across the 1475 posteriormost sacral processes (1.13 times that of Savannasaurus; approximated from 1476 published figures). Saltasaurines also appear to have been broader relative to body size than 1477 Savannasaurus. The transverse breadth of the sacrum in Neuquensaurus ( $\sim 580 \mathrm{~mm}$ across the 1478 posteriormost sacral processes) is 0.62 times that of Savannasaurus, despite the fact that the 1479 humerus (520 mm long proximodistally) is less than half as long (Salgado et al., 2005).

1480 There is little doubt that Savannasaurus would have habitually had a wide-gauge stance 1481 (Fig. 23) and, presumably, a wide-gauge gait, as has been hypothesised for titanosaurs 1482 generally (Wilson and Carrano, 1999; Carrano, 2005). The increased robusticity of the 1483 humerus might have developed in response to this, whereas the marked distal expansion of 1484 metacarpal I implies that more weight was supported by it than the more lateral metacarpals. 1485 The unique morphology of the astragalus of Savannasaurus might also have developed in 
1486 response to increased weight-bearing, although the absence of the femur, tibia and fibula

1487 makes this difficult to discern.

1488 The vertebral column of Savannasaurus shows several features that appear to be linked to 1489 increased flexibility. Prominent among these is the lack of a hyposphene-hypantrum system 1490 throughout the vertebral column. Instead, dorsal vertebrae VI-X of Savannasaurus lack 1491 TPOLs (resulting in the confluence of the CPOF+SPOF), and the CPOLs and 1492 postzygapophyses are separated on the midline. This is unusual among sauropods generally, 1493 but is also observed in Diamantinasaurus (Poropat et al., 2016). In addition, all preserved 1494 dorsal vertebrae of Savannasaurus have a prominent CPRF ventral to the TPRL, an unusual 1495 feature among titanosaurs, but again seen in Diamantinasaurus (S.F.P., P.D.M \& P.U., 1496 unpublished data).

1497 Savannasaurus and Diamantinasaurus inhabited a floodplain environment, characterised 1498 by clay-rich soils and probably dominated by extensive meandering river systems (Fletcher et 1499 al., 2018). Average annual rainfall is thought to have been relatively high (Fletcher et al., 1500 2014b), which implies that the volcanogenic soils surrounding the watercourses on the 1501 floodplain might have been treacherous for multi-tonne sauropods to traverse at certain times 1502 of year. Although it is tempting to suggest that this environmental pressure would have 1503 selected for sauropods with more elongate necks, which would have been able to access 1504 water sources while standing several metres back from the edge, the preserved cervical 1505 vertebrae of both Diamantinasaurus and Savannasaurus suggest that their necks were 1506 relatively short and unspecialised for such a purpose (that said, the elongate cervical ribs of 1507 Savannasaurus [at least] might have improved the stability of the neck when it was held 1508 horizontally). In light of this, it is possible that the environmental pressures to which 1509 sauropods in northeast Australia were subjected might have selected for individuals that were 59

1510 better able to enter, traverse and exit muddy watercourses. In this scenario, more flexible 
1511 dorsal and caudal vertebral series, barrel-like bodies (more akin to those of hippopotamus

1512 than to the slab-sided thoraces of other sauropods), and robust forelimbs might have been

1513 favoured. If other titanosaurian taxa or lineages were independently subjected to similar

1514 environmental pressures elsewhere, then it is possible that the bauplan regarded as 'typical'

1515 for this clade might in fact have developed, or at least been accentuated, multiple times. This

1516 might also serve to explain the many convergences between Savannasaurus and saltasaurids.

CONCLUSION

The postcranial skeleton of Savannasaurus elliottorum shows a mosaic of anatomical

1521 features. Some of these are generally regarded as plesiomorphic for Titanosauria, whereas others are often regarded as apomorphies of Titanosauria or a less inclusive clade thereof. This blend of putative titanosaurian plesiomorphies and apomorphies is also seen in a contemporary of Savannasaurus, Diamantinasaurus matildae, and it is likely that they form a clade. Based on the absence of hyposphene-hypantrum articulations, the pneumatic nature of the caudal vertebral neural arches, the proportions of the appendicular elements, and other features, this clade would appear to occupy a position within Titanosauria, probably outside Lithostrotia. The non-reniform sternal plate presumably represents a reversal within Titanosauriformes, whereas the presence of manual phalanges supports an early-branching 1530 position for Savannasaurus (and Diamantinasaurus) within Titanosauria.

1532 Savannasaurus suggest that it was well adapted to the wet, temperate floodplain environment 1533 it inhabited. The barrel-shaped thorax, reminiscent of that of the hippopotamus, might 
1534 indicate that Savannasaurus spent more time in or near shallow water (or at least waterlogged

1535

1536

1537

1538

1539

1540

1541

1542

1543

1544

1545

1546

1547

1548

1549

1550

1551

1552

1553

1554

1555

1556

1557

sediments) than other sauropods. The increased flexibility of the spinal column potentially

enabled Savannasaurus to more expediently extricate itself from wallows and bogs. By

contrast, the capacity that Savannasaurus clearly possessed to distribute its body weight over

a greater area through its wide-gauge stance might have reduced its risk of becoming bogged

in the first place when traversing the muddy floodplains of northeast Australia during times

of high rainfall or flood.

\section{ACKNOWLEDGMENTS}

The authors would like to thank: additional members of the Elliott family for facilitating the excavation of 'Wade' on Belmont Station in 2005; the volunteers who participated in the 'Wade' digs in 2005 and who prepared the specimen over the course of the next decade; the staff at the Australian Age of Dinosaurs Museum of Natural History; A. Kramarz and M. Ezcurra (Museo Argentino de Ciencias Naturales 'Bernardino Rivadavia'), A. Otero (Museo de La Plata), J. Powell (Universidad Nacional de Tucuman), B. González Riga and L. Ortíz David (Universidad Nacional de Cuyo), J. Calvo and J. Mansilla (Museo de Geología y Paleontología de la Universidad Nacional del Comahue), V. Zurriaguz and I. Cerda (Universidad Nacional de Río Negro; Museo Provincial de Cipolletti “Carlos Ameghino”), D. Pol and J. Carballido (Museo Paleontológico Egidio Feruglio), R. Martínez and M. Luna (Universidad Nacional de la Patagonia San Juan Bosco), L. Ibiricu (Instituto Patagónico de Geología y Paleontología) and others for allowing S.F.P., P.D.M. and P.U. to make firsthand observations of Argentinean sauropod specimens in their care; and reviewers J. Whitlock (Mount Aloysius College) and J. Carballido (Museo Paleontológico Egidio Feruglio), and 
1558 editor M. D’Emic (Adelphi University) for their constructive comments that greatly improved 1559 this manuscript. S.F.P.'s early work on this project was funded by an Australian Research 1560 Council Linkage Grant (LP100100339, awarded to B. Kear) and hosted at Uppsala University 1561 (Sweden). S.F.P. would also like to thank the Winston Churchill Memorial Trust for a 1562 Churchill Fellowship (awarded in 2017) that enabled him to make firsthand observation of 1563 several Argentinian sauropod specimens, and The Paleontological Society for an Arthur 1564 James Boucot Research Grant (awarded in 2017) that funded a trip to Winton to study 1565 Savannasaurus firsthand. P.D.M.'s research is supported by a Royal Society University 1566 Research Fellowship (UF160216). P.U.'s contribution was facilitated by a Leverhulme Trust 1567 Research Grant (RPG-129).

1568

1569

\section{REFERENCES}

1570

Apesteguía, S. 2005. Evolution of the hyposphene-hypantrum complex within Sauropoda; pp. 1572 248-267 in V. Tidwell, and K. Carpenter (eds.), Thunder-lizards: The Sauropodomorph Dinosaurs. Indiana University Press, Bloomington \& Indianapolis, IA.

1574 Averianov, A., and V. Efimov. 2018. The oldest titanosaurian sauropod of the Northern 1575 Hemisphere. Biological Communications 63:145-162.

1576 Bandeira, K. L. N., F. Medeiros Simbras, E. B. Machado, D. d. A. Campos, G. R. Oliveira, and A. W. A. Kellner. 2016. A new giant Titanosauria (Dinosauria: Sauropoda) from 1578 the Late Cretaceous Bauru Group, Brazil. PLOS One 11:e163373.

1579 Berrell, R. W., J. Alvarado-Ortega, Y. Yabumoto, and S. W. Salisbury. 2014. The first record of the ichthyodectiform fish Cladocylcus[sic: Cladocyclus] from eastern Gondwana: a 
1581

1582

1583

1584

1585

1586

1587

1588

1589

1590

1591

1592

1593

1594

1595

1596

1597

1598

1599

1600

1601

1602

new species from the Lower Cretaceous of Queensland, Australia. Acta Palaeontologica Polonica 59:903-920.

Bonaparte, J. F. 1986. Les Dinosaures (Carnosaures, Allosauridés, Sauropodes, Cétiosauridés) du Jurassique Moyen de Cerro Cóndor (Chubut, Argentine) (2 $2^{\mathrm{e}}$ partie et fin). Annales de Paléontologie (Vert.-Invert.) 72:325-386.

Bonaparte, J. F., and R. A. Coria. 1993. Un nuevo y gigantesco saurópodo titanosaurio de la Formación Rio Limay (Albiano-Cenomaniano) de la Provincia del Neuquén, Argentina. Ameghiniana 30:271-282.

Bonaparte, J. F., B. J. González Riga, and S. Apesteguía. 2006. Ligabuesaurus leanzai gen. et sp. nov. (Dinosauria, Sauropoda), a new titanosaur from the Lohan Cura Formation (Aptian, Lower Cretaceous) of Neuquén, Patagonia, Argentina. Cretaceous Research $27: 364-376$.

Borsuk-Białynicka, M. 1977. A new camarasaurid sauropod Opisthocoelicaudia skarzynskii gen. n., sp. n. from the Upper Cretaceous of Mongolia. Palaeontologia Polonica 37:564.

Calvo, J. O., and J. F. Bonaparte. 1991. Andesaurus delgadoi gen. et sp. nov. (SaurischiaSauropoda), dinosaurio Titanosauridae de la Formación Río Limay (AlbianoCenomaniano), Neuquén, Argentina. Ameghiniana 28:303-310.

Calvo, J. O., J. D. Porfiri, B. J. González Riga, and A. W. A. Kellner. 2007. Anatomy of Futalognkosaurus dukei Calvo, Porfiri, González Riga \& Kellner, 2007 (Dinosauria, Titanosauridae) from the Neuquén Group (Late Cretaceous), Patagonia, Argentina. Arquivos do Museu Nacional, Rio de Janeiro 65:511-526. 
1603 Calvo, J. O., and L. Salgado. 1995. Rebbachisaurus tessonei sp. nov. a new Sauropoda from 1604 the Albian-Cenomanian of Argentina: new evidence on the origin of the Diplodocidae. $1605 \quad$ Gaia 11:13-33.

1606 Campos, D. d. A., A. W. A. Kellner, R. J. Bertini, and R. M. Santucci. 2005. On a 1607 titanosaurid (Dinosauria, Sauropoda) vertebral column from the Bauru Group, Late 1608 Cretaceous of Brazil. Arquivos do Museu Nacional, Rio de Janeiro 63:565-593.

1609 Canudo, J. I., R. Royo-Torres, and G. Cuenca-Bescós. 2008. A new sauropod: 1610 Tastavinsaurus sanzi gen. et sp. nov. from the Early Cretaceous (Aptian) of Spain. $1611 \quad$ Journal of Vertebrate Paleontology 28:712-731.

1612 Carballido, J. L., D. Pol, I. Cerda, and L. Salgado. 2011. The osteology of Chubutisaurus 1613 insignis Del Corro, 1975 (Dinosauria: Neosauropoda) from the 'Middle' Cretaceous of 1614 Central Patagonia, Argentina. Journal of Vertebrate Paleontology 31:93-110.

1615 Carballido, J. L., D. Pol, A. Otero, I. A. Cerda, L. Salgado, A. C. Garrido, J. Ramezzani, N. 1616 R. Cúneo, and M. J. Krause. 2017. A new giant titanosaur sheds light on body mass 1617 evolution among sauropod dinosaurs. Proceedings of the Royal Society B 284:20171219.

1619 Carballido, J. L., D. Pol, M. L. Parra Ruge, S. Padilla Bernal, M. E. Páramo-Fonseca, and F. 1620 Etayo-Serna. 2015. A new Early Cretaceous brachiosaurid (Dinosauria, Neosauropoda) 1621 from northwestern Gondwana (Villa de Leiva, Colombia). Journal of Vertebrate $1622 \quad$ Paleontology 35:e980505.

1623 Carballido, J. L., L. Salgado, D. Pol, J. I. Canudo, and A. Garrido. 2012. A new basal 1624 rebbachisaurid (Sauropoda, Diplodocoidea) from the Early Cretaceous of the Neuquén 1625 Basin; evolution and biogeography of the group. Historical Biology 24:631-654. 
1626 Carrano, M. T. 2005. The evolution of sauropod locomotion: morphological diversity of a

1627

1628

1629

1630

1631

1632

1633

1634

1635

1636

1637

1638

1639

1640

1641

1642

1643

1644

1645 secondary quadrupedal rotation; pp. 229-251 in K. A. Curry Rogers, and J. A. Wilson (eds.), The Sauropods: Evolution and Paleobiology. University of California Press, Berkeley.

Cerda, I. A., L. Salgado, and J. E. Powell. 2012. Extreme postcranial pneumaticity in sauropod dinosaurs from South America. Paläontologische Zeitschrift 86:441-449.

Clifford, H. T., and M. E. Dettmann. 2005. First record from Australia of the Cretaceous fern genus Tempskya and the description of a new species, T. judithae. Review of Palaeobotany and Palynology 134:71-84.

Cook, A. G. 2005. First record of fossil freshwater gastropods within the Winton Formation. Memoirs of the Queensland Museum 51:406.

Coombs, W. P., Jr., and R. E. Molnar. 1981. Sauropoda (Reptilia, Saurischia) from the Cretaceous of Queensland. Memoirs of the Queensland Museum 20:351-373.

Coria, R. A., L. S. Filippi, L. M. Chiappe, R. García, and A. B. Arcucci. 2013. Overosaurus paradasorum gen. et sp. nov., a new sauropod dinosaur (Titanosauria: Lithostrotia) from the Late Cretaceous of Neuquén, Patagonia, Argentina. Zootaxa 3683:357-376.

Csiki, Z., V. Codrea, C. Jipa-Murzea, and P. Godefroit. 2010. A partial titanosaur (Sauropoda, Dinosauria) skeleton from the Maastrichtian of Nălaţ-Vad, Haţeg Basin, Romania. Neues Jahrbuch für Geologie und Paläontologie, Abhandlungen 258:297324. 
1646 Curry Rogers, K. 2009. The postcranial osteology of Rapetosaurus krausei (Sauropoda:

1647 Titanosauria) from the Late Cretaceous of Madagascar. Journal of Vertebrate

$1648 \quad$ Paleontology 29:1046-1086.

1649 Curry Rogers, K. A. 2005. Titanosauria: a phylogenetic overview; pp. 50-103 in K. A. Curry

1650 Rogers, and J. A. Wilson (eds.), The Sauropods: Evolution and Paleobiology.

$1651 \quad$ University of California Press, Berkeley.

1652 D’Emic, M. D. 2012. Early evolution of titanosauriform sauropod dinosaurs. Zoological 1653 Journal of the Linnean Society 166:624-671.

1654 D'Emic, M. D. 2013. Revision of the sauropod dinosaurs of the Lower Cretaceous Trinity

1655 Group, southern USA, with the description of a new genus. Journal of Systematic $1656 \quad$ Palaeontology 11:707-726.

1657 D’Emic, M. D., P. D. Mannion, P. Upchurch, R. B. J. Benson, Q. Pang, and Z. Cheng. 2013. 1658 Osteology of Huabeisaurus allocotus (Sauropoda: Titanosauriformes) from the Upper 1659 Cretaceous of China. PLOS One 8:e69375.

1660 D’Emic, M. D., and J. A. Wilson. 2011. New remains attributable to the holotype of the 1661 sauropod dinosaur Neuquensaurus australis, with implications for saltasaurine 1662 systematics. Acta Palaeontologica Polonica 56:61-73.

1663 Del Corro, G. 1975. Un nuevo saurópodo del Cretácico Superior, Chubutisaurus insignis gen. 1664 et sp. nov. (Saurischia, Chubutisauridae nov.) del Cretácico Superior (Chubutiano), 1665 Chubut, Argentina. Actas I Congreso Argentino de Paleontología y Biostratigrafía:2291666240. 
1667 Dettmann, M. E., and H. T. Clifford. 2000. Gemmae of the marchantiales from the Winton Formation (mid-Cretaceous), Eromanga Basin, Queensland. Memoirs of the Queensland Museum 45:285-292.

Dettmann, M. E., H. T. Clifford, and M. Peters. 2009. Lovellea wintonensis gen. et sp. nov. Early Cretaceous (late Albian), anatomically preserved, angiospermous flowers and fruits from the Winton Formation, western Queensland, Australia. Cretaceous Research $30: 339-355$.

Dettmann, M. E., H. T. Clifford, and M. Peters. 2012. Emwadea microcarpa gen. et sp. nov.- - anatomically preserved araucarian seed cones from the Winton Formation (late

Dunstan, B. 1916. Queensland geological formations; pp. in G. Harrap (ed.), A School 1681 Geography of Queensland. Department of Public Instruction, Brisbane, Australia.

Exon, N. F., and B. R. Senior. 1976. The Cretaceous of the Eromanga and Surat Basins. Bureau of Mineral Resources, Geology and Geophysics Bulletin 1:33-50.

1684 Fletcher, T. L., D. J. Cantrill, P. T. Moss, and S. W. Salisbury. 2014a. A new species of 1685 Protophyllocladoxylon from the Upper Cretaceous (Cenomanian-Turonian) portion of 1686 the Winton Formation, central-western Queensland, Australia. Review of Palaeobotany 1687 and Palynology 208:43-49. 
1688 Fletcher, T. L., D. R. Greenwood, P. T. Moss, and S. W. Salisbury. 2014b. Paleoclimate of the Late Cretaceous (Cenomanian-Turonian) portion of the Winton Formation, centralwestern Queensland, Australia: new observations based on CLAMP and bioclimatic analysis. PALAIOS 29:121-128.

1692 Fletcher, T. L., P. T. Moss, and S. W. Salisbury. 2018. The palaeoenvironment of the Upper 1693 Cretaceous (Cenomanian-Turonian) portion of the Winton Formation, Queensland, $1694 \quad$ Australia. PeerJ 6:e5513.

1695 Fletcher, T. L., and S. W. Salisbury. 2014. Probable oribatid mite (Acari: Oribatida) tunnels 1696 and faecal pellets in silicified conifer wood from the Upper Cretaceous (Cenomanian1697 Turonian) portion of the Winton Formation, central-western Queensland, Australia. $1698 \quad$ Alcheringa 38:541-545.

1699 Fronimos, J. 2011. Patterns of postcranial pneumaticity in the Late Cretaceous titanosaur $1700 \quad$ Alamosaurus sanjuanensis. Journal of Vertebrate Paleontology 31:112A-113A.

1701 Gilmore, C. W. 1936. Osteology of Apatosaurus with special reference to specimens in the 1702 Carnegie Museum. Memoirs of the Carnegie Museum 11:175-300.

1703 Gilmore, C. W. 1946. Reptilian fauna of the North Horn Formation of central Utah. United 1704 States Geological Survey Professional Paper 210-C:29-53.

1705 Gomani, E. M. 2005. Sauropod dinosaurs from the Early Cretaceous of Malawi, Africa. 1706 Palaeontologia Electronica 8:27A.

1707 González Riga, B. J. 2003. A new titanosaur (Dinosauria, Sauropoda) from the Upper 1708 Cretaceous of Mendoza Province, Argentina. Ameghiniana 40:155-172. 
1709 González Riga, B. J. 2005. Nuevos restos fósiles de Mendozasaurus neguyelap (Sauropoda,

1710 Titanosauria) del Cretácico Tardío de Mendoza, Argentina. Ameghiniana 42:535-548.

1711 González Riga, B. J., M. C. Lamanna, A. Otero, L. D. Ortíz David, A. W. A. Kellner, and L.

1712 M. Ibiricu. 2019. An overview of the appendicular skeletal anatomy of South American

1713 titanosaurian sauropods, with definition of a newly recognized clade. Anais da

$1714 \quad$ Academia Brasileira de Ciências 91:e20180374.

1715 González Riga, B. J., P. D. Mannion, S. F. Poropat, L. D. Ortíz David, and J. P. Coria. 2018.

1716 Osteology of the Late Cretaceous Argentinean sauropod dinosaur Mendozasaurus

1717 neguyelap: implications for basal titanosaur relationships. Zoological Journal of the

$1718 \quad$ Linnean Society 184:136-181.

1719 González Riga, B. J., E. Previtera, and C. A. Pirrone. 2009. Malarguesaurus florenciae gen.

1720 et sp. nov., a new titanosauriform (Dinosauria, Sauropoda) from the Upper Cretaceous

1721 of Mendoza, Argentina. Cretaceous Research 30:135-148.

1722 Gorscak, E., and P. M. O’Connor. 2019. A new African titanosaurian sauropod dinosaur from 1723 the middle Cretaceous Galula Formation (Mtuka Member), Rukwa Rift Basin, 1724 southwestern Tanzania. PLOS One 14:e0211412.

1725 Gorscak, E., P. M. O’Connor, N. J. Stevens, and E. M. Roberts. 2014. The basal titanosaurian 1726 Rukwatitan bisepultus (Dinosauria, Sauropoda) from the middle Cretaceous Galula 1727 Formation, Rukwa Rift Basin, southwestern Tanzania. Journal of Vertebrate $1728 \quad$ Paleontology 34:1133-1154.

1729 Gray, A. R. G., M. McKillop, and J. L. McKellar. 2002. Eromanga Basin Stratigraphy; pp. $1730 \quad 30-56$ in J. J. Draper (ed.), Geology of the Cooper and Eromanga Basins, Queensland. 1731 Department of Natural Resources and Mines, Brisbane. 
1732 Hocknull, S. A. 1997. Cretaceous freshwater bivalves from Queensland. Memoirs of the 1733 Queensland Museum 42:223-226.

1734 Hocknull, S. A. 2000. Mesozoic freshwater and estuarine bivalves from Australia. Memoirs 1735 of the Queensland Museum 45:405-426.

1736 Hocknull, S. A., and A. G. Cook. 2008. Hypsilophodontid (Dinosauria, Ornithischia) from 1737 latest Albian, Winton Formation, central Queensland. Memoirs of the Queensland $1738 \quad$ Museum 52:212.

1739 Hocknull, S. A., M. A. White, T. R. Tischler, A. G. Cook, N. D. Calleja, T. Sloan, and D. A. 1740 Elliott. 2009. New mid-Cretaceous (latest Albian) dinosaurs from Winton, Queensland, $1741 \quad$ Australia. PLOS One 4:e6190.

1742 Hogg, D. A. 1984. The distribution of pneumatisation in the skeleton of the adult domestic 1743 fowl. Journal of Anatomy 138:617-629.

1744 Jain, S. L., and S. Bandyopadhyay. 1997. New titanosaurid (Dinosauria: Sauropoda) from the 1745 Late Cretaceous of central India. Journal of Vertebrate Paleontology 17:114-136.

1746 Jell, P. A. 2004. Fossil insects of Australia. Memoirs of the Queensland Museum 50:1-123.

1747 Juárez Valieri, R. D., and J. O. Calvo. 2011. Revision of MUCPv 204, a Senonian basal 1748 titanosaur from northern Patagonia; pp. 143-152 in J. Calvo, J. Porfiri, B. González 1749 Riga, and D. Dos Santos (eds.), Paleontología y Dinosaurios desde América Latina. $1750 \quad$ Editorial de la Universidad Nacional de Cuyo, Mendoza.

1751 Kear, B. P. 2016. Cretaceous marine amniotes of Australia: perspectives on a decade of new 1752 research. Memoirs of Museum Victoria 74:17-28. 
1753 Kellner, A. W. A., D. d. A. Campos, and M. N. F. Trotta. 2005. Description of a titanosaurid 1754 caudal series from the Bauru Group, Late Cretaceous of Brazil. Arquivos do Museu 1755 Nacional, Rio de Janeiro 63:529-564.

1756 Kemp, A. 1997. Four species of Metaceratodus (Osteichthyes: Dipnoi, family

1757 Ceratodontidae) from Australian Mesozoic and Cainozoic deposits. Journal of $1758 \quad$ Vertebrate Paleontology 17:26-33.

1759 Kemp, A., and R. E. Molnar. 1981. Neoceratodus forsteri from the Lower Cretaceous of New 1760 South Wales, Australia. Journal of Paleontology 55:211-217.

1761 Klinkhamer, A. J., H. Mallison, S. F. Poropat, G. H. K. Sinapius, and S. Wroe. 2018.

1762 Three-dimensional musculoskeletal modelling of the sauropodomorph hind limb: the 1763 effect of postural change on muscle leverage. Anatomical Record 301:2145-2163.

1764 Klinkhamer, A. J., H. Mallison, S. F. Poropat, T. Sloan, and S. Wroe. 2019. Comparative 1765 three-dimensional moment arm analysis of the sauropod forelimb: implications for the 1766 transition to a wide-gauge stance in titanosaurs. Anatomical Record 302:794-817.

1767 Ksepka, D. T., and M. A. Norell. 2006. Erketu ellisoni, a long-necked sauropod from Bor 1768 Guvé (Dornogov Aimag, Mongolia). American Museum Novitates 3508:1-16.

1769 Ksepka, D. T., and M. A. Norell. 2010. The illusory evidence for Asian Brachiosauridae: new 1770 material of Erketu ellisoni and a phylogenetic reappraisal of basal Titanosauriformes. $1771 \quad$ American Museum Novitates 3700:1-27.

1772 Le Loeuff, J. 2005. Osteology of Ampelosaurus atacis (Titanosauria) from southern France; 1773 pp. 115-137 in V. Tidwell, and K. Carpenter (eds.), Thunder-lizards: The 
1774 Sauropodomorph Dinosaurs. Indiana University Press, Bloomington \& Indianapolis, 1775 IA.

1776 Leahey, L. G., and S. W. Salisbury. 2013. First evidence of ankylosaurian dinosaurs 1777 (Ornithischia: Thyreophora) from the mid-Cretaceous (late Albian-Cenomanian) 1778 Winton Formation of Queensland, Australia. Alcheringa 37:249-257.

1779 Lehman, T. M., and A. B. Coulson. 2002. A juvenile specimen of the sauropod dinosaur 1780 Alamosaurus sanjuanensis from the Upper Cretaceous of Big Bend National Park, $1781 \quad$ Texas. Journal of Paleontology 76:156-172.

1782 Leite, K. J., and D. C. Fortier. 2018. The palate and choanae structure of the Susisuchus 1783 anatoceps (Crocodyliformes, Eusuchia): phylogenetic implications. PeerJ 6:e5372.

1784 Li, L.-G., D.-Q. Li, H.-L. You, and P. Dodson. 2014. A new titanosaurian sauropod from the 1785 Hekou Group (Lower Cretaceous) of the Lanzhou-Minhe Basin, Gansu Province, $1786 \quad$ China. PLOS One 9:e85979.

1787 Longman, H. A. 1933. A new dinosaur from the Queensland Cretaceous. Memoirs of the 1788 Queensland Museum 10:131-144.

1789 Lü, J., Y. Azuma, R. Chen, W. Zheng, and X. Jin. 2008. A new titanosauriform sauropod 1790 from the early Late Cretaceous of Dongyang, Zhejiang Province. Acta Geologica Sinica $1791 \quad 82: 225-235$.

1792 Lü, J., L. Xu, X. Jiang, S. Jia, M. Li, C. Yuan, X. Zhang, and Q. Ji. 2009. A preliminary 1793 report on the new dinosaurian fauna from the Cretaceous of the Ruyang Basin, Henan 1794 Province of central China. Journal of the Paleontological Society of Korea 25:43-56. 
1795 Mannion, P. D., R. Allain, and O. Moine. 2017. The earliest known titanosauriform sauropod dinosaur and the evolution of Brachiosauridae. PeerJ 5:e3217.

1797 Mannion, P. D., and J. O. Calvo. 2011. Anatomy of the basal titanosaur (Dinosauria, 1798 Sauropoda) Andesaurus delgadoi from the mid-Cretaceous (Albian-early Cenomanian) 1799 Río Limay Formation, Neuquén Province, Argentina: implications for titanosaur $1800 \quad$ systematics. Zoological Journal of the Linnean Society 163:155-181.

1801 Mannion, P. D., and A. Otero. 2012. A reappraisal of the Late Cretaceous Argentinean 1802 sauropod dinosaur Argyrosaurus superbus, with a description of a new titanosaur 1803 genus. Journal of Vertebrate Paleontology 32:614-638.

1804 Mannion, P. D., P. Upchurch, R. N. Barnes, and O. Mateus. 2013. Osteology of the Late 1805 Jurassic Portuguese sauropod dinosaur Lusotitan atalaiensis (Macronaria) and the 1806 evolutionary history of basal titanosauriforms. Zoological Journal of the Linnean $1807 \quad$ Society 168:98-206.

1808 Mannion, P. D., P. Upchurch, X. Jin, and W. Zheng. 2019a. New information on the 1809 Cretaceous sauropod dinosaurs of Zhejiang Province, China: impact on Laurasian 1810 titanosauriform phylogeny and biogeography. Royal Society Open Science 6:191057.

1811 Mannion, P. D., P. Upchurch, O. Mateus, R. N. Barnes, and M. E. H. Jones. 2012. New 1812 information on the anatomy and systematic position of Dinheirosaurus lourinhanensis 1813 (Sauropoda: Diplodocoidea) from the Late Jurassic of Portugal, with a review of 1814 European diplodocoids. Journal of Systematic Palaeontology 10:521-551.

1815 Mannion, P. D., P. Upchurch, D. Schwarz, and O. Wings. 2019b. Taxonomic affinities of the 1816 putative titanosaurs from the Late Jurassic Tendaguru Formation of Tanzania: 
1817 phylogenetic and biogeographic implications for eusauropod dinosaur evolution.

1818 Zoological Journal of the Linnean Society 185:784-909.

1819 Marsh, O. C. 1878. Principal characters of American Jurassic dinosaurs: Part I. American $1820 \quad$ Journal of Science 16 (series 3):411-416.

1821 Martínez, R., O. Giménez, J. Rodríguez, M. Luna, and M. C. Lamanna. 2004. An articulated 1822 specimen of the basal titanosaurian (Dinosauria: Sauropoda) Epachthosaurus sciuttoi 1823 from the early Late Cretaceous Bajo Barreal Formation of Chubut Province, Argentina. $1824 \quad$ Journal of Vertebrate Paleontology 24:107-120.

1825 McIntosh, J. S. 1990. Sauropoda; pp. 345-401 in D. B. Weishampel, P. Dodson, and H. 1826 Osmólska (eds.), The Dinosauria. University of California Press, Berkeley.

1827 McLoughlin, S., A. N. Drinnan, and A. C. Rozefelds. 1995. A Cenomanian flora from the 1828 Winton Formation, Eromanga Basin, Queensland, Australia. Memoirs of the 1829 Queensland Museum 38:273-313.

1830 McLoughlin, S., C. Pott, and D. Elliott. 2010. The Winton Formation flora (Albian1831 Cenomanian, Eromanga Basin): implications for vascular plant diversification and 1832 decline in the Australian Cretaceous. Alcheringa 34:303-323.

1833 Mocho, P., A. Pérez-García, M. Martin Jiménez, and F. Ortega. 2019a. New remains from the 1834 Spanish Cenomanian shade light on the Gondwanan origin of European Early 1835 Cretaceous titanosaurs. Cretaceous Research 95:164-190.

1836 Mocho, P., R. Royo-Torres, and F. Ortega. 2019b. A new macronarian sauropod from the 1837 Upper Jurassic of Portugal. Journal of Vertebrate Paleontology 39:e1578782. 
1838 Molnar, R. E. 1991. Fossil reptiles in Australia; pp. 605-702 in P. Vickers-Rich, J. M.

1839 Monaghan, R. F. Baird, and T. H. Rich (eds.), Vertebrate Palaeontology of Australasia.

$1840 \quad$ Pioneer Design Studio, Melbourne.

1841 Molnar, R. E. 2001. A reassessment of the phylogenetic position of Cretaceous sauropod

1842 dinosaurs from Queensland, Australia; pp. 139-144 in H. A. Leanza (ed.), VII

1843 International Symposium on Mesozoic Terrestrial Ecosystems: Asociacíon

1844 Paleontológica Argentina Publicación Especial No. 7. Asociacion Paleontologica

1845 Argentina, Buenos Aires.

1846 Molnar, R. E. 2010. Taphonomic observations on eastern Australian Cretaceous sauropods.

$1847 \quad$ Alcheringa 34:421-429.

1848 Molnar, R. E. 2011a. New morphological information about Cretaceous sauropod dinosaurs

1849 from the Eromanga Basin, Queensland, Australia. Alcheringa 35:329-339.

1850 Molnar, R. E. 2011b. Sauropod (Saurischia: Dinosauria) material from the Early Cretaceous

1851 Griman Creek Formation of the Surat Basin, Queensland, Australia. Alcheringa

$1852 \quad 35: 303-307$.

1853 Molnar, R. E., and S. W. Salisbury. 2005. Observations on Cretaceous sauropods from

1854 Australia; pp. 454-465 in V. Tidwell, and K. Carpenter (eds.), Thunder-lizards: The

1855 Sauropodomorph Dinosaurs. Indiana University Press, Bloomington \& Indianapolis, $1856 \quad$ IA

1857 Osborn, H. F. 1899. A skeleton of Diplodocus. Memoirs of the American Museum of Natural $1858 \quad$ History 1:191-214. 
1859 Otero, A. 2010. The appendicular skeleton of Neuquensaurus, a Late Cretaceous saltasaurine 1860 sauropod from Patagonia, Argentina. Acta Palaeontologica Polonica 55:399-426.

1861 Pentland, A. H., and S. F. Poropat. 2019. Reappraisal of Mythunga camara Molnar \& 1862 Thulborn, 2007 (Pterosauria, Pterodactyloidea, Anhangueria) from the upper Albian 1863 Toolebuc Formation of Queensland, Australia. Cretaceous Research 93:151-169.

1864 Pentland, A. H., S. F. Poropat, T. R. Tischler, T. Sloan, R. A. Elliott, H. A. Elliott, J. A. $1865 \quad$ Elliott, and D. A. Elliott. 2019. Ferrodraco lentoni gen. et sp. nov., a new 1866 ornithocheirid pterosaur from the Winton Formation (Cenomanian-lower Turonian) of 1867 Queensland, Australia. Scientific Reports 9:13454.

1868 Peters, M. D., and D. C. Christophel. 1978. Austrosequoia wintonensis, a new taxodiaceous 1869 cone from Queensland, Australia. Canadian Journal of Botany 56:3119-3128.

1870 Poropat, S. F. 2013. Carl Wiman's sauropods: The Uppsala Museum of Evolution's $1871 \quad$ collection. GFF 135:104-119.

1872 Poropat, S. F., P. D. Mannion, P. Upchurch, S. A. Hocknull, B. P. Kear, and D. A. Elliott. 1873 2015a. Reassessment of the non-titanosaurian somphospondylan Wintonotitan wattsi 1874 (Dinosauria: Sauropoda: Titanosauriformes) from the mid-Cretaceous Winton 1875 Formation, Queensland, Australia. Papers in Palaeontology 1:59-106.

1876 Poropat, S. F., P. D. Mannion, P. Upchurch, S. A. Hocknull, B. P. Kear, M. Kundrát, T. R. 1877 Tischler, T. Sloan, G. H. K. Sinapius, J. A. Elliott, and D. A. Elliott. 2016. New 1878 Australian sauropods shed light on Cretaceous dinosaur palaeobiogeography. Scientific $1879 \quad$ Reports 6:34467. 
1880 Poropat, S. F., S. K. Martin, A.-M. P. Tosolini, B. E. Wagstaff, L. B. Bean, B. P. Kear, P.

1881 Vickers-Rich, and T. H. Rich. 2018. Early Cretaceous polar biotas of Victoria,

1882 southeastern Australia — an overview of research to date. Alcheringa 42:157-229.

1883 Poropat, S. F., J. P. Nair, C. E. Syme, P. D. Mannion, P. Upchurch, S. A. Hocknull, A. G.

1884 Cook, T. R. Tischler, and T. Holland. 2017. Reappraisal of Austrosaurus mckillopi

1885 Longman, 1933 from the Allaru Mudstone of Queensland, Australia's first named

1886 Cretaceous sauropod dinosaur. Alcheringa 41:543-580.

1887 Poropat, S. F., P. Upchurch, P. D. Mannion, S. A. Hocknull, B. P. Kear, T. Sloan, G. H. K.

1888 Sinapius, and D. A. Elliott. 2015b. Revision of the sauropod dinosaur

1889 Diamantinasaurus matildae Hocknull et al. 2009 from the middle Cretaceous of

1890 Australia: implications for Gondwanan titanosauriform dispersal. Gondwana Research

$1891 \quad 27: 995-1033$.

1892 Powell, J. E. 1992. Osteologia de Saltasaurus loricatus (Sauropoda-Titanosauridae) del

1893 Cretácico Superior del noroeste Argentino; pp. 165-230 in J. L. Sanz, and A. D.

1894 Buscalioni (eds.), Los Dinosaurios y Su Entorno Biótico: Actas del Segundo Curso de

1895 Paleontologia in Cuenca. Instituto "Juan de Valdés", Cuenca, Spain.

1896 Powell, J. E. 2003. Revision of South American titanosaurid dinosaurs: palaeobiological,

1897 palaeobiogeographical and phylogenetic aspects. Records of the Queen Victoria

$1898 \quad$ Museum 111:1-173.

1899 Romilio, A., and S. W. Salisbury. 2011. A reassessment of large theropod dinosaur tracks 1900 from the mid-Cretaceous (late Albian-Cenomanian) Winton Formation of Lark Quarry, 1901 central-western Queensland, Australia: A case for mistaken identity. Cretaceous

$1902 \quad$ Research 32:135-142. 
1903 Romilio, A., and S. W. Salisbury. 2014. Large dinosaurian tracks from the Upper Cretaceous 1904 (Cenomanian-Turonian) portion of the Winton Formation, Lark Quarry, central1905 western Queensland, Australia: 3D photogrammetric analysis renders the 'stampede 1906 trigger' scenario unlikely. Cretaceous Research 51:186-207.

1907 Romilio, A., R. T. Tucker, and S. W. Salisbury. 2013. Reevaluation of the Lark Quarry 1908 dinosaur Tracksite (late Albian-Cenomanian Winton Formation, central-western 1909 Queensland, Australia): no longer a stampede? Journal of Vertebrate Paleontology $1910 \quad 33: 102-120$.

1911 Rose, P. J. 2007. A new titanosauriform sauropod (Dinosauria: Saurischia) from the Early 1912 Cretaceous of central Texas and its phylogenetic relationships. Palaeontologia $1913 \quad$ Electronica 10:8A.

1914 Royo-Torres, R., C. Fuentes, M. Meijide, F. Meijide-Fuentes, and M. Meijide-Fuentes. 2017. 1915 A new Brachiosauridae sauropod dinosaur from the lower Cretaceous of Europe (Soria 1916 Province, Spain). Cretaceous Research 80:38-55.

1917 Salgado, L. 1993. Comments on Chubutisaurus insignis Del Corro (Saurischia, Sauropoda). $1918 \quad$ Ameghiniana 30:265-270.

1919 Salgado, L., S. Apesteguía, and S. E. Heredia. 2005. A new specimen of Neuquensaurus 1920 australis, a Late Cretaceous saltasaurine titanosaur from north Patagonia. Journal of $1921 \quad$ Vertebrate Paleontology 25:623-634.

1922 Salgado, L., and J. O. Calvo. 1993. Report of a sauropod with amphiplatyan mid-caudal 1923 vertebrae from the Late Cretaceous of Neuquen Province (Argentina). Ameghiniana $1924 \quad 30: 215-218$. 
1925 Salgado, L., and I. d. S. Carvalho. 2008. Uberabatitan ribeiroi, a new titanosaur from the Marília Formation (Bauru Group, Upper Cretacous), Minas Gerais, Brazil.

1927 Palaeontology 51:881-901.

1928

1929

1930

1931

1932

1933

1934

1935

1936

1937

1938

1939

1940

1941

1942

1943

1944

Salgado, L., R. A. Coria, and J. O. Calvo. 1997. Evolution of titanosaurid sauropods. I: Phylogenetic analysis based on the postcranial evidence. Ameghiniana 34:3-32.

Salgado, L., R. A. García, and J. D. Daza. 2006. Consideraciones sobre las laminas neurales de los dinosaurios saurópodos y su significado morfofuncional. Revista del Museo Argentino de Ciencias Naturales 8:69-79.

Salgado, L., and J. E. Powell. 2010. Reassessment of the vertebral laminae in some South American titanosaurian sauropods. Journal of Vertebrate Paleontology 30:1760-1772.

Salisbury, S., R. E. Molnar, E. Frey, and P. M. A. Willis. 2006. The origin of modern crocodyliforms: new evidence from the Cretaceous of Australia. Proceedings of the Royal Society B 273:2439-2448.

Salisbury, S. W., A. Romilio, M. C. Herne, R. T. Tucker, and J. P. Nair. 2017. The dinosaurian ichnofauna of the Lower Cretaceous (Valanginian-Barremian) Broome Sandstone of the Walmadany Area (James Price Point), Dampier Peninsula, Western Australia. Society of Vertebrate Paleontology Memoir 16:1-152.

Santucci, R. M., and A. C. Arruda-Campos. 2011. A new sauropod (Macronaria, Titanosauria) from the Adamantina Formation, Bauru Group, Upper Cretaceous of Brazil and the phylogenetic relationships of Aeolosaurini. Zootaxa 3085:1-33. 
1945 Santucci, R. M., and R. J. Bertini. 2006. A large sauropod titanosaur from Peirópolis, Bauru 1946 Group, Brazil. Neues Jahrbuch für Geologie und Paläontologie, Monatshefte 2006:344360.

1948 Sanz, J. L., J. E. Powell, J. Le Loeuff, R. Martínez, and X. Pereda Suberbiola. 1999.

1949 Sauropod remains from the Upper Cretaceous of Laño (northcentral Spain), titanosaur 1950 phylogenetic relationships. Estudios del Museo de Ciencias Naturales de Alava 14:235255.

1952 Scanlon, J. D., and S. A. Hocknull. 2008. A dolichosaurid lizard from the latest Albian (mid1953 Cretaceous) Winton Formation, Queensland, Australia; pp. 131-136 in M. J. Everhart 1954 (ed.), Proceedings of the Second Mosasaur Meeting. Fort Hays Studies, Special Issue 3. 1955 Fort Hays State University, Hays, Kansas.

1956 Senior, B. R., and J. A. Mabbutt. 1979. A proposed method of defining deeply weathered 1957 rock units based on regional geological mapping in southwest Queensland. Journal of 1958 the Geological Society of Australia 26:237-254.

1959 Silva Junior, J. C. G., T. S. Marinho, A. G. Martinelli, and M. C. Langer. 2019. Osteology 1960 and systematics of Uberabatitan ribeiroi (Dinosauria; Sauropoda): a Late Cretaceous 1961 titanosaur from Minas Gerais, Brazil. Zootaxa 4577:401-438.

1962 Simón, E., L. Salgado, and J. O. Calvo. 2018. A new titanosaur sauropod from the Upper 1963 Cretaceous of Patagonia, Neuquén Province, Argentina. Ameghiniana 55:1-29.

1964 Syme, C. E., and S. W. Salisbury. 2018. Taphonomy of Isisfordia duncani specimens from 1965 the Lower Cretaceous (upper Albian) portion of the Winton Formation, Isisford, 1966 central-west Queensland. Royal Society Open Science 5:171651. 
1967 Syme, C. E., K. J. Welsh, E. M. Roberts, and S. W. Salisbury. 2016. Depositional

1968

1969

1970

1971

1972

1973

1974

1975

1976

1977

1978

1979

1980

1981

1982

1983

1984

1985

1986 environment of the Lower Cretaceous (upper Albian) Winton Formation at Isisford, Central-West Queensland, Australia, inferred from sandstone concretions. Journal of Sedimentary Research 86:1067-1082.

Thulborn, R. A. 2013. Lark Quarry revisited: a critique of methods used to identify a large dinosaurian track-maker in the Winton Formation (Albian-Cenomanian), western Queensland, Australia. Alcheringa 37:312-330.

Thulborn, R. A., and M. Wade. 1979. Dinosaur stampede in the Cretaceous of Queensland. Lethaia 12:275-279.

Thulborn, R. A., and M. Wade. 1984. Dinosaur trackways in the Winton Formation (midCretaceous) of Queensland. Memoirs of the Queensland Museum 21:413-517.

Thulborn, T. 2012. Impact of sauropod dinosaurs on lagoonal substrates in the Broome Sandstone (Lower Cretaceous), Western Australia. PLOS One 7:e36208.

Thulborn, T. 2017. Behaviour of dinosaurian track-makers in the Winton Formation (Cretaceous, Albian-Cenomanian) at Lark Quarry, western Queensland, Australia: running or swimming? Ichnos 24:1-18.

Thulborn, T., T. Hamley, and P. Foulkes. 1994. Preliminary report on sauropod dinosaur tracks in the Broome Sandstone (Lower Cretaceous) of Western Australia; pp. 85-94 in M. G. Lockley, V. F. Santos, C. A. Meyer, and A. P. Hunt (eds.), Aspects of Sauropod Paleobiology; Gaia, 10, Lisbon, Portugal. 
Tschopp, E., and O. Mateus. 2013. Clavicles, interclavicles, gastralia, and sternal ribs in sauropod dinosaurs: new reports from Diplodocidae and their morphological, functional and evolutionary implications. Journal of Anatomy 222:321-340.

Tucker, R. T., E. M. Roberts, V. Darlington, and S. W. Salisbury. 2017. Investigating the stratigraphy and palaeoenvironments for a suite of newly discovered mid-Cretaceous vertebrate fossil-localities in the Winton Formation, Queensland, Australia. Sedimentary Geology 358:210-229.

Tucker, R. T., E. M. Roberts, Y. Hu, A. I. S. Kemp, and S. W. Salisbury. 2013. Detrital zircon age constraints for the Winton Formation, Queensland: contextualizing Australia's Late Cretaceous dinosaur faunas. Gondwana Research 24:767-779.

Turner, A. H., and A. C. Pritchard. 2015. The monophyly of Susisuchidae (Crocodyliformes) and its phylogenetic placement in Neosuchia. PeerJ 3:e759.

Upchurch, P. 1995. The evolutionary history of sauropod dinosaurs. Philosophical Transactions: Biological Sciences 349:365-390.

Upchurch, P. 1998. The phylogenetic relationships of sauropod dinosaurs. Zoological Journal of the Linnean Society 124:43-103.

Upchurch, P., P. M. Barrett, and P. Dodson. 2004. Sauropoda; pp. 259-322 in D. B. Weishampel, P. Dodson, and H. Osmólska (eds.), The Dinosauria: Second Edition. University of California Press, Berkeley.

Upchurch, P., P. D. Mannion, and M. P. Taylor. 2015. The anatomy and phylogenetic relationships of "Pelorosaurus" becklesii (Neosauropoda, Macronaria) from the Early Cretaceous of England. PLOS One 10:e0125819. 
2009 Vine, R. R. 1964. Mackunda, Queensland. 1:250 000 Geological Series Sheet SF54-11.

2010 Bureau of Mineral Resources, Geology and Geophysics, Canberra, Australia.

2011 Vine, R. R., and D. J. Casey. 1967. Winton, Queensland. 1:250 000 geological series sheet

2012 SF54-12. Bureau of Mineral Resources, Geology and Geophysics, Canberra, Australia.

2013 Vine, R. R., and R. W. Day. 1965. Nomenclature of the Rolling Downs Group, northern

2014 Eromanga Basin, Queensland. Queensland Government Mineral Journal 66:416-421.

2015 Voegele, K. K., M. C. Lamanna, and K. J. Lacovara. 2017. Osteology of the dorsal vertebrae

2016 of the giant titanosaurian sauropod dinosaur Dreadnoughtus schrani from the Late

2017 Cretaceous of Argentina. Acta Palaeontologica Polonica 62:667-681.

2018 Wedel, M. J. 2003. The evolution of vertebral pneumaticity in sauropod dinosaurs. Journal of $2019 \quad$ Vertebrate Paleontology 23:344-357.

2020 Wedel, M. J. 2009. Evidence for bird-like air sacs in saurischian dinosaurs. Journal of 2021 Experimental Zoology Part A: Ecological Genetics and Physiology 311A:611-628.

2022 Wedel, M. J., and M. P. Taylor. 2013. Caudal pneumaticity and pneumatic hiatuses in the 2023 sauropod dinosaurs Giraffatitan and Apatosaurus. PLOS One 8:e78213.

2024 White, M. A., P. R. Bell, A. G. Cook, S. F. Poropat, and D. A. Elliott. 2015. The dentary of 2025 Australovenator wintonensis (Theropoda, Megaraptoridae); implications for 2026 megaraptorid dentition. PeerJ 3:e1512.

2027 White, M. A., R. B. J. Benson, T. R. Tischler, S. A. Hocknull, A. G. Cook, D. G. Barnes, S. 2028 F. Poropat, S. J. Wooldridge, T. Sloan, G. H. K. Sinapius, and D. A. Elliott. 2013. New 2029 Australovenator hind limb elements pertaining to the holotype reveal the most complete 2030 neovenatorid leg. PLOS One 8:e68649. 
2031 White, M. A., A. G. Cook, S. A. Hocknull, T. Sloan, G. H. K. Sinapius, and D. A. Elliott.

2032 2012. New forearm elements discovered of holotype specimen Australovenator

2033 wintonensis from Winton, Queensland, Australia. PLOS One 7:e39364.

2034 Whitehouse, F. W. 1954. The geology of the Queensland portion of the Great Australian 2035 Artesian Basin; pp. 1-20, Artesian Water Supplies in Queensland. Department of the 2036 Co-ordinator-General of Public Works, Brisbane, Australia.

2037 Whitlock, J. A., M. D. D’Emic, and J. A. Wilson. 2011. Cretaceous diplodocids in Asia? Re2038 evaluating the phylogenetic affinities of a fragmentary specimen. Palaeontology $2039 \quad 54: 351-364$.

2040 Wilson, J. A. 1999. A nomenclature for vertebral laminae in sauropods and other saurischian 2041 dinosaurs. Journal of Vertebrate Paleontology 19:639-653.

2042 Wilson, J. A. 2002. Sauropod dinosaur phylogeny: critique and cladistic analysis. Zoological $2043 \quad$ Journal of the Linnean Society 136:217-276.

2044 Wilson, J. A. 2012. New vertebral laminae and patterns of serial variation in vertebral 2045 laminae of sauropod dinosaurs. Contributions from the Museum of Paleontology, The $2046 \quad$ University of Michigan 32:91-110.

2047 Wilson, J. A., and M. T. Carrano. 1999. Titanosaurs and the origin of "wide-gauge" 2048 trackways: a biomechanical and systematic perspective on sauropod locomotion. 2049 Paleobiology 25:252-267.

2050 Wilson, J. A., M. D. D’Emic, T. Ikejiri, E. M. Moacdieh, and J. A. Whitlock. 2011. A 2051 nomenclature for vertebral fossae in sauropods and other saurischian dinosaurs. PLOS $2052 \quad$ One 6:e17114. 
2053 Wilson, J. A., and P. C. Sereno. 1998. Early evolution and higher-level phylogeny of 2054 sauropod dinosaurs. Society of Vertebrate Paleontology Memoir 5 (Journal of 2055 Vertebrate Paleontology Vol. 18, supplement to No. 2, June 1998):68 pp.

2056 Wilson, J. A., and P. Upchurch. 2003. A revision of Titanosaurus Lydekker (Dinosauria 2057 Sauropoda), the first dinosaur genus with a 'Gondwanan' distribution. Journal of 2058 Systematic Palaeontology 1:125-160.

2059 Wilson, J. A., and P. Upchurch. 2009. Redescription and reassessment of Euhelopus zdanskyi 2060 (Dinosauria: Sauropoda) from the Early Cretaceous of China. Journal of Systematic $2061 \quad$ Palaeontology 7:199-239.

2062 Wiman, C. 1929. Die Kreide-Dinosaurier aus Shantung. Palaeontologia Sinica (Series C) $2063 \quad 6: 1-67$.

2064 Xu, X., X. Zhang, Q. Tan, X. Zhao, and L. Tan. 2006. A new titanosaurian sauropod from 2065 Late Cretaceous of Nei Mongol, China. Acta Geologica Sinica 80:20-26.

2066 You, H.-1., D.-q. Li, L.-q. Zhou, and Q. Ji. 2008. Daxiatitan binglingi: a giant sauropod 2067 dinosaur from the Early Cretaceous of China. Gansu Geology 17:1-10.

2068 Zhang, X., J. Lü, L. Xu, J. Li, L. Yang, W. Hu, S. Jia, Q. Ji, and C. Zhang. 2009. A new 2069 sauropod dinosaur from the Late Cretaceous Gaogou Formation of Nanyang, Henan $2070 \quad$ Province. Acta Geologica Sinica 83:212-221.

2071 Zurriaguz, V., and J. Powell. 2015. New contributions to the presacral osteology of 2072 Saltasaurus loricatus (Sauropoda, Titanosauria) from the Upper Cretaceous of northern 2073 Argentina. Cretaceous Research 54:283-300. 
2075 End section with: Submitted December 1, 2019; revisions received Month DD, YYYY;

2076 accepted Month DD, YYYY

2077

10

11 
FIGURE CAPTIONS

2080

2081 FIGURE 1. Locality maps for Savannasaurus elliottorum (modified from Poropat et al., 2016 2082 and Pentland et al., 2019). A, Map of Australia showing the location of Queensland. B, Map 2083 of Queensland showing the distribution of Winton Formation outcrop. C, Map of the Winton 2084 area showing Winton Formation outcrop, the location of Belmont Station and other stations 2085 on which sauropod body fossils have been recovered from the Winton Formation, and 2086 museums in the region. This map incorporates geological information from Vine (1964) and 2087 Vine and Casey (1967) [C Commonwealth of Australia (Geoscience Australia) 2019. This 2088 product is released under the Creative Commons Attribution 4.0 International Licence. $2089 \mathrm{http} / /$ creativecommons.org/licenses/by/4.0/legalcode]. [INTENDED FOR FULL-PAGE 2090 WIDTH]

2091 FIGURE 2. Stratigraphy of the Eromanga Basin, Queensland, with silhouettes representing 2092 known tetrapod taxa. WINTON FORMATION: Australovenator wintonensis; Ankylosauria 2093 indet.; Ornithopoda indet.; Wintonotitan wattsi; Diamantinasaurus matildae; Savannasaurus 2094 elliottorum; Ferrodraco lentoni; Isisfordia duncani; Varanoidea indet.; and Chelidae indet. 2095 MACKUNDA FORMATION: Ctenochasmatoidea indet.; Muttaburrasaurus langdoni; and 2096 Polycotylidae indet. ALLARU MUDSTONE (following faunal summary in Poropat et al. 2097 (2017)): Kunbarrasaurus ieversi; Muttaburrasaurus sp.; Austrosaurus mckillopi; 2098 Elasmosauridae indet.; Polycotylidae indet.; Kronosaurus queenslandicus; Platypterygius 2099 australis; and Chelonioidea indet. TOOLEBUC FORMATION (following faunal summary in 2100 Pentland and Poropat (2019)): Mythunga camara; Aussiedraco molnari; Nanantius eos; 2101 Ankylosauria indet.; Iguanodontia indet.; Titanosauriformes indet.; Platypterygius australis; 2102 Eromangasaurus australis; Cratochelone berneyi; Kronosaurus queenslandicus; 
Bouliachelys suteri; Notochelone costata; and Polycotylidae indet. WALLUMBILLA

2104

FORMATION (DONCASTER MEMBER): Platypterygius sp.; Elasmosauridae indet.;

\section{5}

2106

Polycotylidae indet.; and Kronosaurus queenslandicus. [INTENDED FOR FULL-PAGE

\section{WIDTH]}

2107

FIGURE 3. Savannasaurus elliottorum holotype specimen. A, Skeletal reconstruction, based

\section{8} on the preserved elements, by Travis Tischler (modified from Poropat et al., 2016). B-C, 'Ho-Hum' Site (AODL 82) map in B, bird's-eye view (from Poropat et al., 2016) and C, sub2110 surface view. [INTENDED FOR TWO-THIRDS PAGE WIDTH]

2111 FIGURE 4. Savannasaurus elliottorum posterior cervical vertebra in A, left lateral, B, dorsal 2112 (with anterior to top), $\mathbf{C}$, posterior, and $\mathbf{D}$, ventral (with anterior to bottom) views, and left 2113 cervical ribs in $\mathbf{E}$, medial, F, lateral and $\mathbf{G}$, ventral views. Scale bar equals $100 \mathrm{~mm}$.

\section{4 [INTENDED FOR FULL-PAGE WIDTH]}

2115 FIGURE 5. Savannasaurus elliottorum dorsal vertebra III in A, anterior, B, left lateral, C, 2116 ventral, D, posterior, E, dorsal, and F, right lateral views. Scale bar equals $200 \mathrm{~mm}$.

2117 [INTENDED FOR FULL-PAGE WIDTH]

2118 FIGURE 6. Savannasaurus elliottorum dorsal vertebra IV in A, anterior, B, dorsal, C, left 2119 lateral, D, posterior, E, right lateral, and F, ventral views. Scale bar equals $200 \mathrm{~mm}$.

2120 [INTENDED FOR FULL-PAGE WIDTH]

2121 FIGURE 7. Savannasaurus elliottorum dorsal vertebra V in posterior view. Scale bar equals $2122200 \mathrm{~mm}$. [INTENDED FOR SINGLE COLUMN WIDTH]

2123 FIGURE 8. Savannasaurus elliottorum dorsal vertebra VI in A, anterior, B, left lateral, C, 2124 posterior, D, dorsal, E, right lateral, and F, ventral views. Scale bar equals $200 \mathrm{~mm}$.

2125 [INTENDED FOR FULL-PAGE WIDTH] 
2126 FIGURE 9. Savannasaurus elliottorum dorsal vertebra VII in A, anterior, B, left lateral, C,

2127 ventral, D, posterior, E, dorsal, and F, right lateral views. Scale bar equals $200 \mathrm{~mm}$.

2128 [INTENDED FOR FULL-PAGE WIDTH]

2129 FIGURE 10. Savannasaurus elliottorum dorsal vertebra VIII in A, anterior, B, left lateral, C,

2130 posterior, D, dorsal, E, right lateral, and F, ventral views. Scale bar equals $200 \mathrm{~mm}$.

2131 [INTENDED FOR FULL-PAGE WIDTH]

2132 FIGURE 11. Savannasaurus elliottorum dorsal vertebra IX in A, anterior, B, left lateral, C,

2133 posterior, D, dorsal, E, right lateral, and F, ventral views. Scale bar equals $200 \mathrm{~mm}$.

2134 [INTENDED FOR FULL-PAGE WIDTH]

2135 FIGURE 12. Savannasaurus elliottorum dorsal vertebra X in A, posterior, B, right lateral, C,

2136 anterior, D, dorsal, E, left lateral, and F, ventral views. Scale bar equals $200 \mathrm{~mm}$.

2137 [INTENDED FOR FULL-PAGE WIDTH]

2138 FIGURE 13. Savannasaurus elliottorum dorsal rib head in A, posterior and $\mathbf{B}$, anterior views.

2139 Scale bar equals $50 \mathrm{~mm}$. [INTENDED FOR SINGLE COLUMN WIDTH]

2140 FIGURE 14. Savannasaurus elliottorum sacrum in ventral view (posterior to the left, anterior

2141 to the right). Scale bar equals $200 \mathrm{~mm}$. [INTENDED FOR SINGLE COLUMN WIDTH]

2142 FIGURE 15. Savannasaurus elliottorum caudal vertebrae. Caudal vertebra A in A, anterior,

$2143 \mathbf{B}$, dorsal, C, left lateral, and D, posterior views, and $\mathbf{E}$, broken left neural arch in lateral

2144 view. Caudal vertebra B in F, anterior, G, dorsal, H, left lateral, I, posterior, and $\mathbf{J}$, right

2145 lateral views. Caudal vertebra $\mathrm{C}$ in $\mathbf{K}$, anterior, $\mathbf{L}$, left lateral, $\mathbf{M}$, dorsal, $\mathbf{N}$, posterior, $\mathbf{O}$,

2146 ventral, and $\mathbf{P}$, right lateral views. Caudal vertebra D in $\mathbf{Q}$, dorsal, $\mathbf{R}$, right lateral, and $\mathbf{S}$,

2147 anterior views. Scale bar for A-D and $\mathbf{F}-\mathbf{S}$ equals $100 \mathrm{~mm}$; scale bar for $\mathbf{E}$ equals $50 \mathrm{~mm}$.

2148 [INTENDED FOR FULL-PAGE WIDTH] 
2149 FIGURE 16. Savannasaurus elliottorum left coracoid in A, lateral, B, posterior, C, dorsal, D,

2150 medial, E, ventral, and $\mathbf{F}$, anterior views. Scale bar equals $100 \mathrm{~mm}$. [INTENDED FOR

\section{FULL-PAGE WIDTH]}

2152 FIGURE 17. Savannasaurus elliottorum left sternal plate in $\mathbf{A}$, ventral and $\mathbf{B}$, dorsal views, 2153 with the anterior end towards the top of the page. The dashed line represents the division 2154 between the convex portion of the ventral surface (medial to the line) and the concave portion 2155 (lateral to the line). Scale bar equals $200 \mathrm{~mm}$. [INTENDED FOR SINGLE COLUMN 2156 WIDTH]

2157 FIGURE 18. Savannasaurus elliottorum right humerus in A, posterior, B, lateral, C, anterior, 2158 and $\mathbf{D}$, medial views. Scale bar equals $200 \mathrm{~mm}$. [INTENDED FOR FULL-PAGE WIDTH]

2159 FIGURE 19. Savannasaurus elliottorum left radius in A, posterior, B, proximal and $\mathbf{C}$, distal 2160 views. Scale bar equals 100 mm. [INTENDED FOR SINGLE COLUMN WIDTH]

2161 FIGURE 20. Savannasaurus elliottorum manus. Articulated left metacarpals I-V in A, 2162 proximal and $\mathbf{B}$, distal views. Left metacarpal I in $\mathbf{C}$, anterior, D, distal, E, lateral, F, 2163 proximal, $\mathbf{G}$, posterior, and $\mathbf{H}$, medial views. Left metacarpal II in I, anterior, $\mathbf{J}$, distal, $\mathbf{K}$, 2164 lateral, $\mathbf{L}$, proximal, $\mathbf{M}$, posterior, and $\mathbf{N}$, medial views. Left metacarpal III in $\mathbf{O}$, anterior, $\mathbf{P}$, 2165 distal, Q, lateral, R, proximal, S, posterior, and T, medial views. Left metacarpal IV in $\mathbf{U}$, 2166 anterior, $\mathbf{V}$, distal, $\mathbf{W}$, lateral, $\mathbf{X}$, proximal, $\mathbf{Y}$, posterior, and $\mathbf{Z}$, medial views. Left metacarpal 2167 V in $\mathbf{A A}$, anterior, $\mathbf{A B}$, distal, $\mathbf{A C}$, lateral, $\mathbf{A D}$, proximal, $\mathbf{A E}$, posterior, and $\mathbf{A F}$, medial 2168 views. Right metacarpal IV in $\mathbf{A G}$, anterior, $\mathbf{A H}$, medial, $\mathbf{A I}$, proximal, $\mathbf{A J}$, posterior, and 2169 AK, lateral views. Left manual phalanx II-1 in AL, dorsal, AM, medial, AN, ventral, AO, 2170 distal, AP, lateral, and AQ, proximal views. Scale bar equals $100 \mathrm{~mm}$. [INTENDED FOR 2171 FULL-PAGE WIDTH] 
2172 FIGURE 21. Savannasaurus elliottorum co-ossified left and right pubes and ischia in A,

2173 posterior, $\mathbf{B}$, dorsal, $\mathbf{C}$, right lateral, $\mathbf{D}$, ventral (right pubis and ischium not included in this

2174 photograph), and E, anterior views. Scale bar equals $500 \mathrm{~mm}$. [INTENDED FOR FULL-

2175 PAGE WIDTH]

2176 FIGURE 22. Savannasaurus elliottorum tarsus and metatarsus. Left astragalus in A,

2177 proximal, B, posterior, C, medial, D, distal, E, anterior, and F, lateral views. Right metatarsal

2178 III in G, proximal, H, dorsal, I, lateral, J, distal, K, ventral, and L, medial views. Scale bar

2179 equals $100 \mathrm{~mm}$. [INTENDED FOR FULL-PAGE WIDTH]

2180 FIGURE 23. Savannasaurus elliottorum life restoration by Travis R. Tischler. [INTENDED

2181 FOR FULL-PAGE WIDTH]

2182 
FIGURE 1. Locality maps for Savannasaurus elliottorum (modified from Poropat et al., 2016 and Pentland et al., 2019). A, Map of Australia showing the location of Queensland. B, Map of Queensland showing the distribution of Winton Formation outcrop. C, Map of the Winton area showing Winton Formation outcrop, the location of Belmont Station and other stations on which sauropod body fossils have been recovered from the Winton Formation, and museums in the region. This map incorporates geological information from Vine (1964) and Vine and Casey (1967) [ (C) Commonwealth of Australia (Geoscience Australia) 2019. This product is released under the Creative Commons Attribution 4.0 International Licence. http://creativecommons.org/licenses/by/4.0/legalcode].

$$
182 \times 121 \mathrm{~mm}(300 \times 300 \mathrm{DPI})
$$




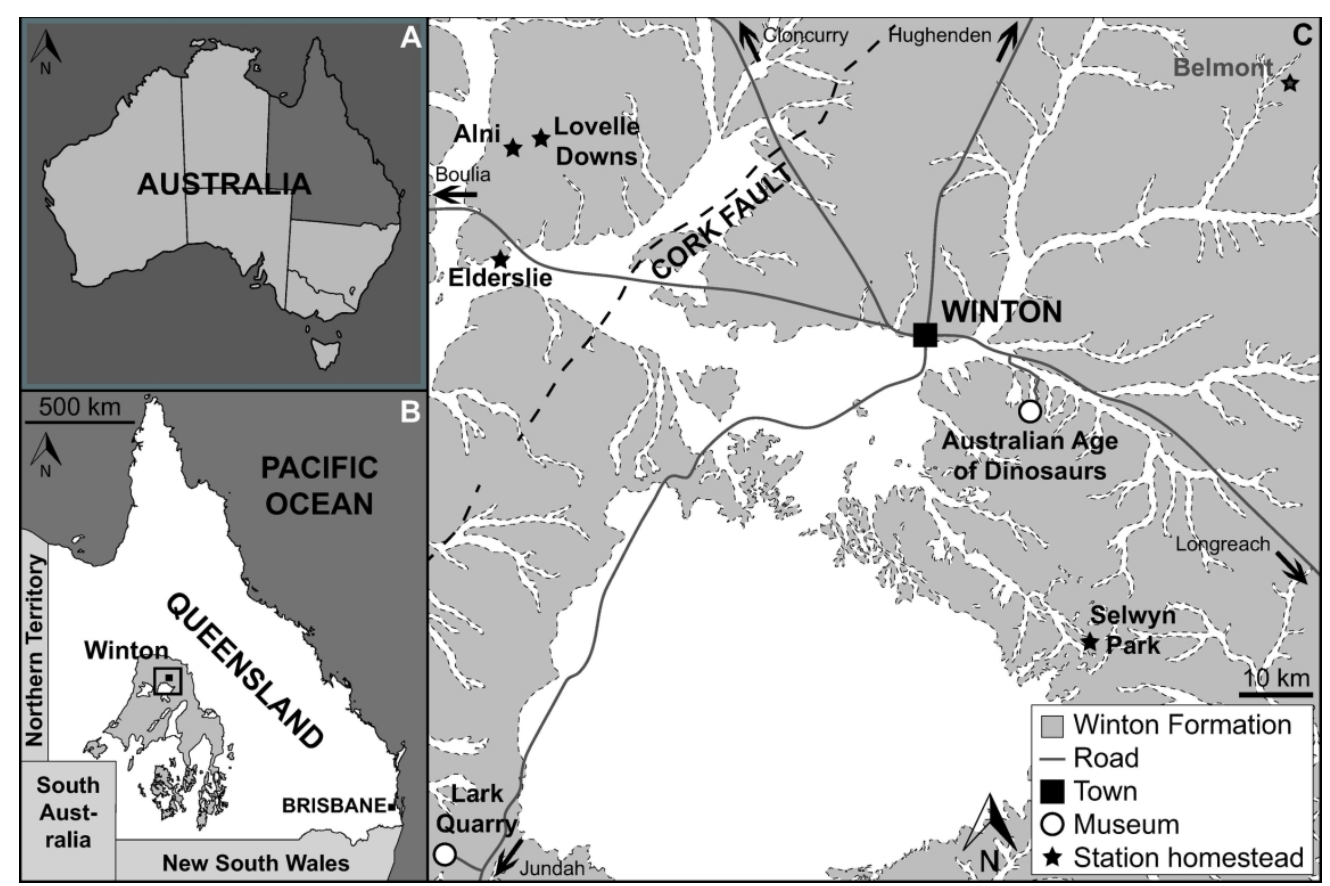

FIGURE 1. Locality maps for Savannasaurus elliottorum (modified from Poropat et al., 2016 and Pentland et al., 2019). A, Map of Australia showing the location of Queensland. B, Map of Queensland showing the distribution of Winton Formation outcrop. C, Map of the Winton area showing Winton Formation outcrop, the location of Belmont Station and other stations on which sauropod body fossils have been recovered from the Winton Formation, and museums in the region. This map incorporates geological information from Vine

(1964) and Vine and Casey (1967) [@ Commonwealth of Australia (Geoscience Australia) 2019. This product is released under the Creative Commons Attribution 4.0 International Licence. http://creativecommons.org/licenses/by/4.0/legalcode].

$182 \times 121 \mathrm{~mm}(300 \times 300 \mathrm{DPI})$ 


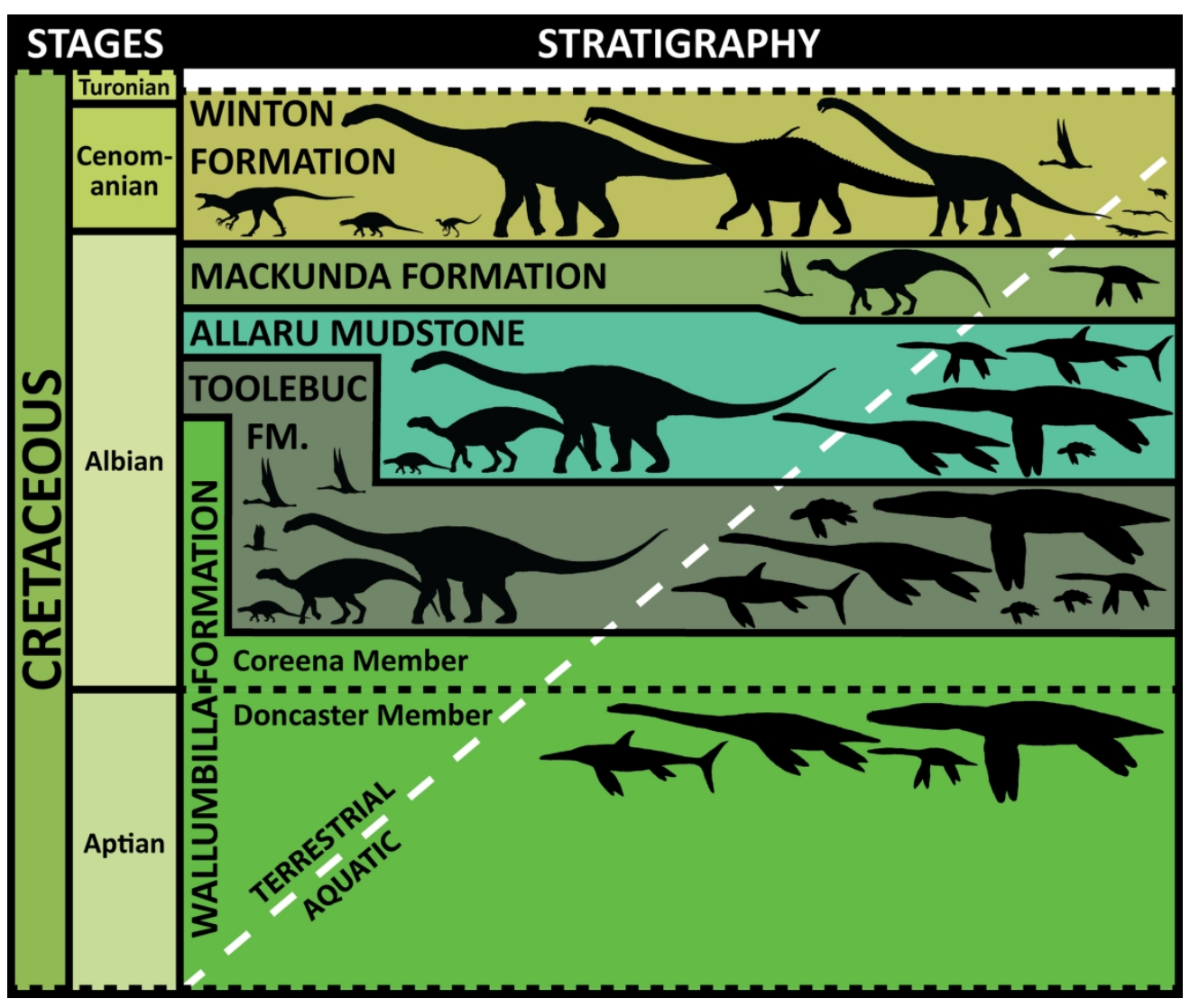

FIGURE 2. Stratigraphy of the Eromanga Basin, Queensland, with silhouettes representing known tetrapod taxa. WINTON FORMATION: Australovenator wintonensis; Ankylosauria indet.; Ornithopoda indet.; Wintonotitan wattsi; Diamantinasaurus matildae; Savannasaurus elliottorum; Ferrodraco lentoni; Isisfordia duncani; Varanoidea indet.; and Chelidae indet. MACKUNDA FORMATION: Ctenochasmatoidea indet.; Muttaburrasaurus langdoni; and Polycotylidae indet. ALLARU MUDSTONE (following faunal summary in Poropat et al. (2017)): Kunbarrasaurus ieversi; Muttaburrasaurus sp.; Austrosaurus mckillopi; Elasmosauridae indet.; Polycotylidae indet.; Kronosaurus queenslandicus; Platypterygius australis; and Chelonioidea indet. TOOLEBUC FORMATION (following faunal summary in Pentland and Poropat (2019)): Mythunga camara; Aussiedraco molnari; Nanantius eos; Ankylosauria indet.; Iguanodontia indet.; Titanosauriformes indet.; Platypterygius australis; Eromangasaurus australis; Cratochelone berneyi; Kronosaurus queenslandicus; Bouliachelys suteri; Notochelone costata; and Polycotylidae indet. WALLUMBILLA FORMATION (DONCASTER MEMBER): Platypterygius sp.; Elasmosauridae indet.; Polycotylidae indet.; and Kronosaurus queenslandicus.

\section{$182 \times 153 \mathrm{~mm}(300 \times 300 \mathrm{DPI})$}




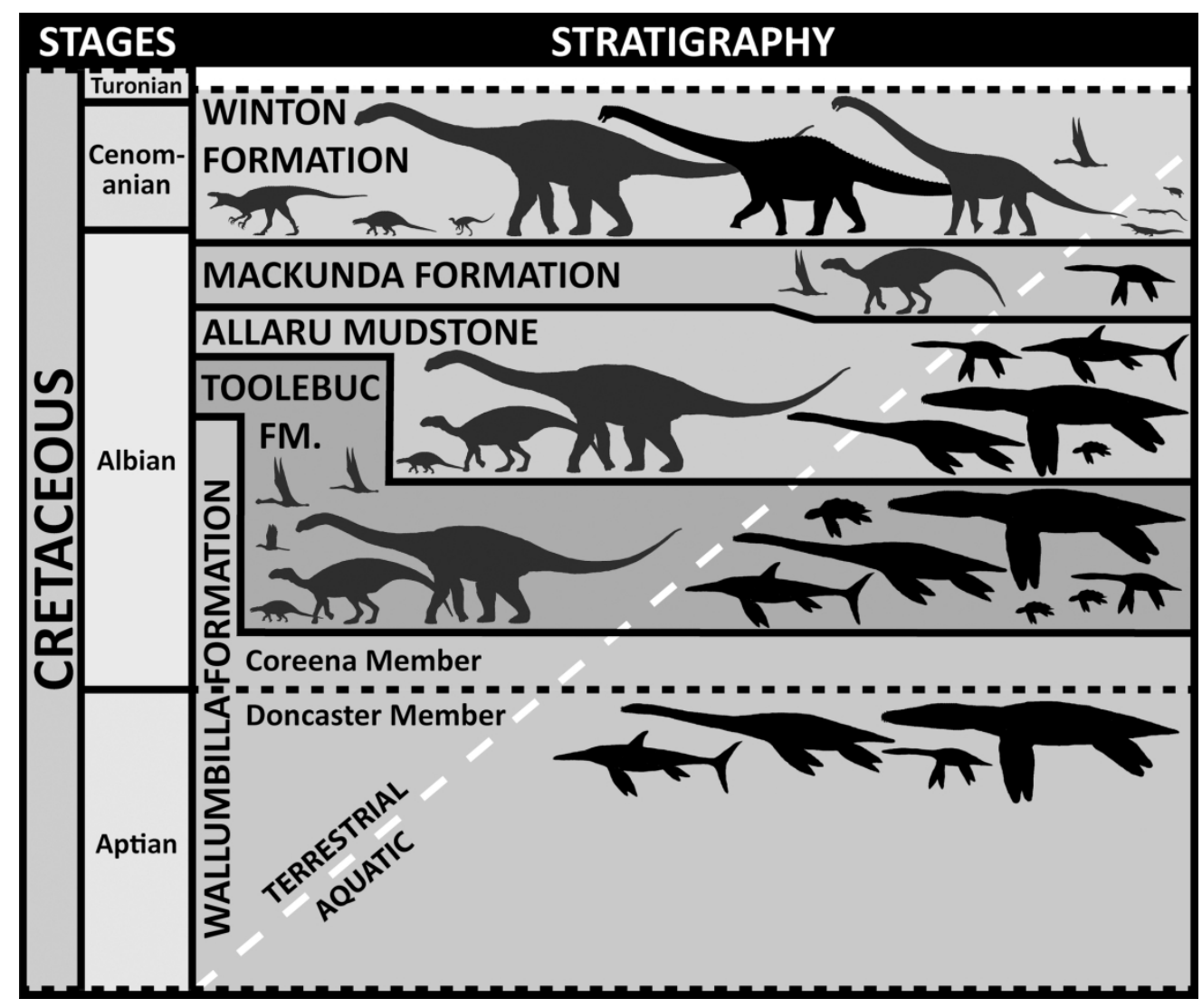

FIGURE 2. Stratigraphy of the Eromanga Basin, Queensland, with silhouettes representing known tetrapod taxa. WINTON FORMATION: Australovenator wintonensis; Ankylosauria indet.; Ornithopoda indet.; Wintonotitan wattsi; Diamantinasaurus matildae; Savannasaurus elliottorum; Ferrodraco lentoni; Isisfordia duncani; Varanoidea indet.; and Chelidae indet. MACKUNDA FORMATION: Ctenochasmatoidea indet.; Muttaburrasaurus langdoni; and Polycotylidae indet. ALLARU MUDSTONE (following faunal summary in Poropat et al. (2017)): Kunbarrasaurus ieversi; Muttaburrasaurus sp.; Austrosaurus mckillopi; Elasmosauridae indet.; Polycotylidae indet.; Kronosaurus queenslandicus; Platypterygius australis; and Chelonioidea indet. TOOLEBUC FORMATION (following faunal summary in Pentland and Poropat (2019)): Mythunga camara; Aussiedraco molnari; Nanantius eos; Ankylosauria indet.; Iguanodontia indet.; Titanosauriformes indet.; Platypterygius australis; Eromangasaurus australis; Cratochelone berneyi; Kronosaurus queenslandicus; Bouliachelys suteri; Notochelone costata; and Polycotylidae indet. WALLUMBILLA FORMATION (DONCASTER MEMBER): Platypterygius sp.; Elasmosauridae indet.; Polycotylidae indet.; and Kronosaurus queenslandicus.

\section{$182 \times 153 \mathrm{~mm}(300 \times 300 \mathrm{DPI})$}



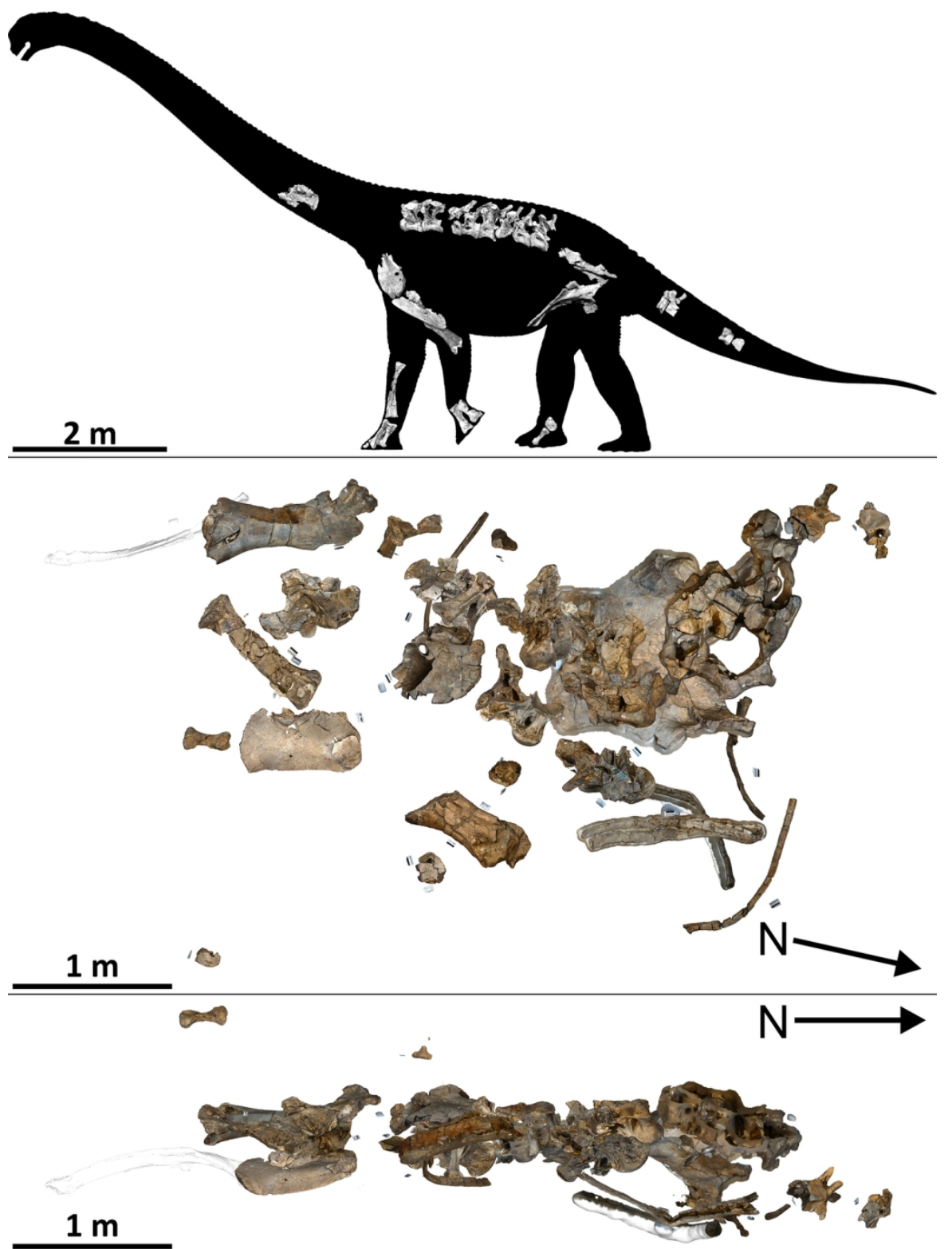

FIGURE 3. Savannasaurus elliottorum holotype specimen. A, Skeletal reconstruction, based on the preserved elements, by Travis Tischler (modified from Poropat et al., 2016). B-C, 'Ho-Hum' Site (AODL 82) map in B, bird's-eye view (from Poropat et al., 2016) and C, sub-surface view.

$122 \times 163 \mathrm{~mm}(300 \times 300 \mathrm{DPI})$ 

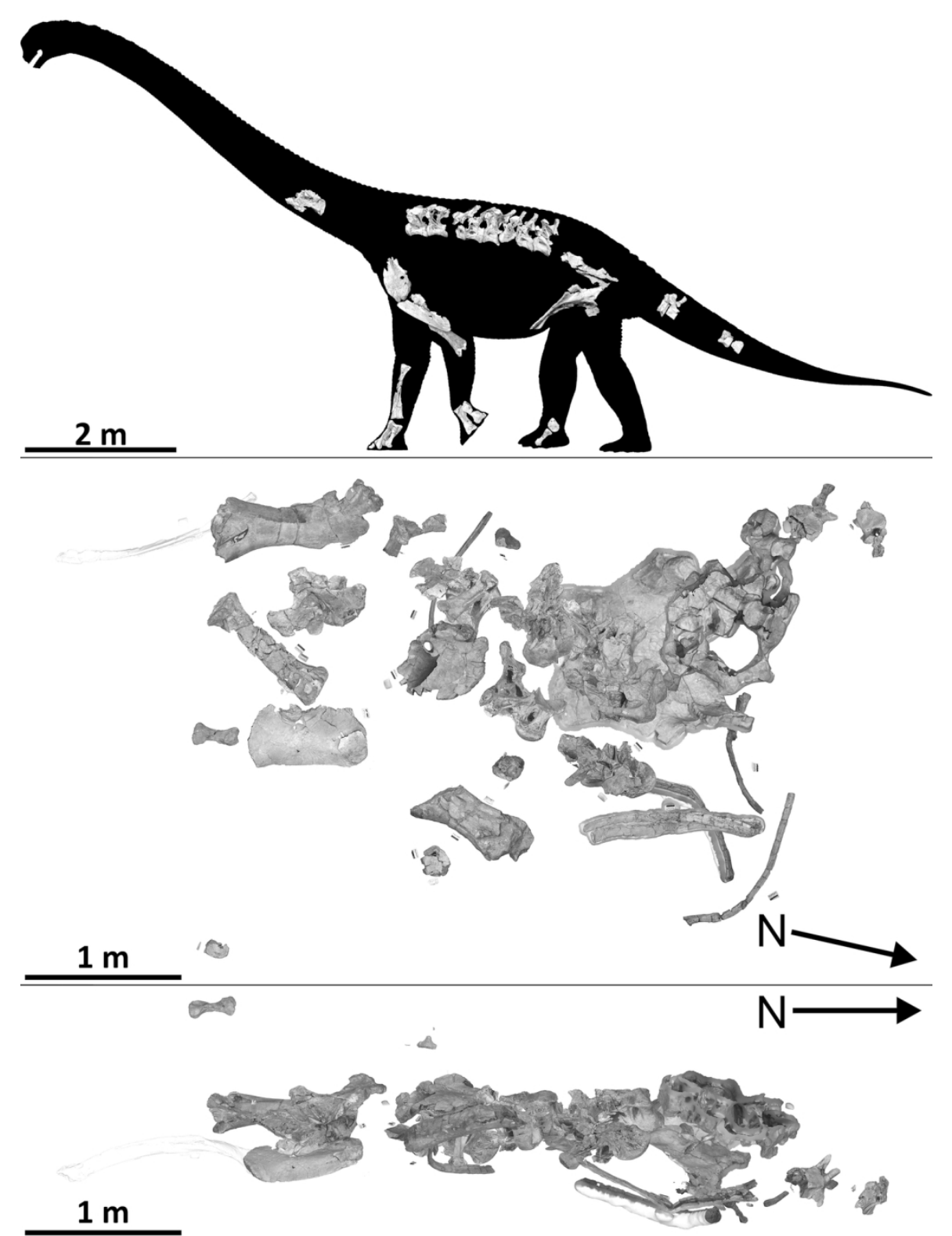

FIGURE 3. Savannasaurus elliottorum holotype specimen. A, Skeletal reconstruction, based on the preserved elements, by Travis Tischler (modified from Poropat et al., 2016). B-C, 'Ho-Hum' Site (AODL 82) map in B, bird's-eye view (from Poropat et al., 2016) and C, sub-surface view.

$$
122 \times 163 \mathrm{~mm} \text { ( } 300 \times 300 \text { DPI) }
$$




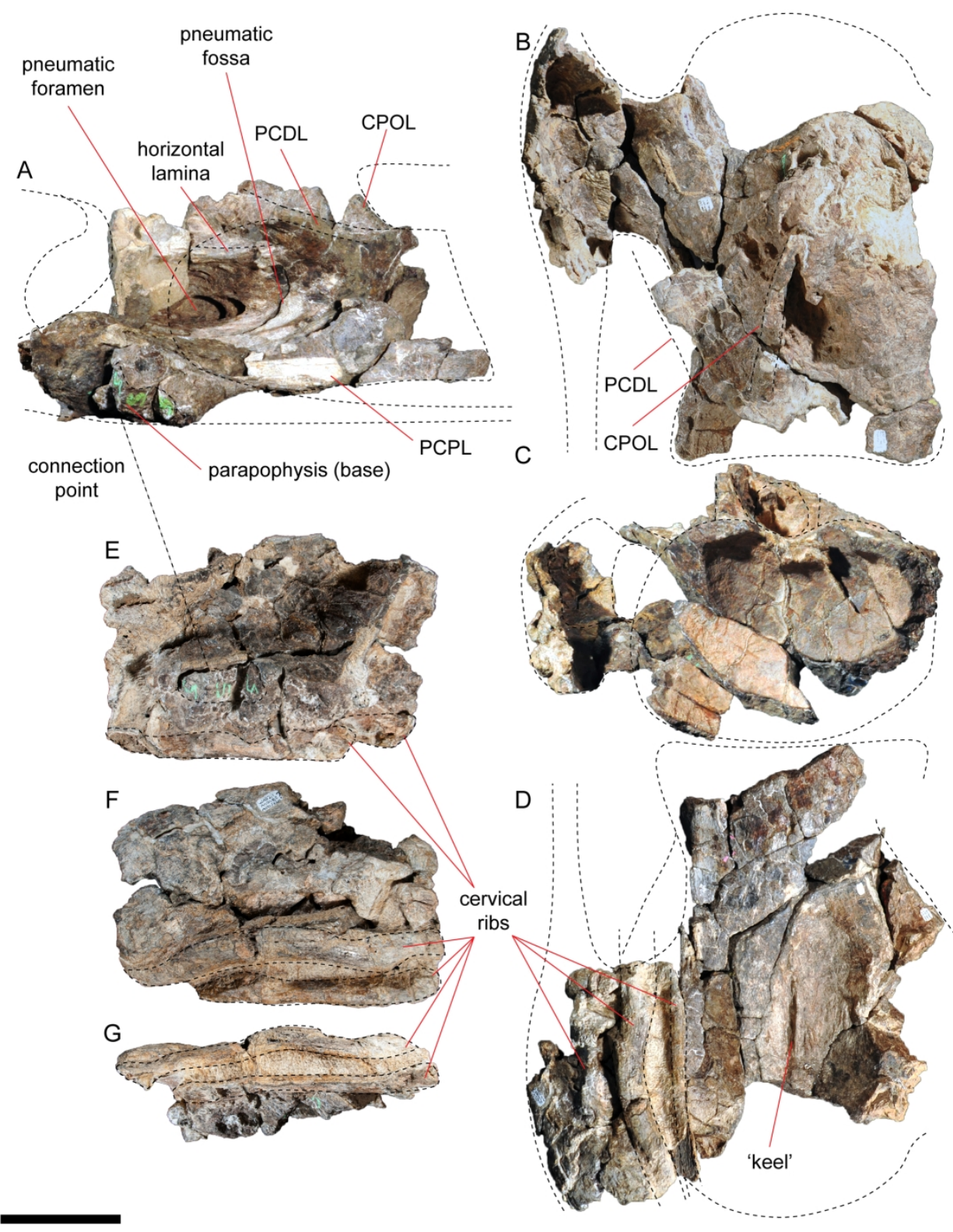

FIGURE 4. Savannasaurus elliottorum posterior cervical vertebra in A, left lateral, B, dorsal (with anterior to top), C, posterior, and D, ventral (with anterior to bottom) views, and left cervical ribs in E, medial, $\mathbf{F}$, lateral and G, ventral views. Scale bar equals $100 \mathrm{~mm}$.

$182 \times 232 \mathrm{~mm}(300 \times 300 \mathrm{DPI})$ 


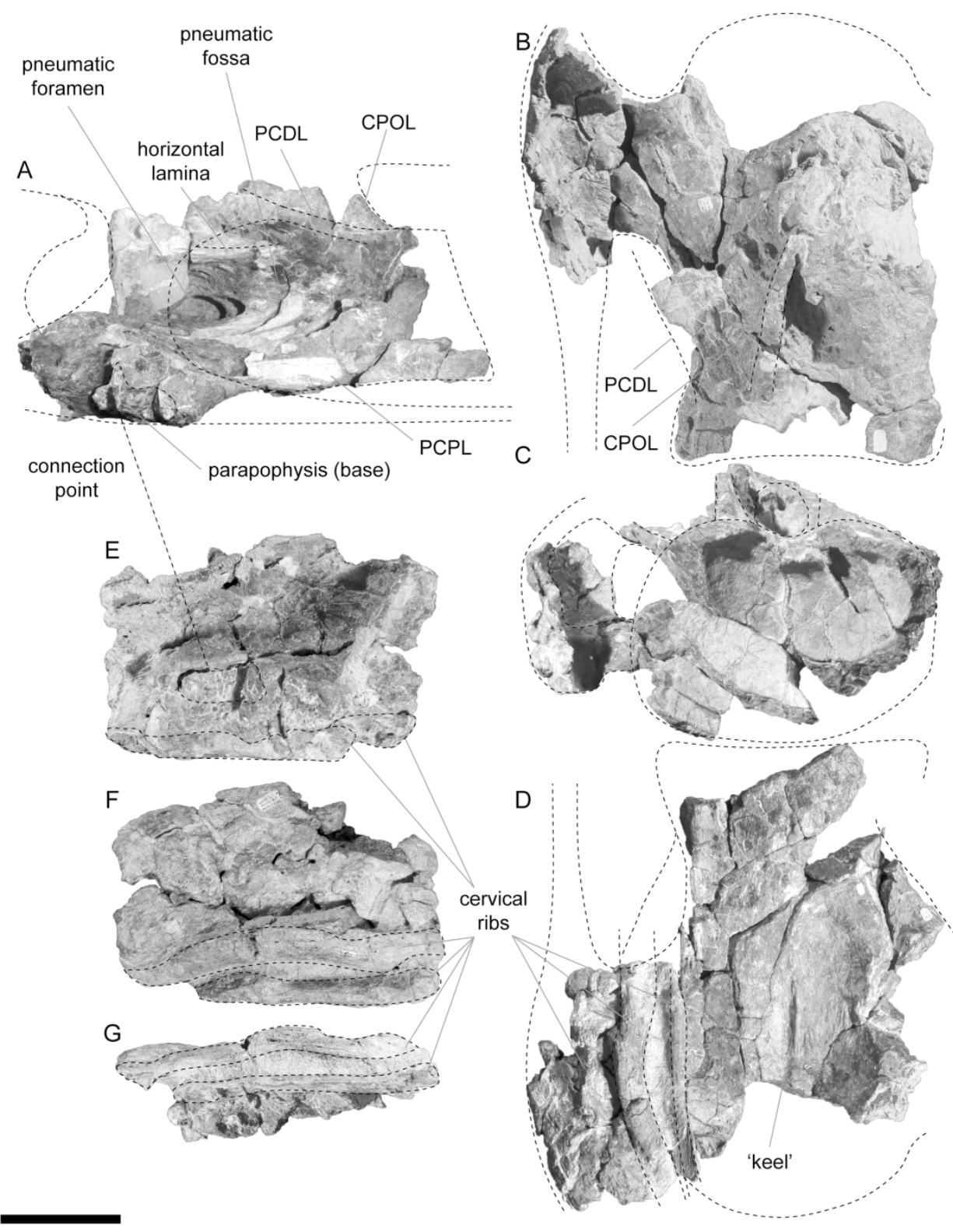

FIGURE 4. Savannasaurus elliottorum posterior cervical vertebra in A, left lateral, B, dorsal (with anterior to top), C, posterior, and $\mathbf{D}$, ventral (with anterior to bottom) views, and left cervical ribs in $\mathbf{E}$, medial, $\mathbf{F}$, lateral and G, ventral views. Scale bar equals $100 \mathrm{~mm}$.

$182 \times 232 \mathrm{~mm}(300 \times 300 \mathrm{DPI})$ 


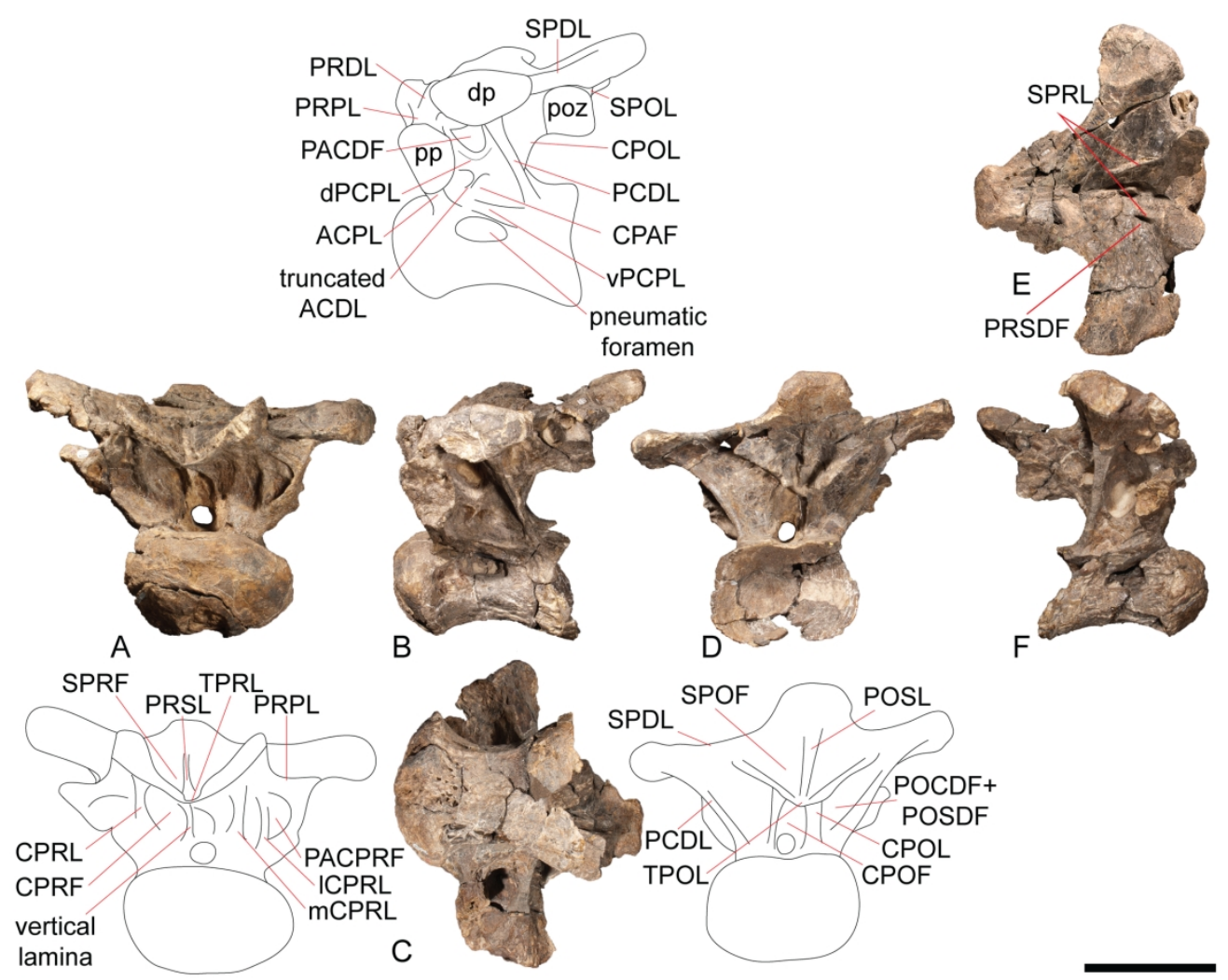

FIGURE 5. Savannasaurus elliottorum dorsal vertebra III in A, anterior, B, left lateral, C, ventral, D, posterior, E, dorsal, and F, right lateral views. Scale bar equals $200 \mathrm{~mm}$.

$182 \times 146 \mathrm{~mm}(300 \times 300 \mathrm{DPI})$ 

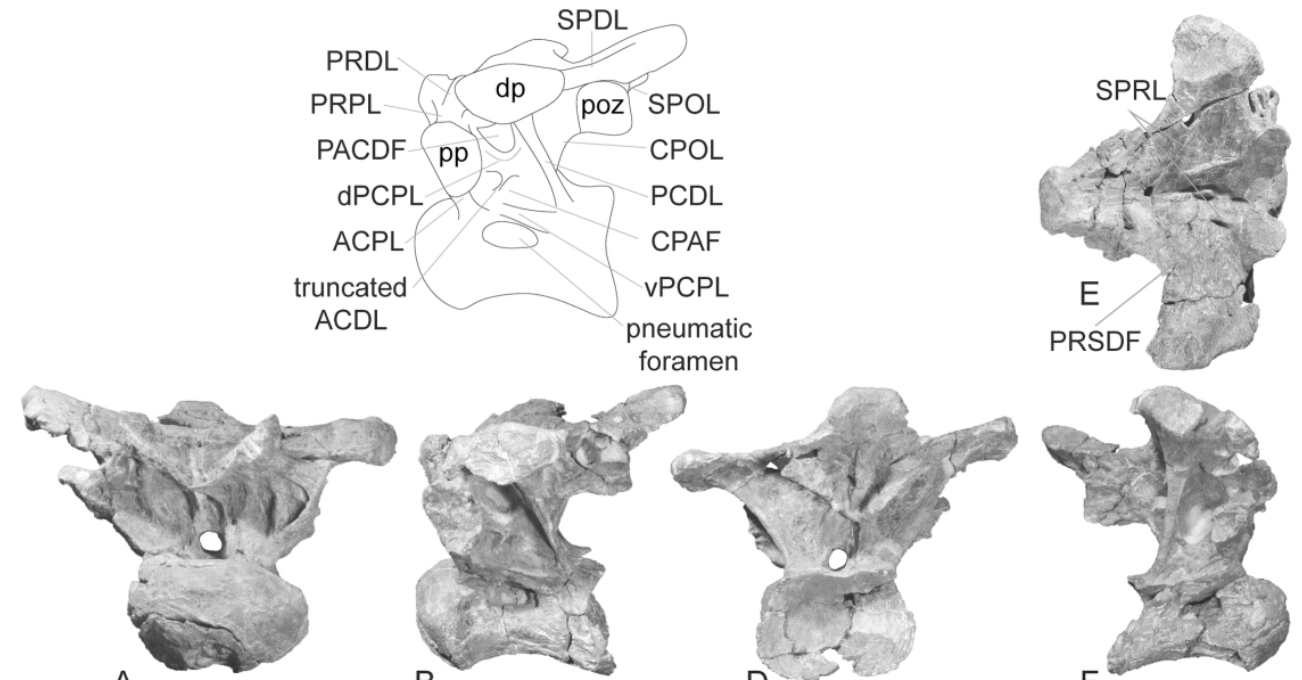

A

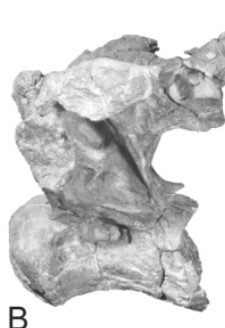
foramen

PRSDF
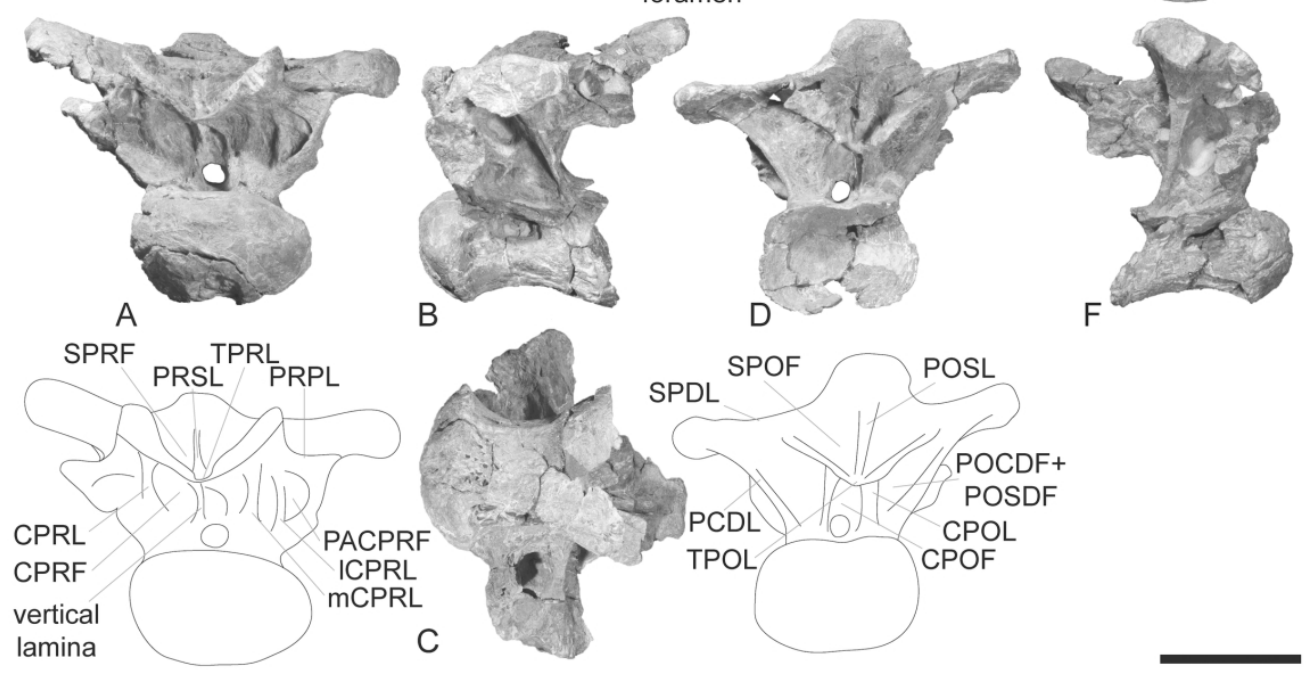

FIGURE 5. Savannasaurus elliottorum dorsal vertebra III in A, anterior, B, left lateral, C, ventral, D, posterior, E, dorsal, and $\mathbf{F}$, right lateral views. Scale bar equals $200 \mathrm{~mm}$.

\section{$182 \times 146 \mathrm{~mm}(300 \times 300$ DPI $)$}




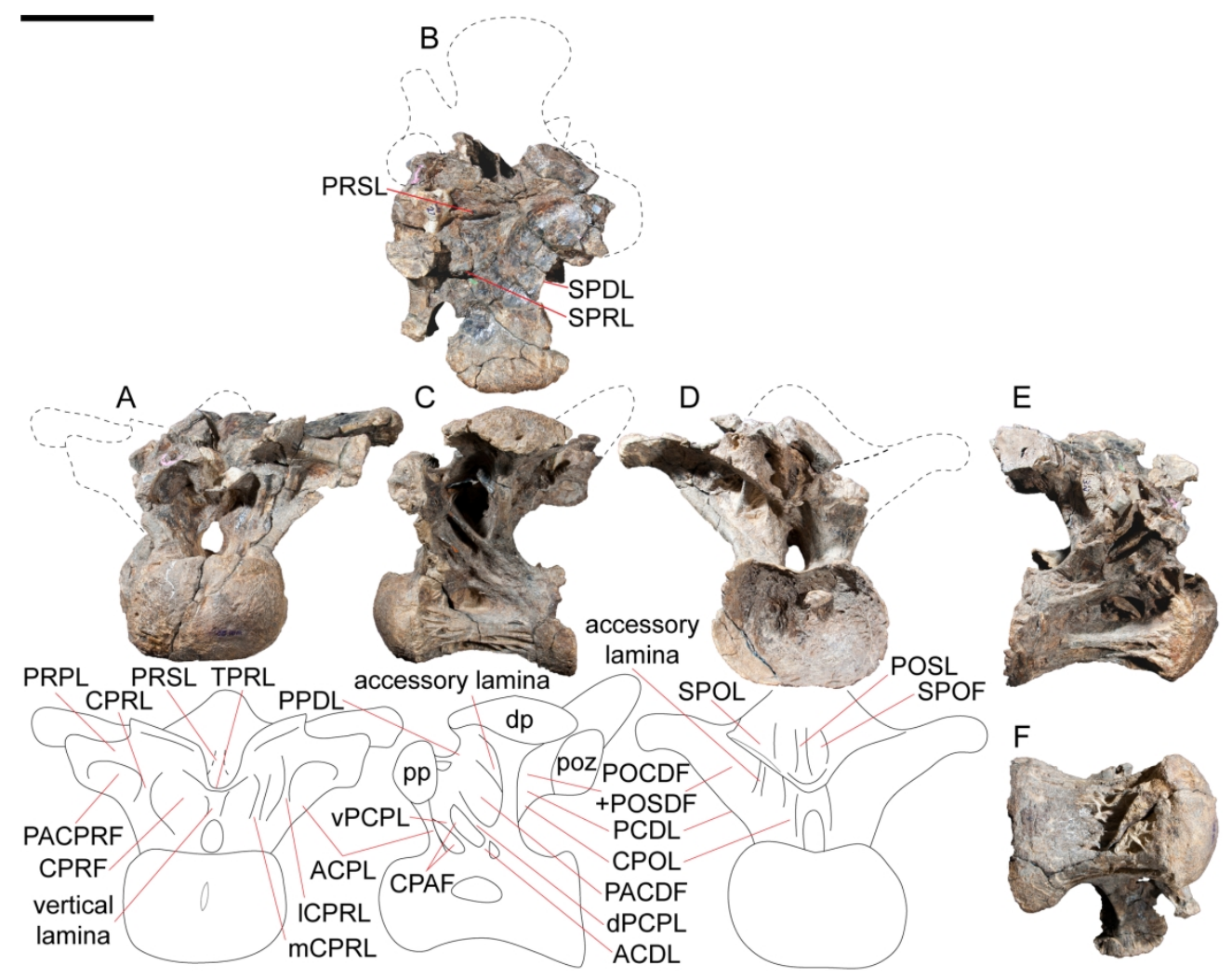

FIGURE 6. Savannasaurus elliottorum dorsal vertebra IV in A, anterior, B, dorsal, C, left lateral, D, posterior, E, right lateral, and F, ventral views. Scale bar equals $200 \mathrm{~mm}$.

$182 \times 144 \mathrm{~mm}(300 \times 300 \mathrm{DPI})$ 


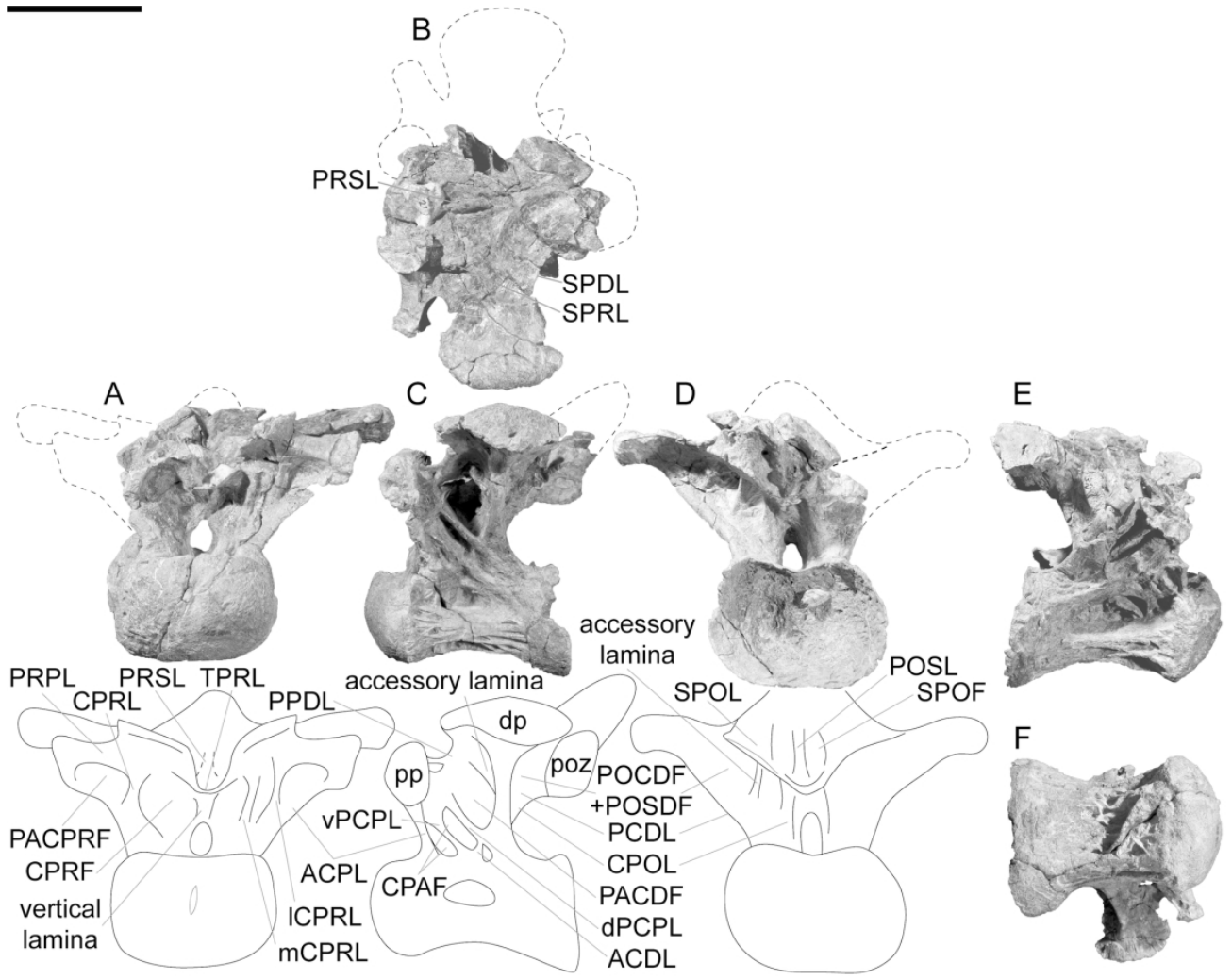

FIGURE 6. Savannasaurus elliottorum dorsal vertebra IV in A, anterior, B, dorsal, C, left lateral, D, posterior, E, right lateral, and F, ventral views. Scale bar equals $200 \mathrm{~mm}$.

$182 \times 144 \mathrm{~mm}(300 \times 300 \mathrm{DPI})$ 


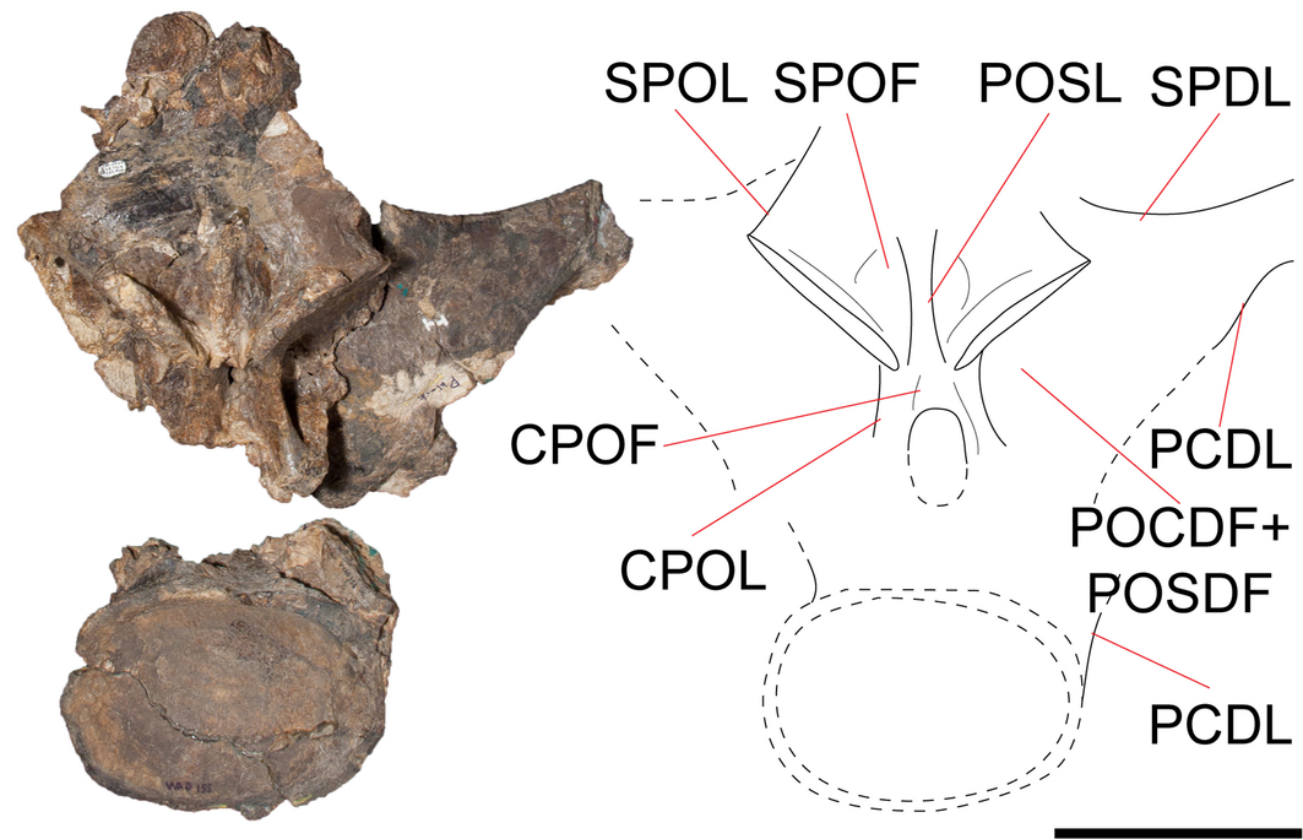

FIGURE 7. Savannasaurus elliottorum dorsal vertebra V in posterior view. Scale bar equals $200 \mathrm{~mm}$. $90 \times 57 \mathrm{~mm}(300 \times 300$ DPI $)$ 


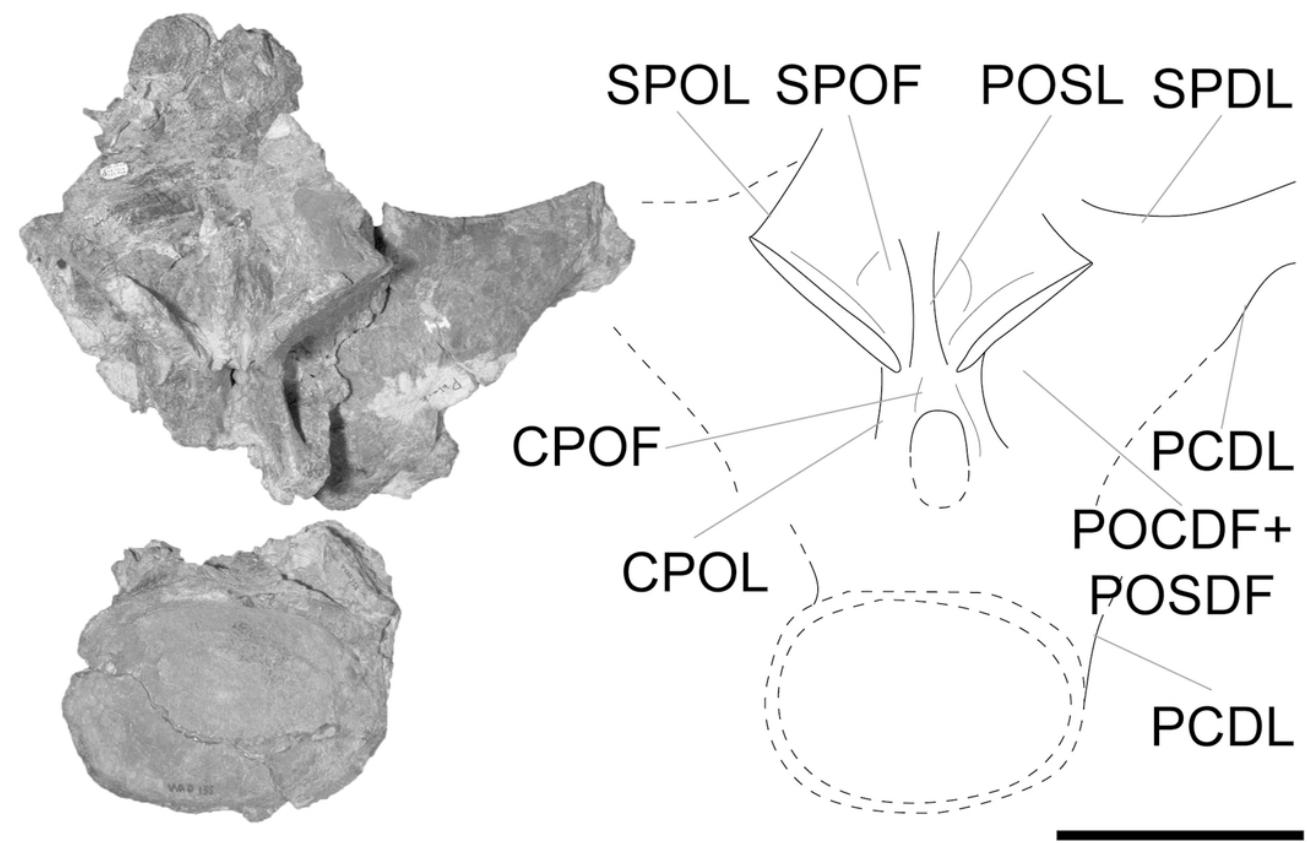

FIGURE 7. Savannasaurus elliottorum dorsal vertebra V in posterior view. Scale bar equals $200 \mathrm{~mm}$. $90 \times 57 \mathrm{~mm}(300 \times 300$ DPI $)$ 


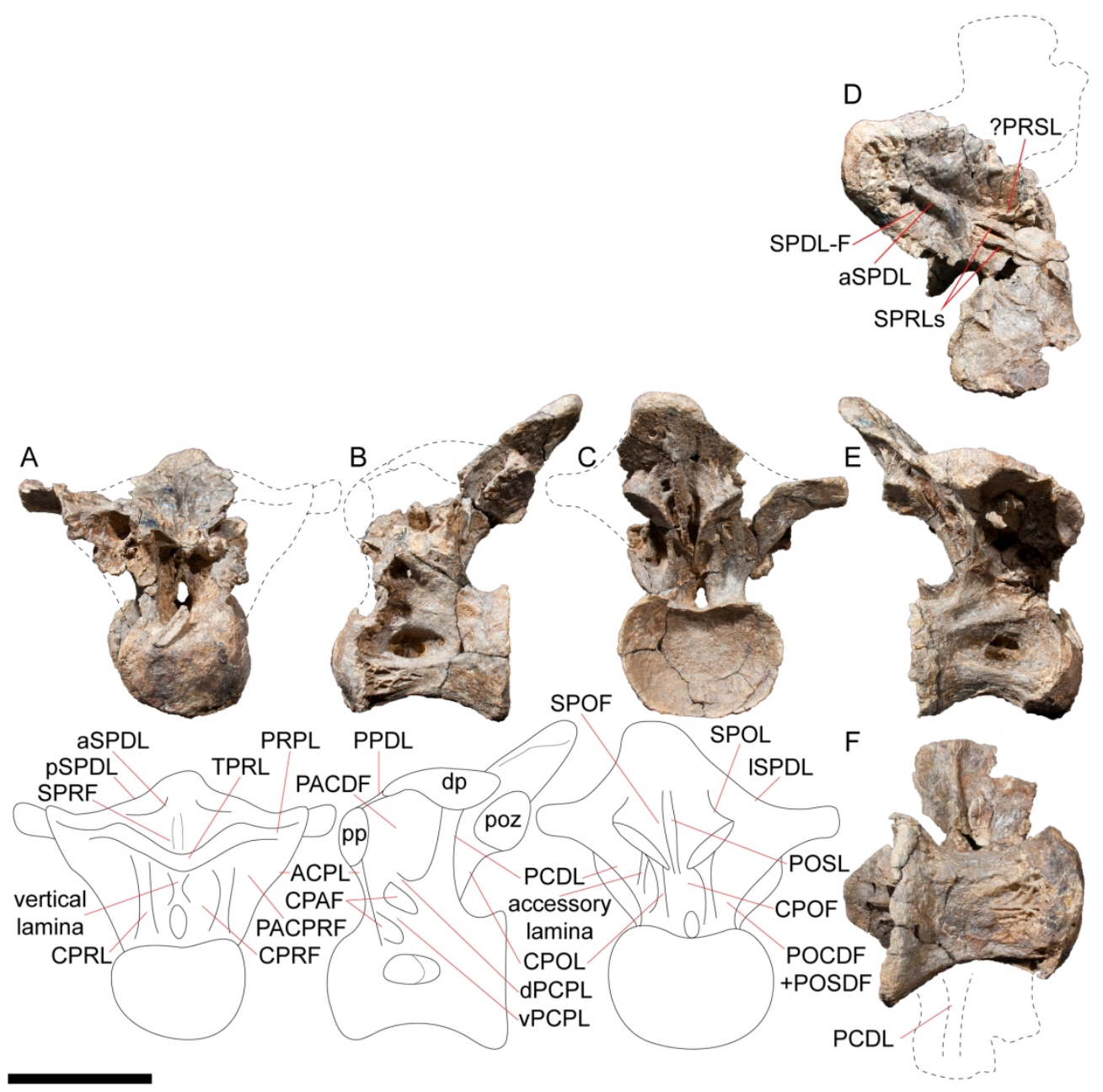

FIGURE 8. Savannasaurus elliottorum dorsal vertebra VI in A, anterior, B, left lateral, C, posterior, D, dorsal, E, right lateral, and F, ventral views. Scale bar equals $200 \mathrm{~mm}$.

$182 \times 178 \mathrm{~mm}(300 \times 300 \mathrm{DPI})$ 


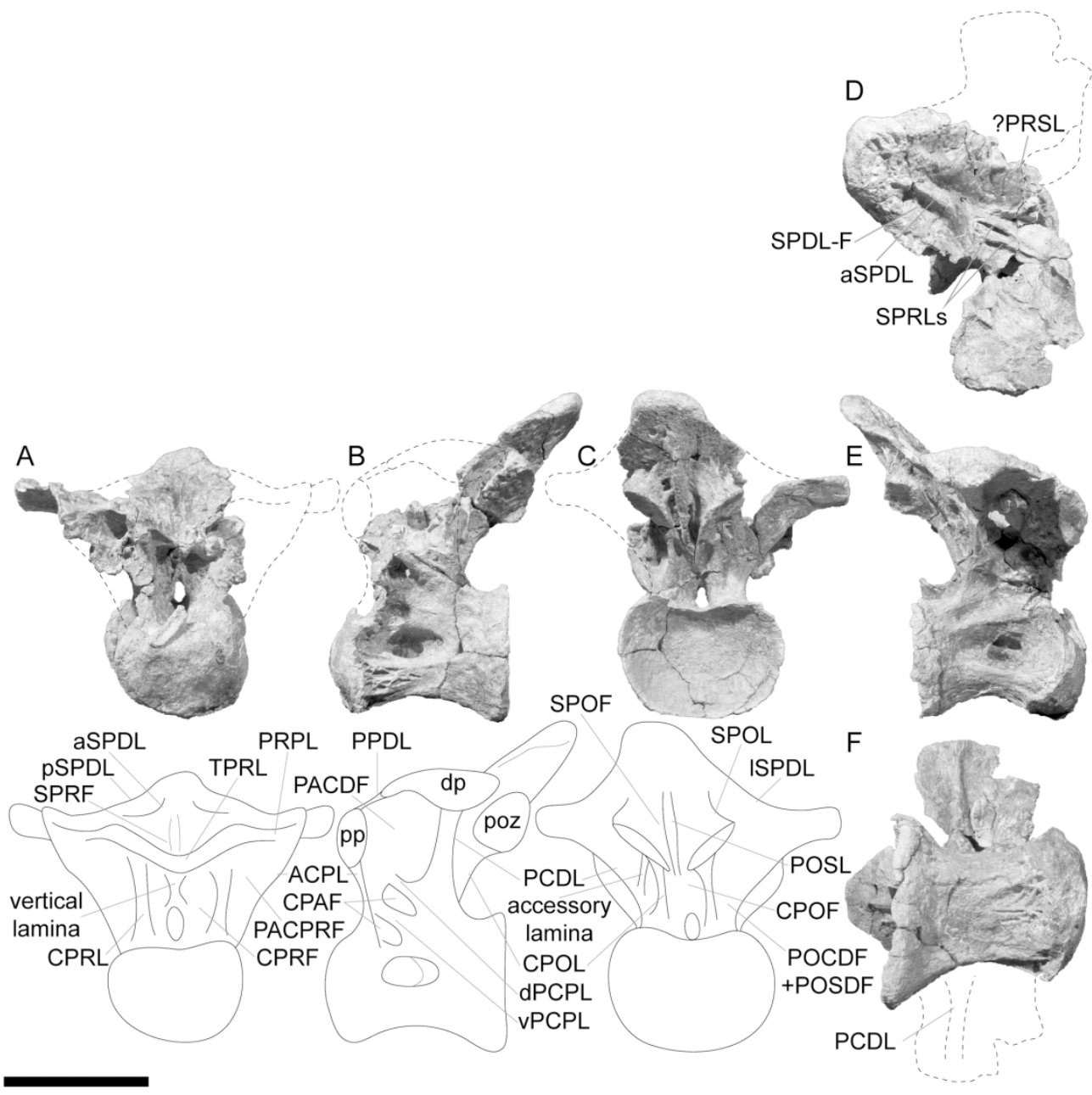

FIGURE 8. Savannasaurus elliottorum dorsal vertebra VI in A, anterior, B, left lateral, C, posterior, D, dorsal, E, right lateral, and $\mathbf{F}$, ventral views. Scale bar equals $200 \mathrm{~mm}$.

$182 \times 178 \mathrm{~mm}(300 \times 300 \mathrm{DPI})$ 


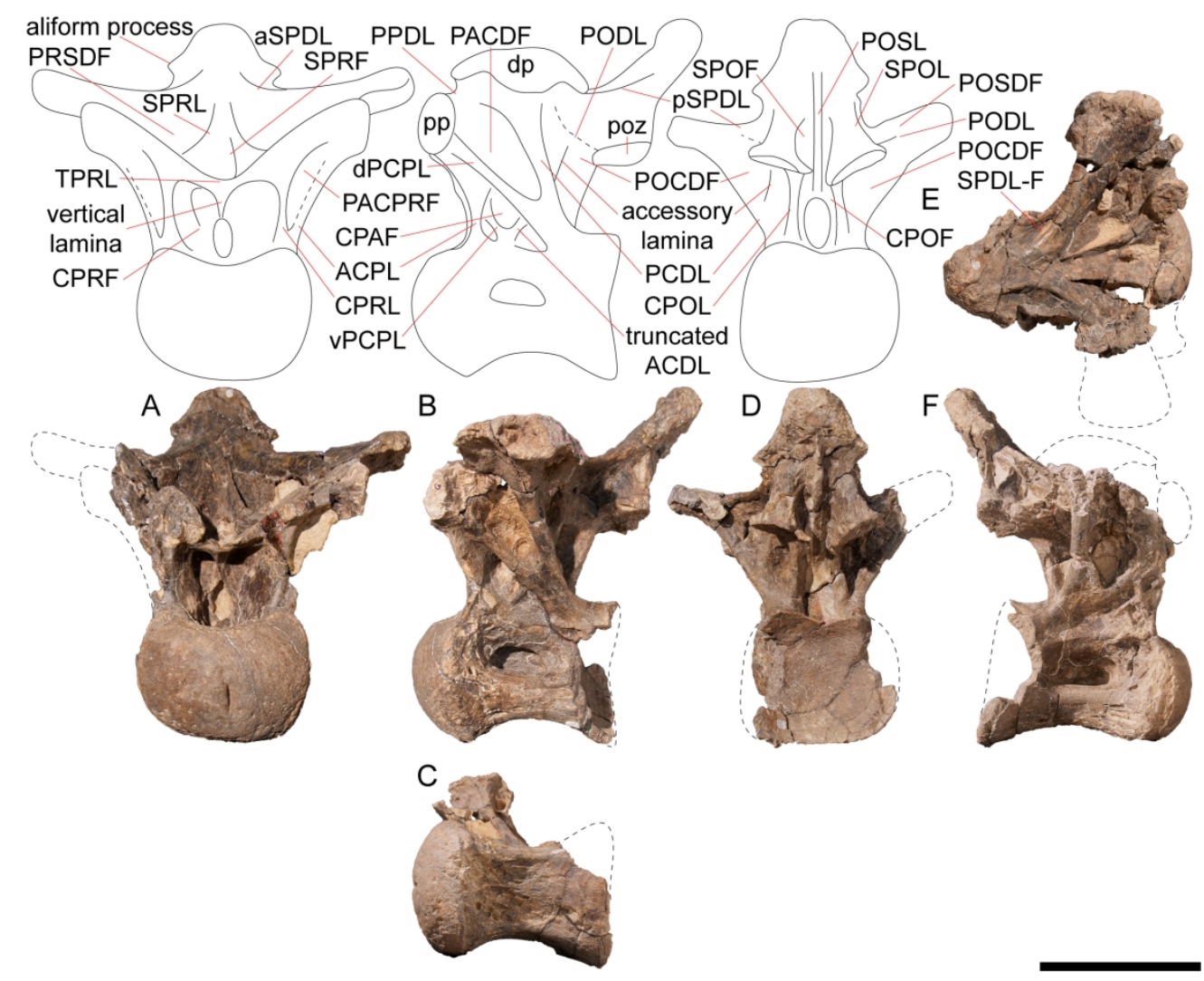

FIGURE 9. Savannasaurus elliottorum dorsal vertebra VII in A, anterior, B, left lateral, C, ventral, D, posterior, E, dorsal, and $\mathbf{F}$, right lateral views. Scale bar equals $200 \mathrm{~mm}$.

$182 \times 149 \mathrm{~mm}(300 \times 300 \mathrm{DPI})$ 


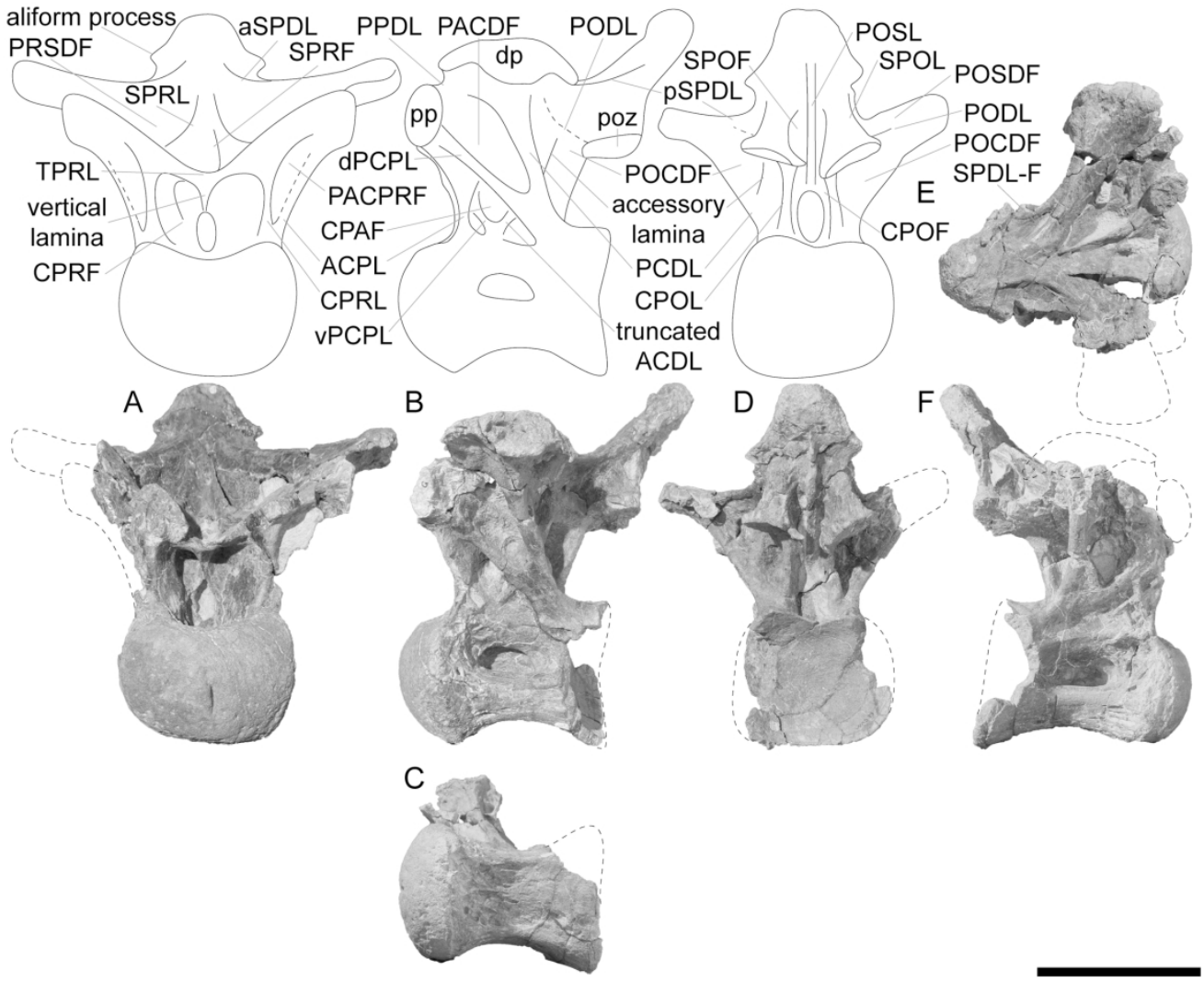

FIGURE 9. Savannasaurus elliottorum dorsal vertebra VII in A, anterior, B, left lateral, C, ventral, D, posterior, E, dorsal, and $\mathbf{F}$, right lateral views. Scale bar equals $200 \mathrm{~mm}$.

$182 \times 149 \mathrm{~mm}(300 \times 300 \mathrm{DPI})$ 


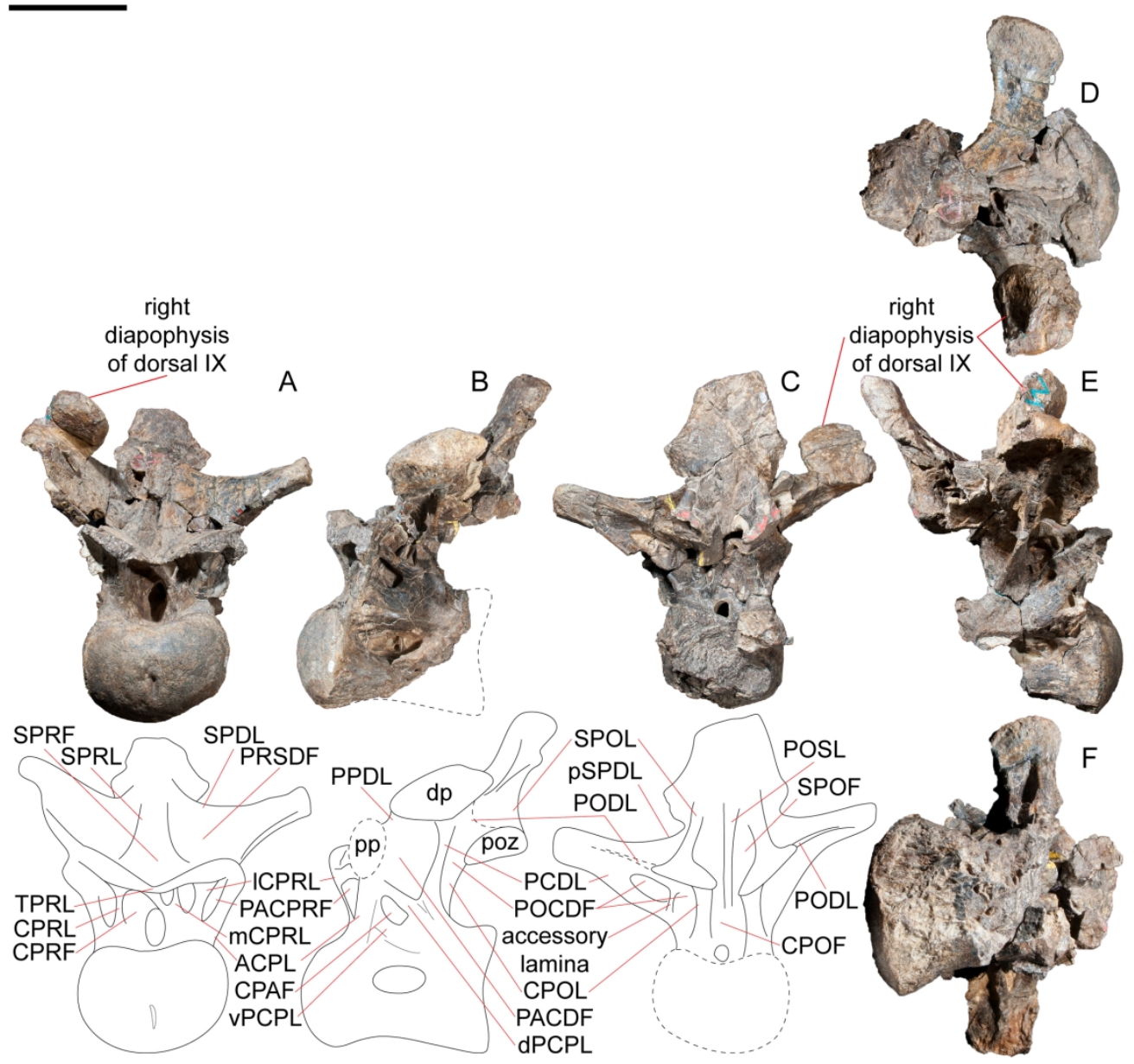

FIGURE 10. Savannasaurus elliottorum dorsal vertebra VIII in A, anterior, B, left lateral, C, posterior, D, dorsal, E, right lateral, and F, ventral views. Scale bar equals $200 \mathrm{~mm}$.

$182 \times 172 \mathrm{~mm}(300 \times 300 \mathrm{DPI})$ 


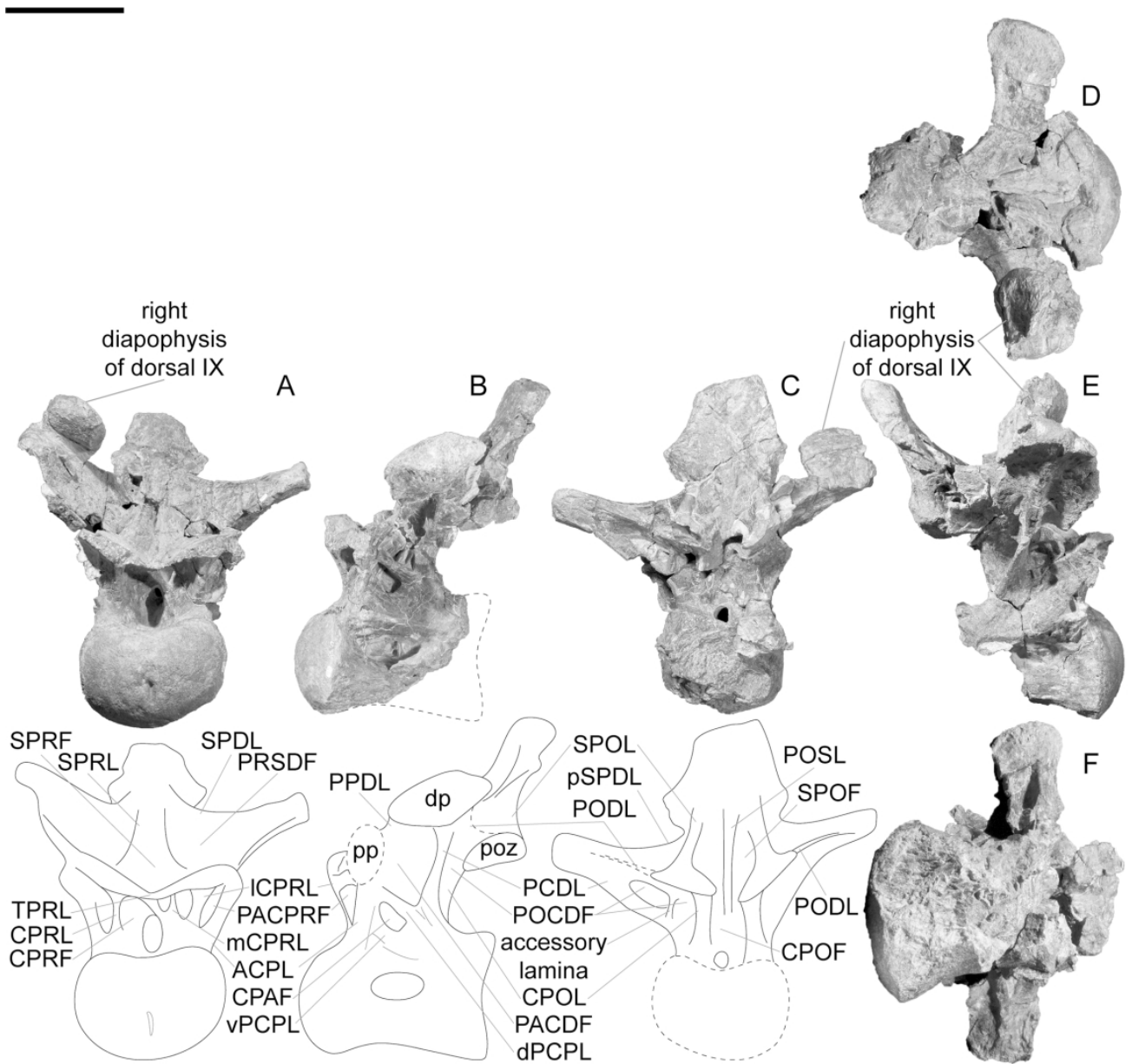

FIGURE 10. Savannasaurus elliottorum dorsal vertebra VIII in A, anterior, B, left lateral, C, posterior, D, dorsal, E, right lateral, and $\mathbf{F}$, ventral views. Scale bar equals $200 \mathrm{~mm}$.

$182 \times 172 \mathrm{~mm}(300 \times 300 \mathrm{DPI})$ 

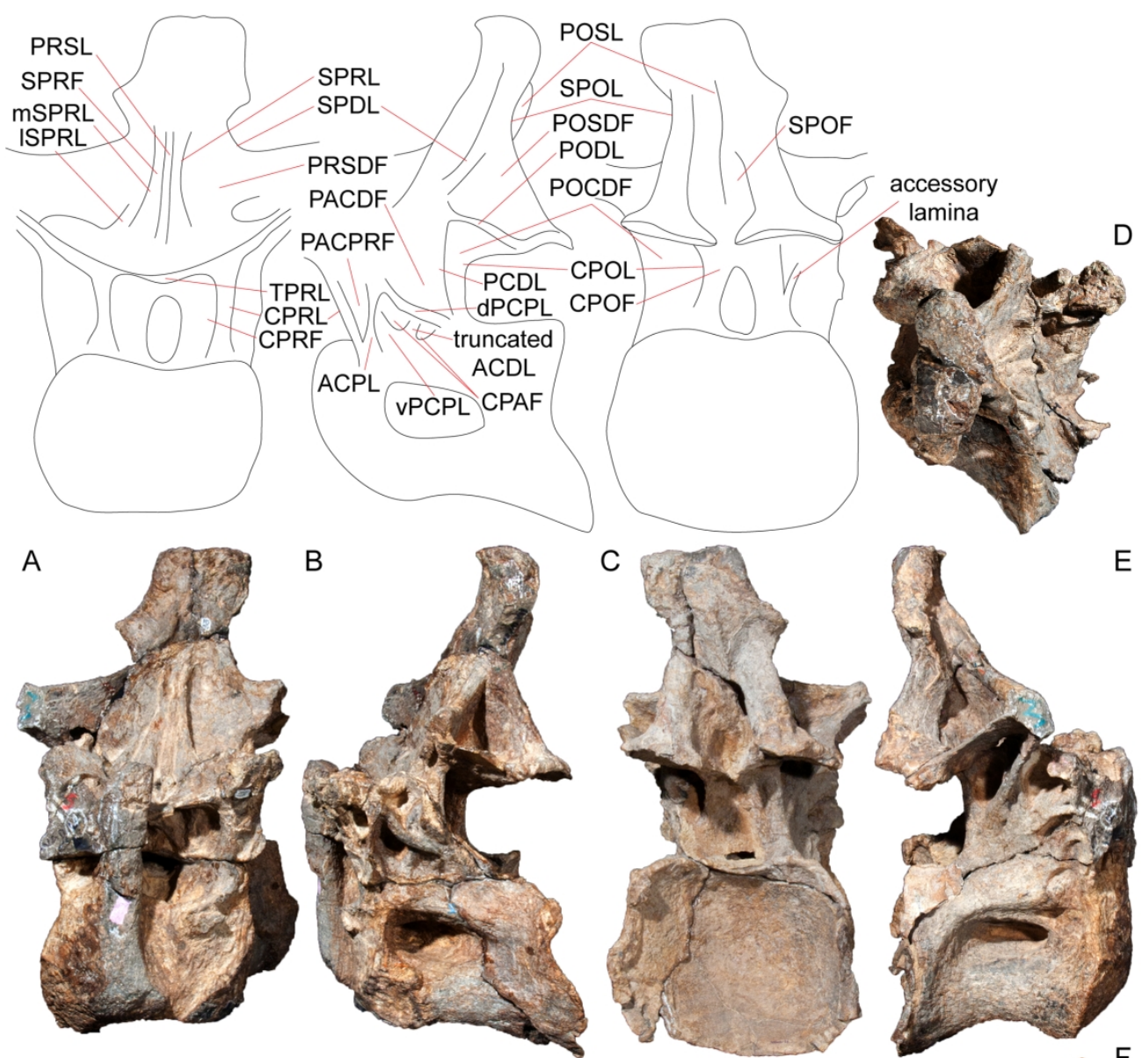

E 

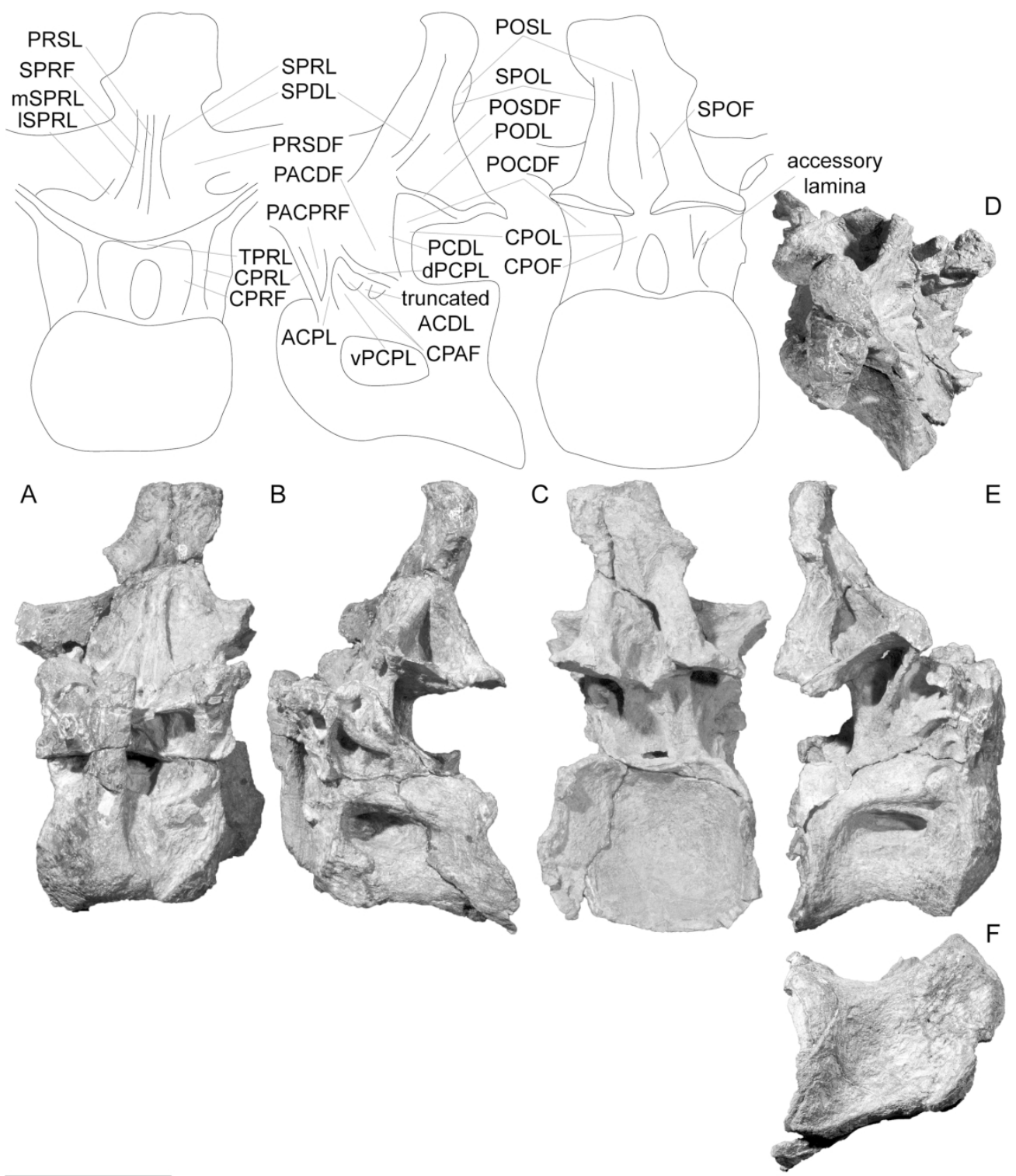

FIGURE 11. Savannasaurus elliottorum dorsal vertebra IX in A, anterior, B, left lateral, C, posterior, D, dorsal, E, right lateral, and F, ventral views. Scale bar equals $200 \mathrm{~mm}$.

$$
182 \times 213 \mathrm{~mm}(300 \times 300 \mathrm{DPI})
$$




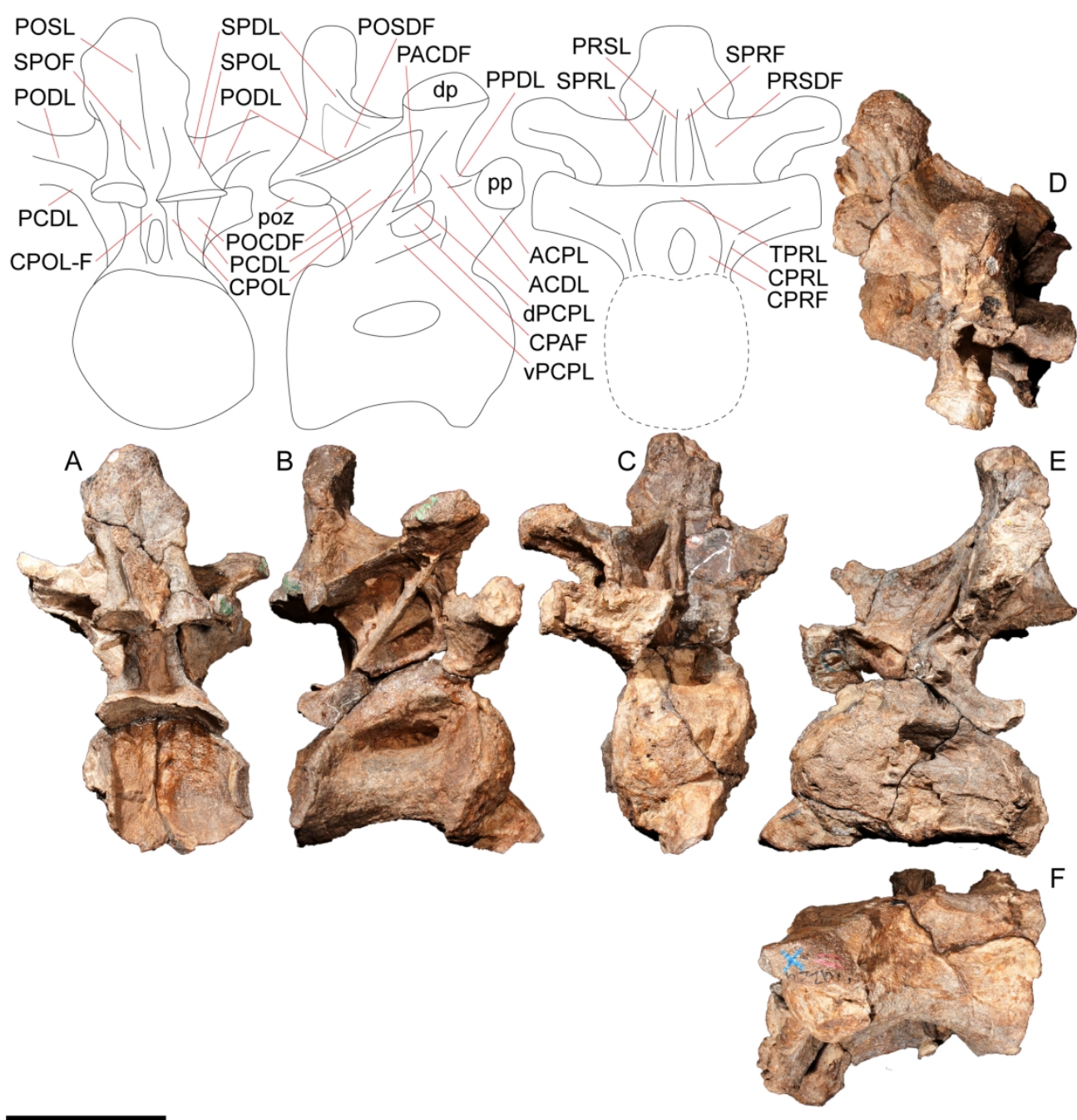

FIGURE 12. Savannasaurus elliottorum dorsal vertebra $X$ in A, posterior, B, right lateral, C, anterior, D, dorsal, E, left lateral, and F, ventral views. Scale bar equals $200 \mathrm{~mm}$.

$182 \times 188 \mathrm{~mm}(300 \times 300 \mathrm{DPI})$ 

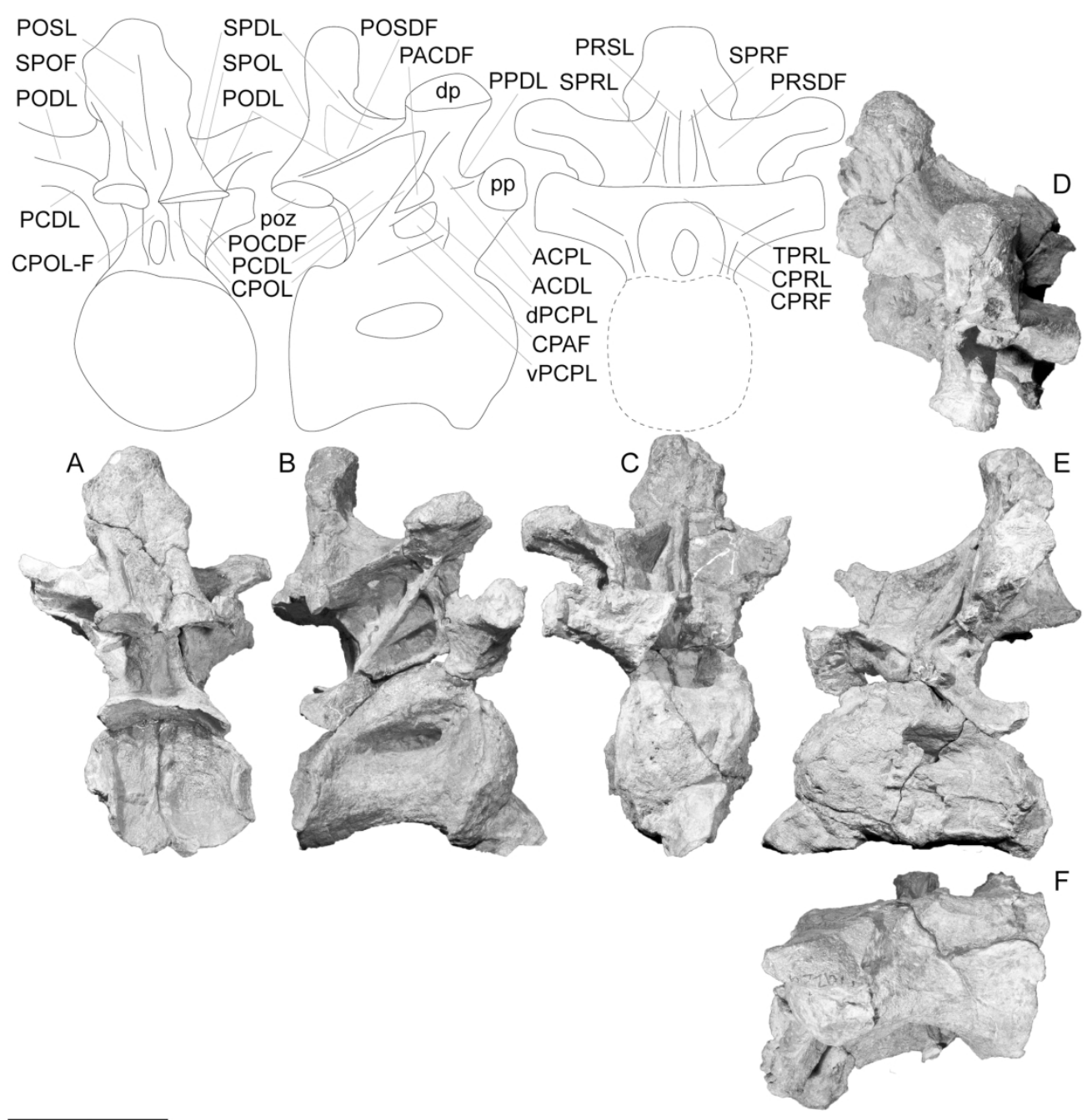

FIGURE 12. Savannasaurus elliottorum dorsal vertebra $X$ in A, posterior, B, right lateral, C, anterior, D, dorsal, E, left lateral, and $\mathbf{F}$, ventral views. Scale bar equals $200 \mathrm{~mm}$.

$182 \times 188 \mathrm{~mm}(300 \times 300 \mathrm{DPI})$ 


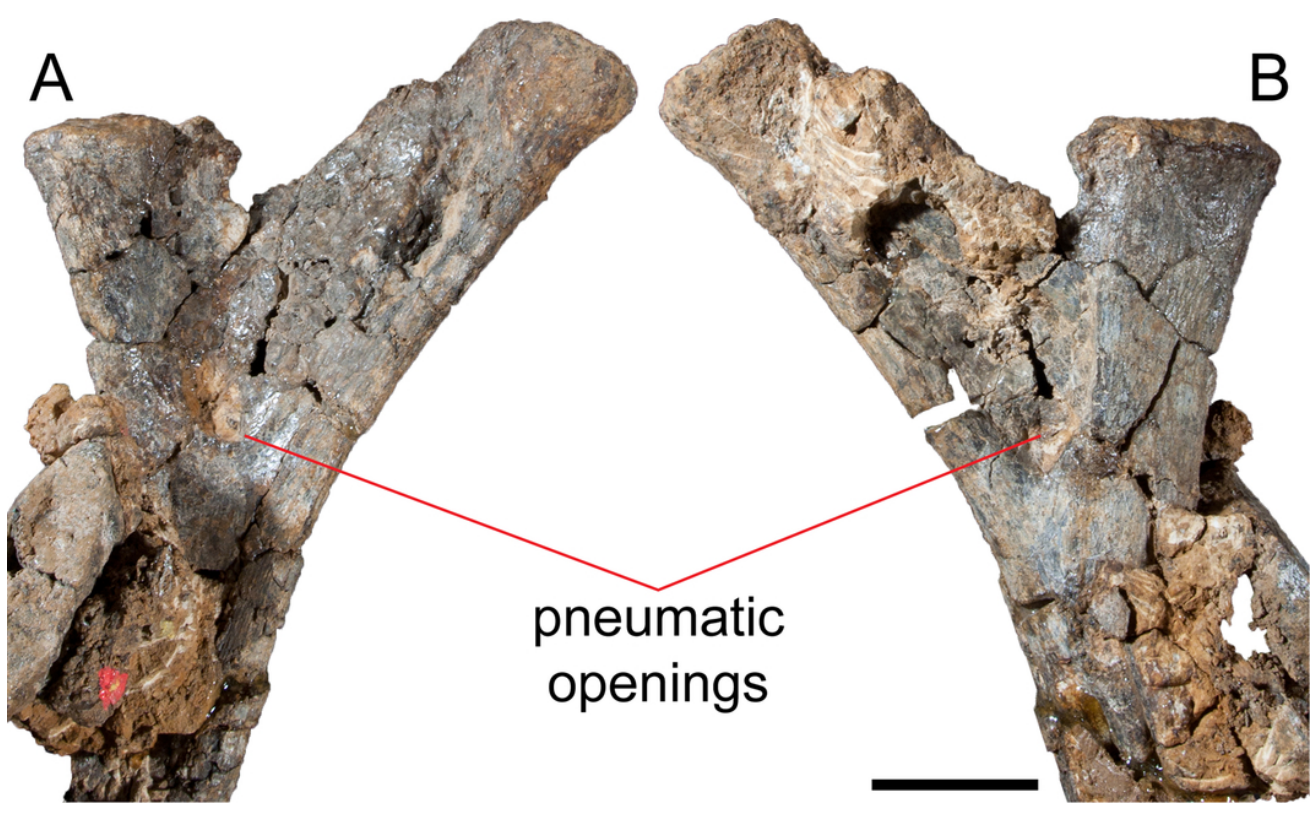

FIGURE 13. Savannasaurus elliottorum dorsal rib head in A, posterior and B, anterior views. Scale bar equals $50 \mathrm{~mm}$.

$90 \times 54 \mathrm{~mm}(300 \times 300 \mathrm{DPI})$ 


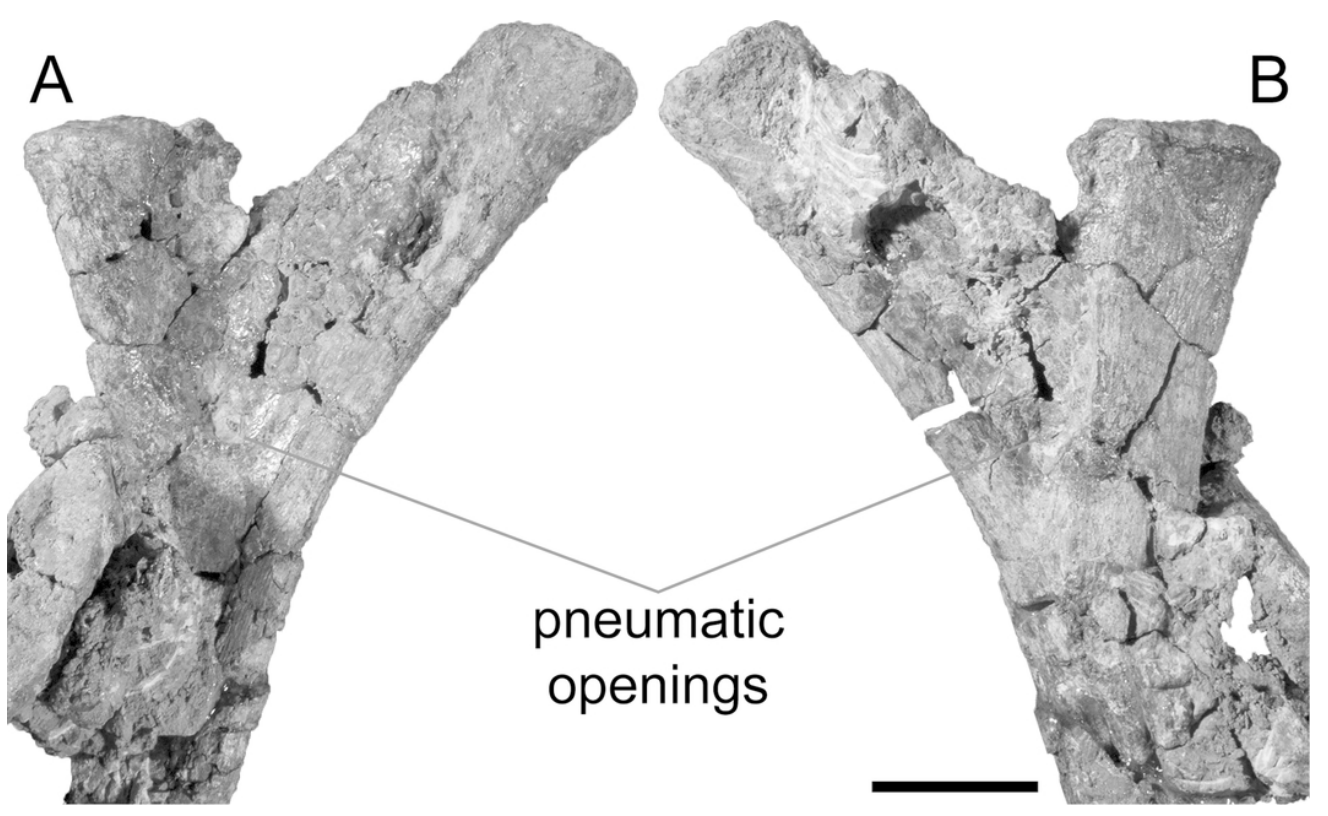

FIGURE 13. Savannasaurus elliottorum dorsal rib head in A, posterior and B, anterior views. Scale bar equals $50 \mathrm{~mm}$.

$90 \times 54 \mathrm{~mm}(300 \times 300 \mathrm{DPI})$ 


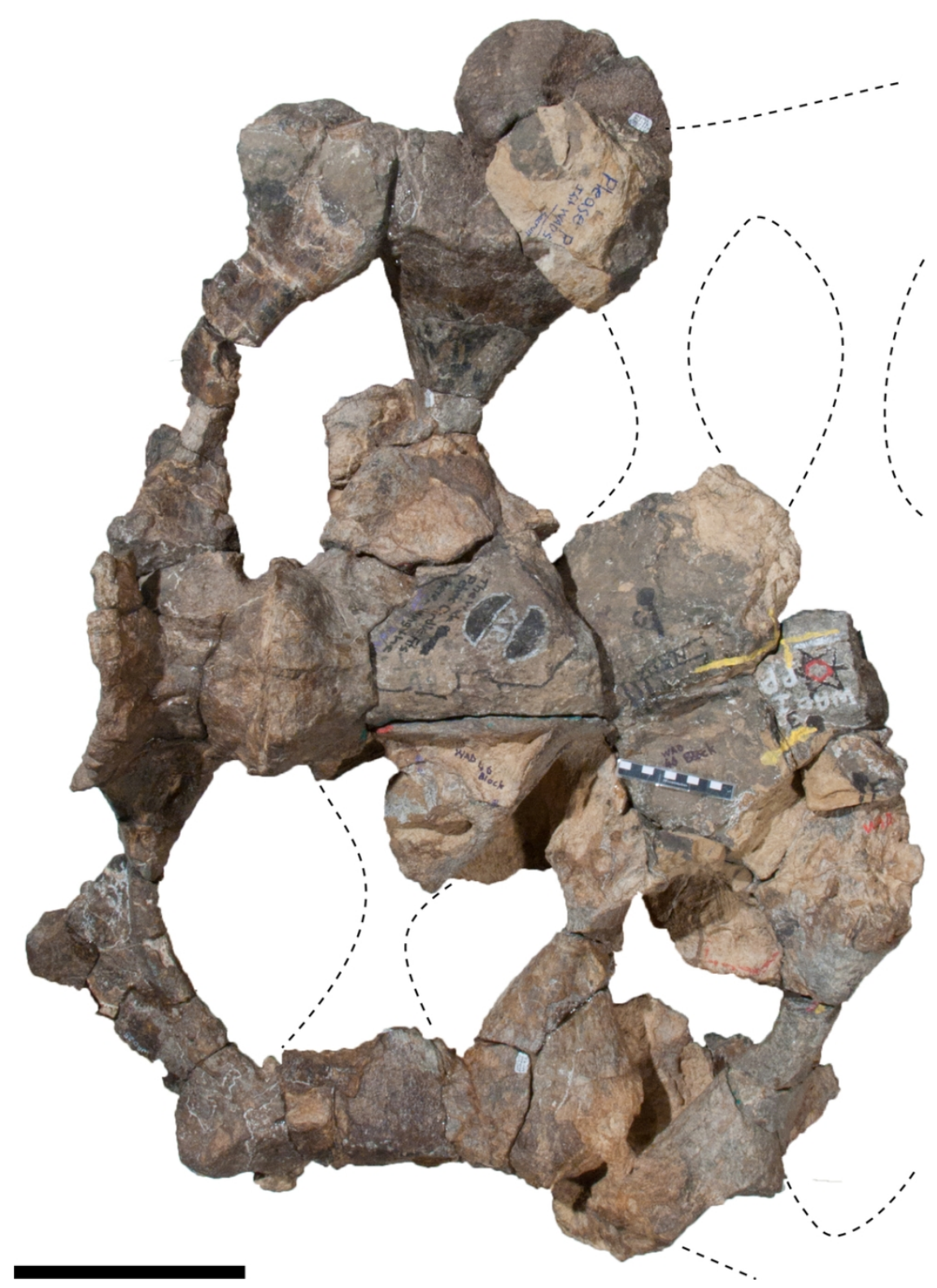

FIGURE 14. Savannasaurus elliottorum sacrum in ventral view (posterior to the left, anterior to the right). Scale bar equals $200 \mathrm{~mm}$.

$90 \times 123 \mathrm{~mm}(300 \times 300 \mathrm{DPI})$ 


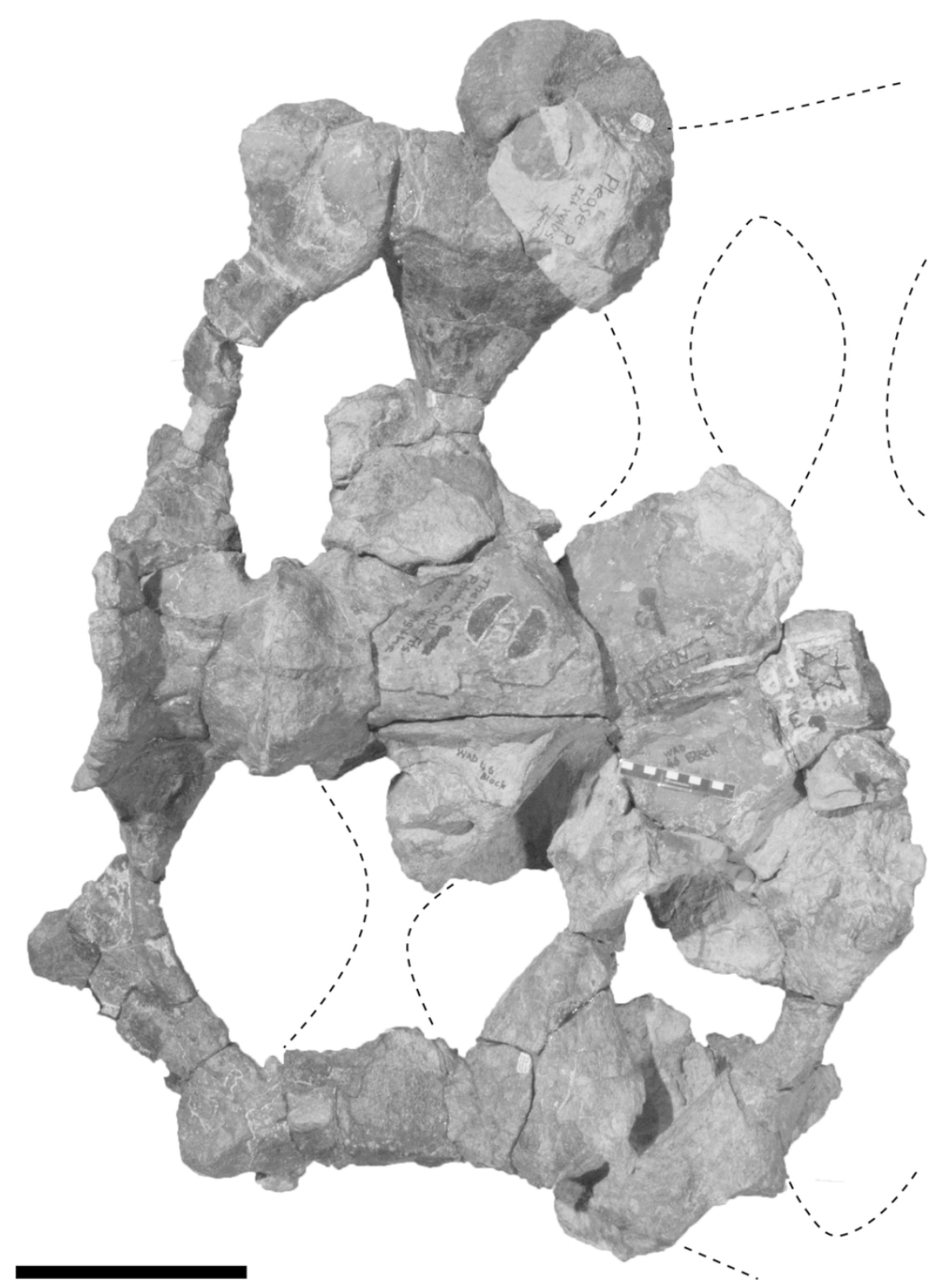

FIGURE 14. Savannasaurus elliottorum sacrum in ventral view (posterior to the left, anterior to the right). Scale bar equals $200 \mathrm{~mm}$.

$90 \times 123 \mathrm{~mm}(300 \times 300 \mathrm{DPI})$ 
FIGURE 15. Savannasaurus elliottorum caudal vertebrae. Caudal vertebra A in A, anterior, B, dorsal, C, left lateral, and $\mathbf{D}$, posterior views, and $\mathbf{E}$, broken left neural arch in lateral view. Caudal vertebra B in $\mathbf{F}$, anterior, G, dorsal, $\mathbf{H}$, left lateral, I, posterior, and J, right lateral views. Caudal vertebra $\mathbf{C}$ in $\mathbf{K}$, anterior, $\mathbf{L}$, left lateral, $\mathbf{M}$, dorsal, $\mathbf{N}$, posterior, $\mathbf{0}$, ventral, and $\mathbf{P}$, right lateral views. Caudal vertebra $\mathrm{D}$ in $\mathbf{Q}$, dorsal, $\mathbf{R}$, right lateral, and $\mathbf{S}$, anterior views. Scale bar for A-D and $\mathbf{F}-\mathbf{S}$ equals $100 \mathrm{~mm}$; scale bar for $\mathbf{E}$ equals 50 $\mathrm{mm}$.

$182 \times 114 \mathrm{~mm}(300 \times 300 \mathrm{DPI})$ 
FIGURE 15. Savannasaurus elliottorum caudal vertebrae. Caudal vertebra A in A, anterior, B, dorsal, C, left lateral, and D, posterior views, and $\mathbf{E}$, broken left neural arch in lateral view. Caudal vertebra $\mathbf{B}$ in $\mathbf{F}$, anterior, G, dorsal, $\mathbf{H}$, left lateral, $\mathbf{I}$, posterior, and $\mathbf{J}$, right lateral views. Caudal vertebra $\mathbf{C}$ in $\mathbf{K}$, anterior, $\mathbf{L}$, left lateral, $\mathbf{M}$, dorsal, $\mathbf{N}$, posterior, $\mathbf{O}$, ventral, and $\mathbf{P}$, right lateral views. Caudal vertebra D in $\mathbf{Q}$, dorsal, $\mathbf{R}$, right lateral, and S, anterior views. Scale bar for A-D and F-S equals $100 \mathrm{~mm}$; scale bar for $\mathbf{E}$ equals 50 $\mathrm{mm}$.

$182 \times 114 \mathrm{~mm}(300 \times 300 \mathrm{DPI})$ 


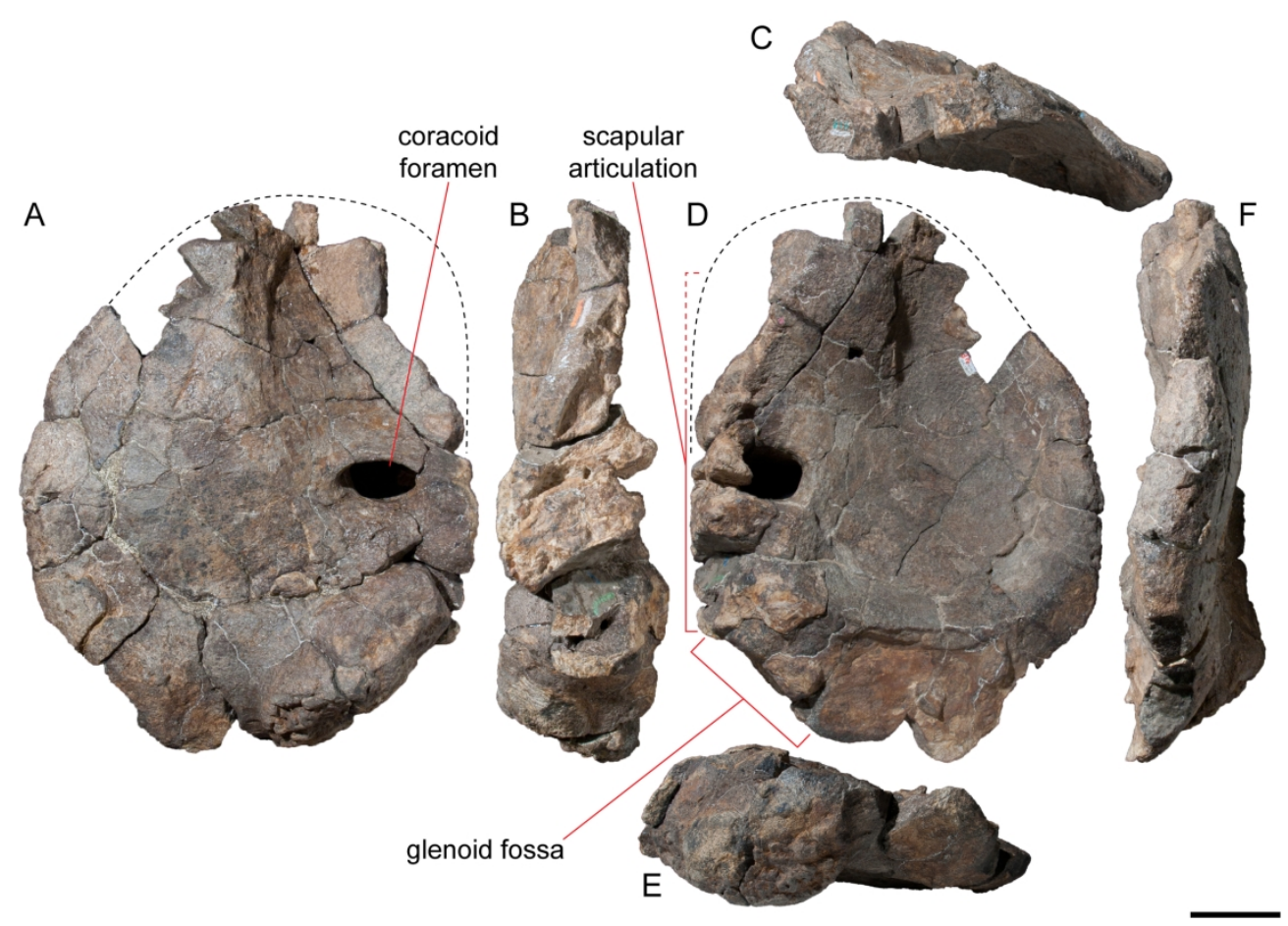

FIGURE 16. Savannasaurus elliottorum left coracoid in A, lateral, B, posterior, C, dorsal, D, medial, E, ventral, and $\mathbf{F}$, anterior views. Scale bar equals $100 \mathrm{~mm}$.

$182 \times 129 \mathrm{~mm}(300 \times 300 \mathrm{DPI})$ 


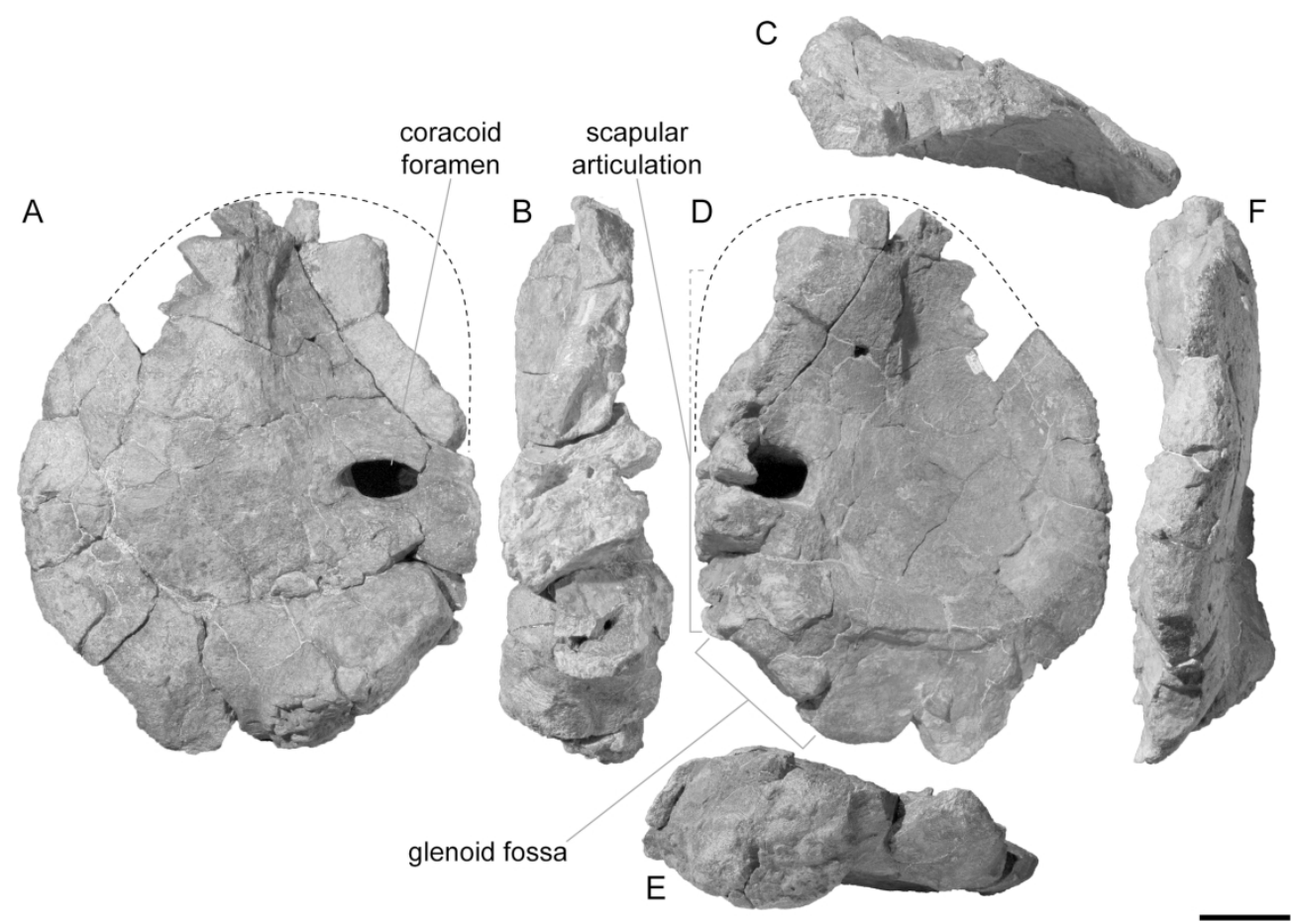

FIGURE 16. Savannasaurus elliottorum left coracoid in A, lateral, B, posterior, C, dorsal, D, medial, E, ventral, and $\mathbf{F}$, anterior views. Scale bar equals $100 \mathrm{~mm}$.

$182 \times 129 \mathrm{~mm}(300 \times 300 \mathrm{DPI})$ 


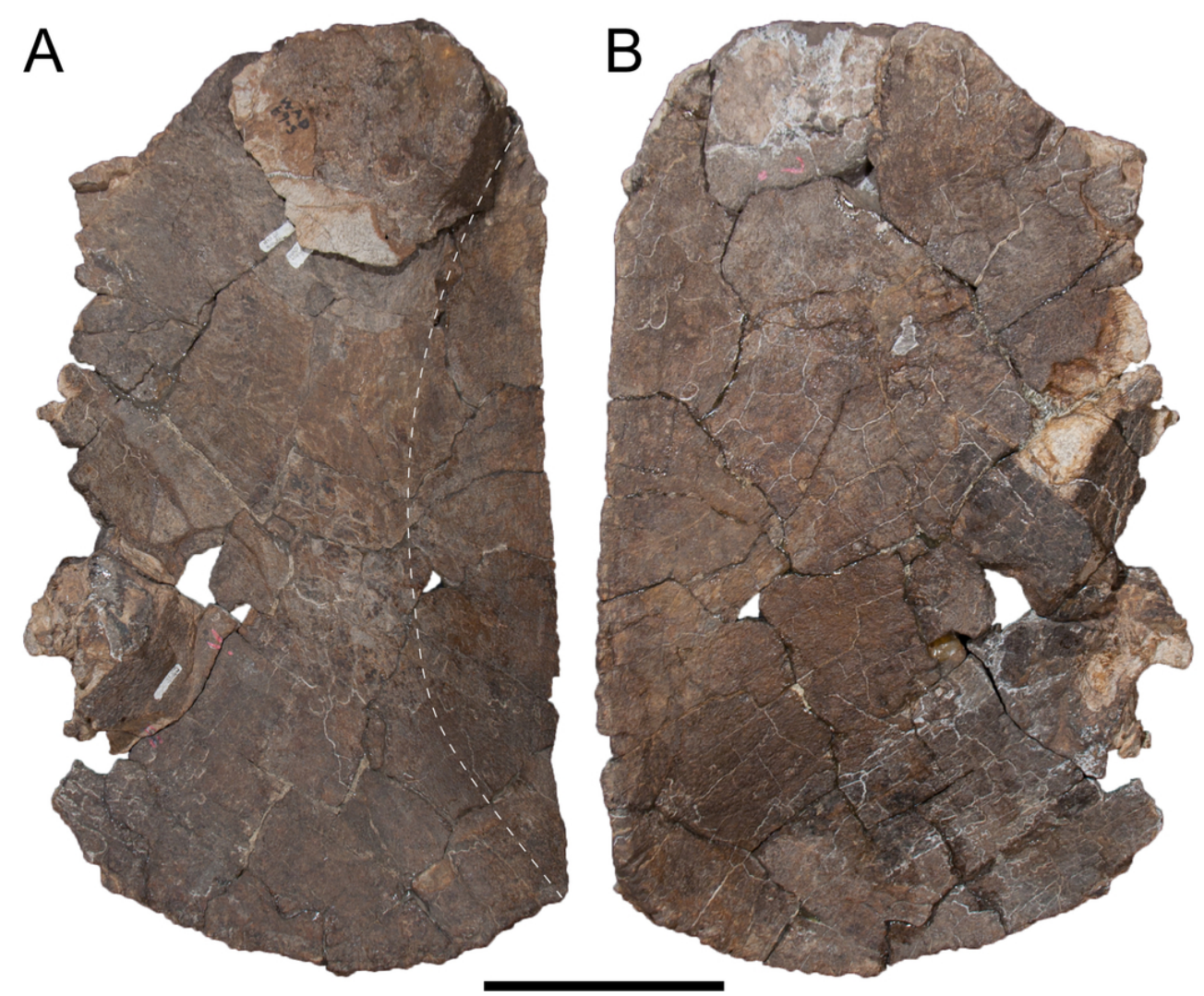

FIGURE 17. Savannasaurus elliottorum left sternal plate in A, ventral and B, dorsal views, with the anterior end towards the top of the page. The dashed line represents the division between the convex portion of the ventral surface (medial to the line) and the concave portion (lateral to the line). Scale bar equals $200 \mathrm{~mm}$.

$90 \times 73 \mathrm{~mm}(300 \times 300 \mathrm{DPI})$ 


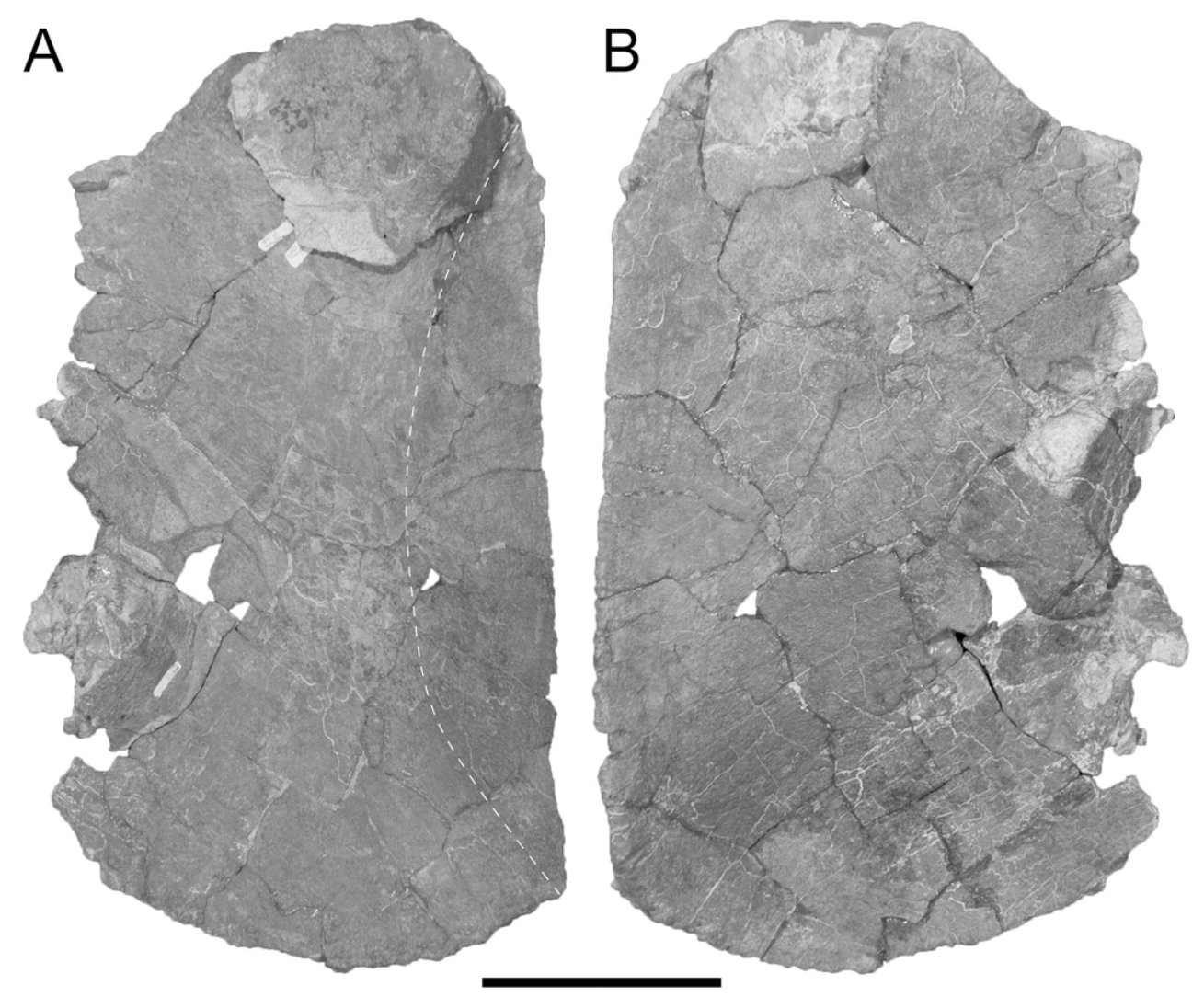

FIGURE 17. Savannasaurus elliottorum left sternal plate in A, ventral and B, dorsal views, with the anterior end towards the top of the page. The dashed line represents the division between the convex portion of the ventral surface (medial to the line) and the concave portion (lateral to the line). Scale bar equals $200 \mathrm{~mm}$.

$90 \times 73 \mathrm{~mm}(300 \times 300$ DPI $)$ 

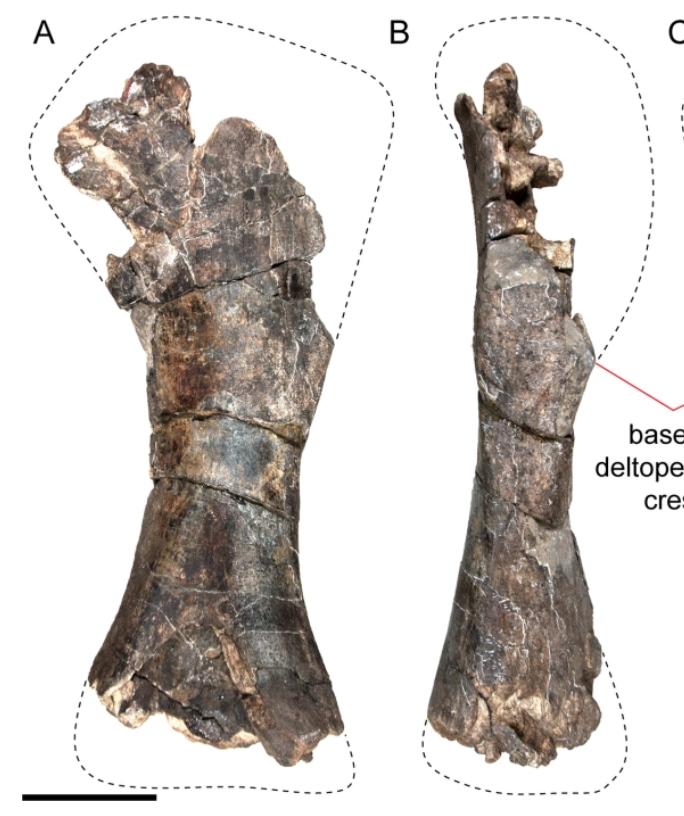

C
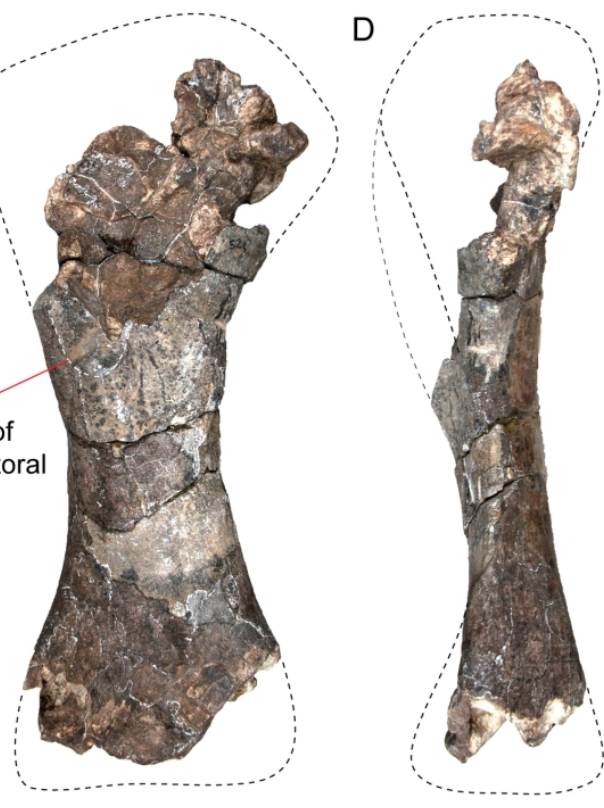

FIGURE 18. Savannasaurus elliottorum right humerus in $\mathbf{A}$, posterior, B, lateral, C, anterior, and $\mathbf{D}$, medial views. Scale bar equals $200 \mathrm{~mm}$.

$182 \times 110 \mathrm{~mm}(300 \times 300 \mathrm{DPI})$ 


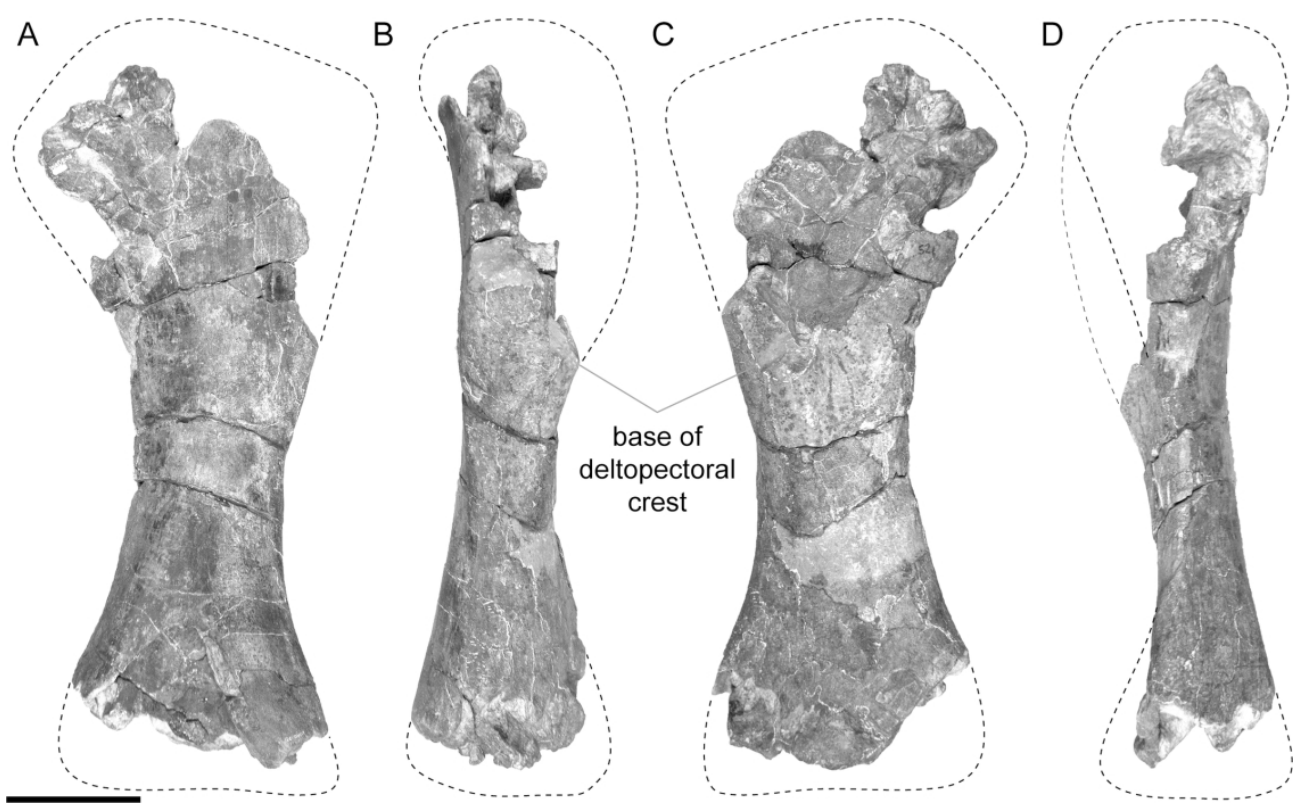

FIGURE 18. Savannasaurus elliottorum right humerus in A, posterior, B, lateral, C, anterior, and D, medial views. Scale bar equals $200 \mathrm{~mm}$.

$182 \times 110 \mathrm{~mm}(300 \times 300 \mathrm{DPI})$ 


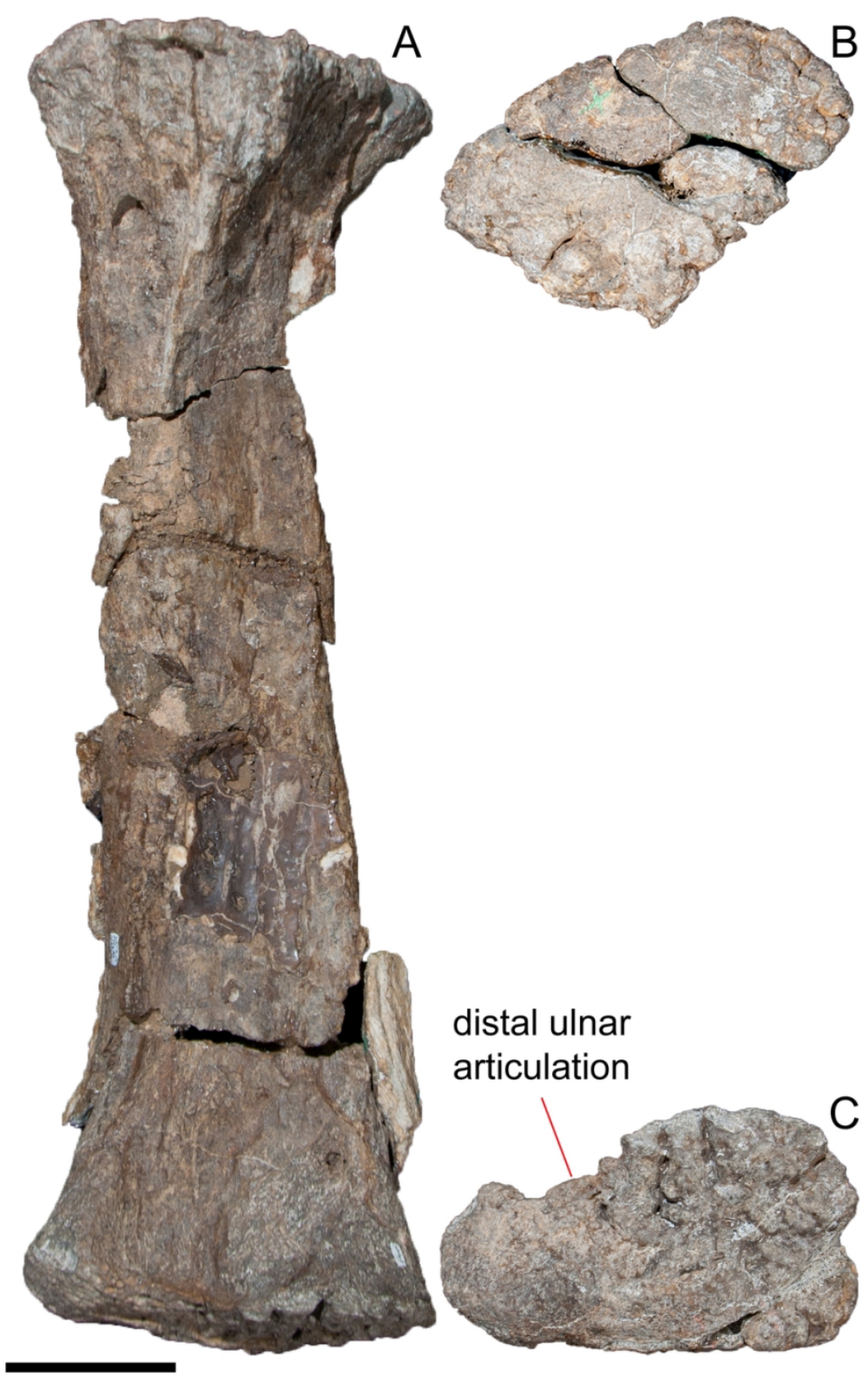

FIGURE 19. Savannasaurus elliottorum left radius in A, posterior, B, proximal and C, distal views. Scale bar equals $100 \mathrm{~mm}$.

$90 \times 140 \mathrm{~mm}(300 \times 300 \mathrm{DPI})$ 


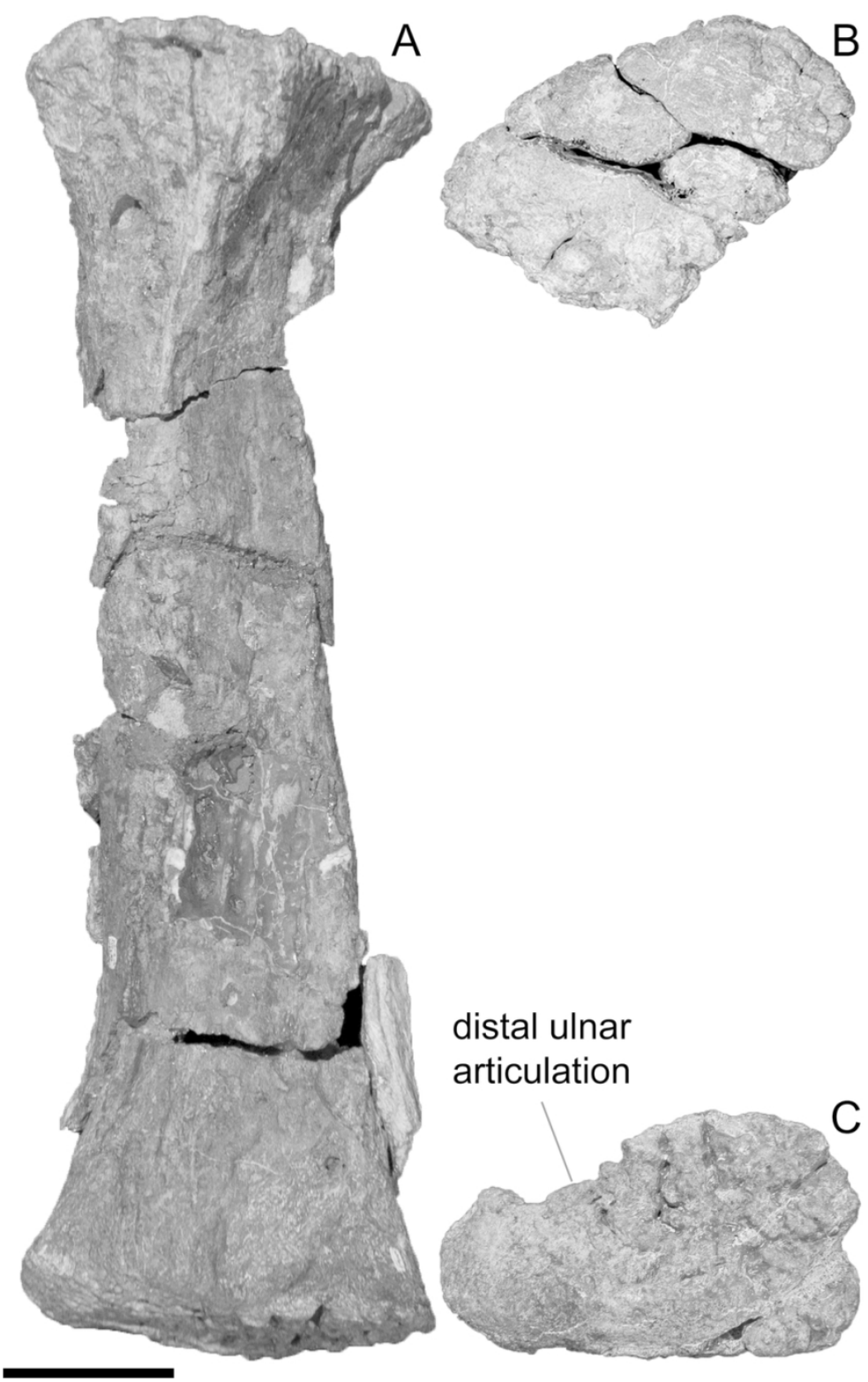

FIGURE 19. Savannasaurus elliottorum left radius in A, posterior, B, proximal and C, distal views. Scale bar equals $100 \mathrm{~mm}$.

$90 \times 140 \mathrm{~mm}(300 \times 300 \mathrm{DPI})$ 




FIGURE 20. Savannasaurus elliottorum manus. Articulated left metacarpals I-V in A, proximal and $\mathbf{B}$, distal views. Left metacarpal I in $\mathbf{C}$, anterior, $\mathbf{D}$, distal, $\mathbf{E}$, lateral, $\mathbf{F}$, proximal, $\mathbf{G}$, posterior, and $\mathbf{H}$, medial views. Left metacarpal II in $\mathbf{I}$, anterior, $\mathbf{J}$, distal, $\mathbf{K}$, lateral, $\mathbf{L}$, proximal, $\mathbf{M}$, posterior, and $\mathbf{N}$, medial views. Left metacarpal III in $\mathbf{O}$, anterior, $\mathbf{P}$, distal, $\mathbf{Q}$, lateral, $\mathbf{R}$, proximal, $\mathbf{S}$, posterior, and $\mathbf{T}$, medial views. Left metacarpal IV in $\mathbf{U}$, anterior, $\mathbf{V}$, distal, $\mathbf{W}$, lateral, $\mathbf{X}$, proximal, $\mathbf{Y}$, posterior, and $\mathbf{Z}$, medial views. Left metacarpal $\mathbf{V}$ in $\mathbf{A A}$, anterior, $\mathbf{A B}$, distal, $\mathbf{A C}$, lateral, $\mathbf{A D}$, proximal, $\mathbf{A E}$, posterior, and $\mathbf{A F}$, medial views. Right metacarpal IV in AG, anterior, $\mathbf{A H}$, medial, $\mathbf{A I}$, proximal, $\mathbf{A J}$, posterior, and $\mathbf{A K}$, lateral views. Left manual phalanx II-1 in AL, dorsal, AM, medial, AN, ventral, AO, distal, AP, lateral, and $\mathbf{A Q}$, proximal views. Scale bar equals $100 \mathrm{~mm}$.

$182 \times 167 \mathrm{~mm}(300 \times 300$ DPI) 


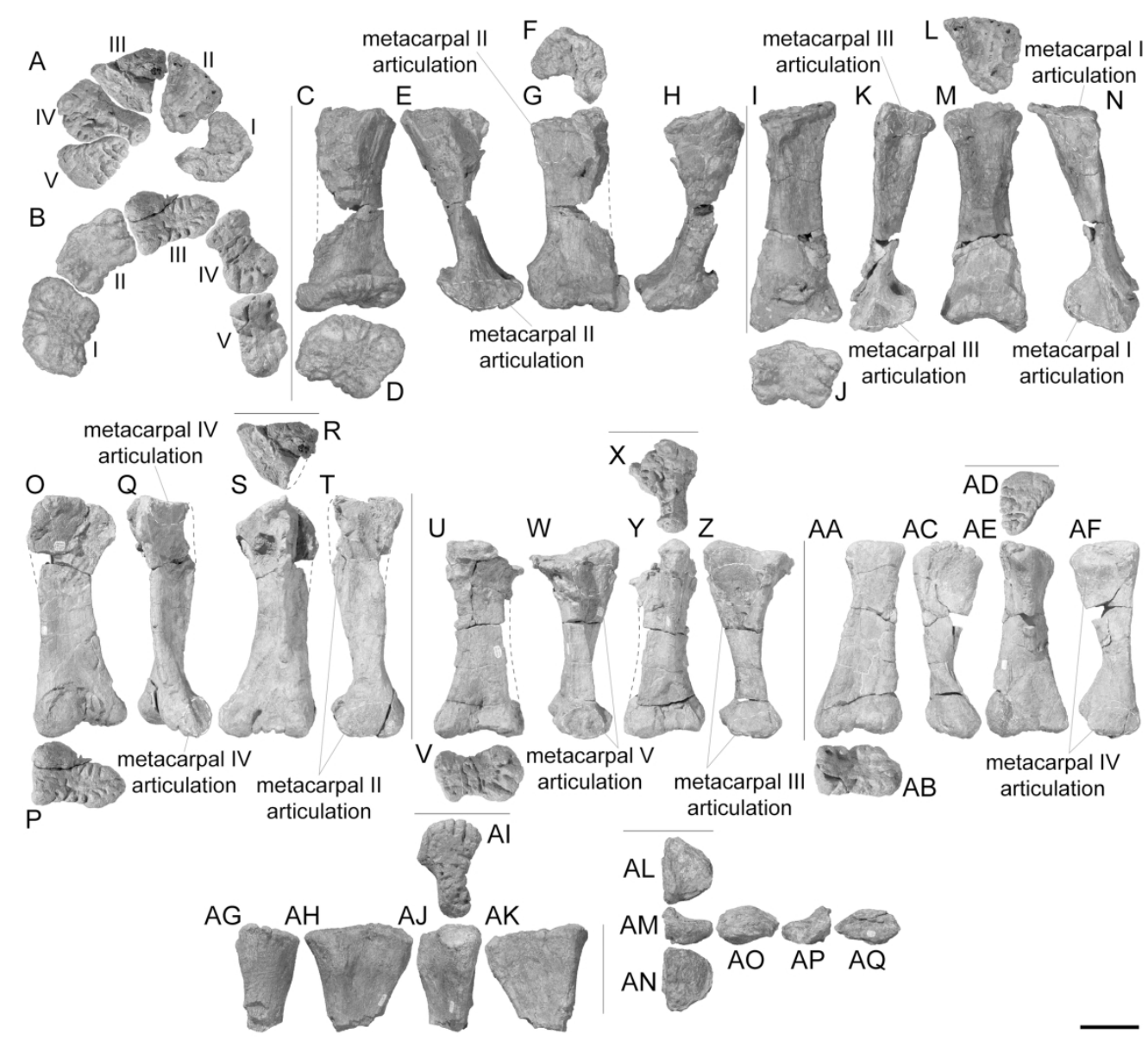

FIGURE 20. Savannasaurus elliottorum manus. Articulated left metacarpals I-V in A, proximal and $\mathbf{B}$, distal views. Left metacarpal I in $\mathbf{C}$, anterior, D, distal, E, lateral, $\mathbf{F}$, proximal, $\mathbf{G}$, posterior, and $\mathbf{H}$, medial views. Left metacarpal II in I, anterior, J, distal, $\mathbf{K}$, lateral, L, proximal, $\mathbf{M}$, posterior, and $\mathbf{N}$, medial views. Left metacarpal III in $\mathbf{O}$, anterior, $\mathbf{P}$, distal, $\mathbf{Q}$, lateral, $\mathbf{R}$, proximal, $\mathbf{S}$, posterior, and $\mathbf{T}$, medial views. Left metacarpal IV in $\mathbf{U}$, anterior, $\mathbf{V}$, distal, $\mathbf{W}$, lateral, $\mathbf{X}$, proximal, $\mathbf{Y}$, posterior, and $\mathbf{Z}$, medial views. Left metacarpal $\mathbf{V}$ in $\mathbf{A A}$, anterior, $\mathbf{A B}$, distal, AC, lateral, AD, proximal, $\mathbf{A E}$, posterior, and $\mathbf{A F}$, medial views. Right metacarpal IV in AG, anterior, AH, medial, AI, proximal, AJ, posterior, and AK, lateral views. Left manual phalanx II-1 in $\mathbf{A L}$, dorsal, $\mathbf{A M}$, medial, $\mathbf{A N}$, ventral, $\mathbf{A O}$, distal, $\mathbf{A P}$, lateral, and $\mathbf{A Q}$, proximal views. Scale bar equals $100 \mathrm{~mm}$.

$182 \times 167 \mathrm{~mm}(300 \times 300 \mathrm{DPI})$ 


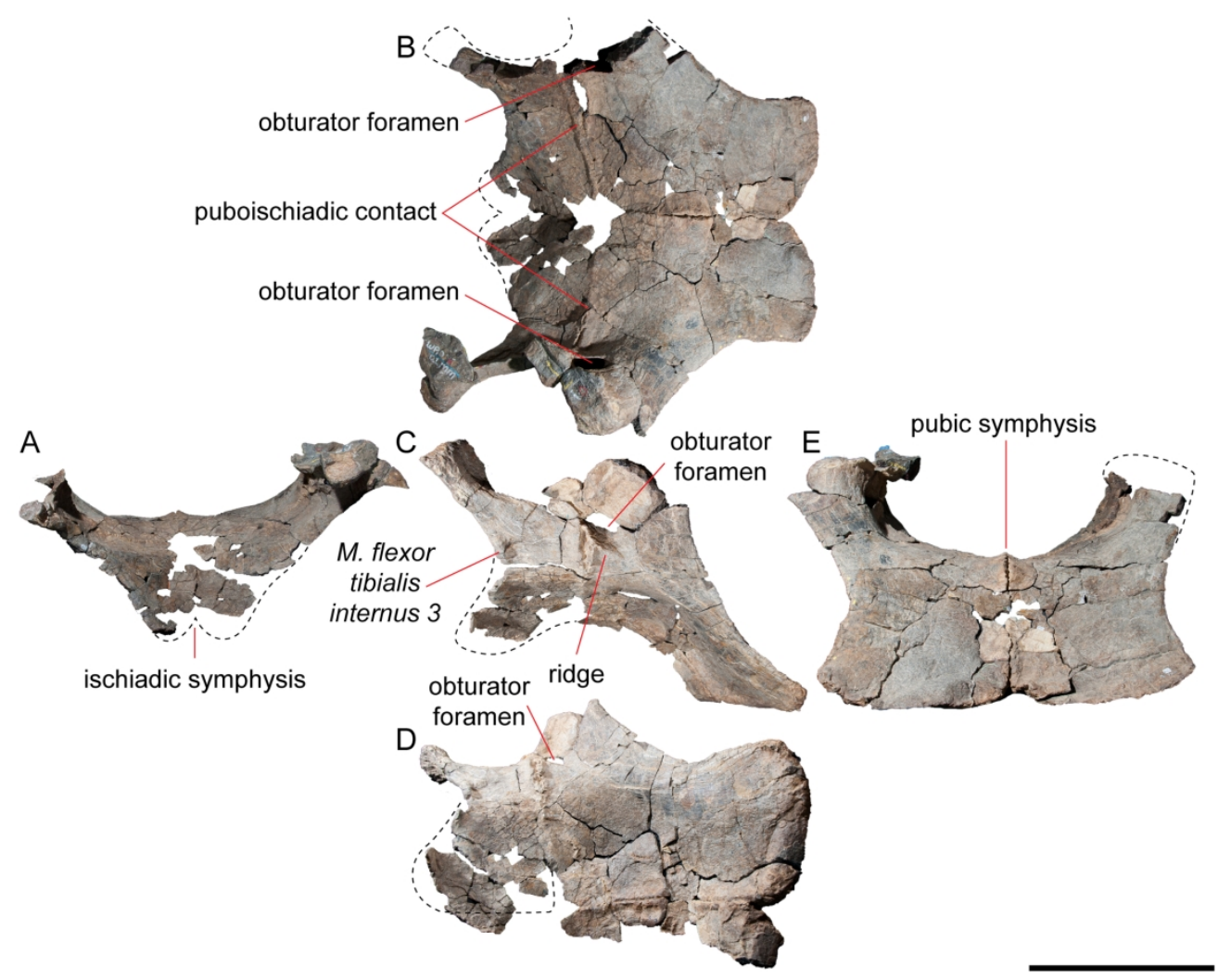

FIGURE 21. Savannasaurus elliottorum co-ossified left and right pubes and ischia in A, posterior, B, dorsal, C, right lateral, D, ventral (right pubis and ischium not included in this photograph), and E, anterior views. Scale bar equals $500 \mathrm{~mm}$.

$182 \times 145 \mathrm{~mm}(300 \times 300 \mathrm{DPI})$ 


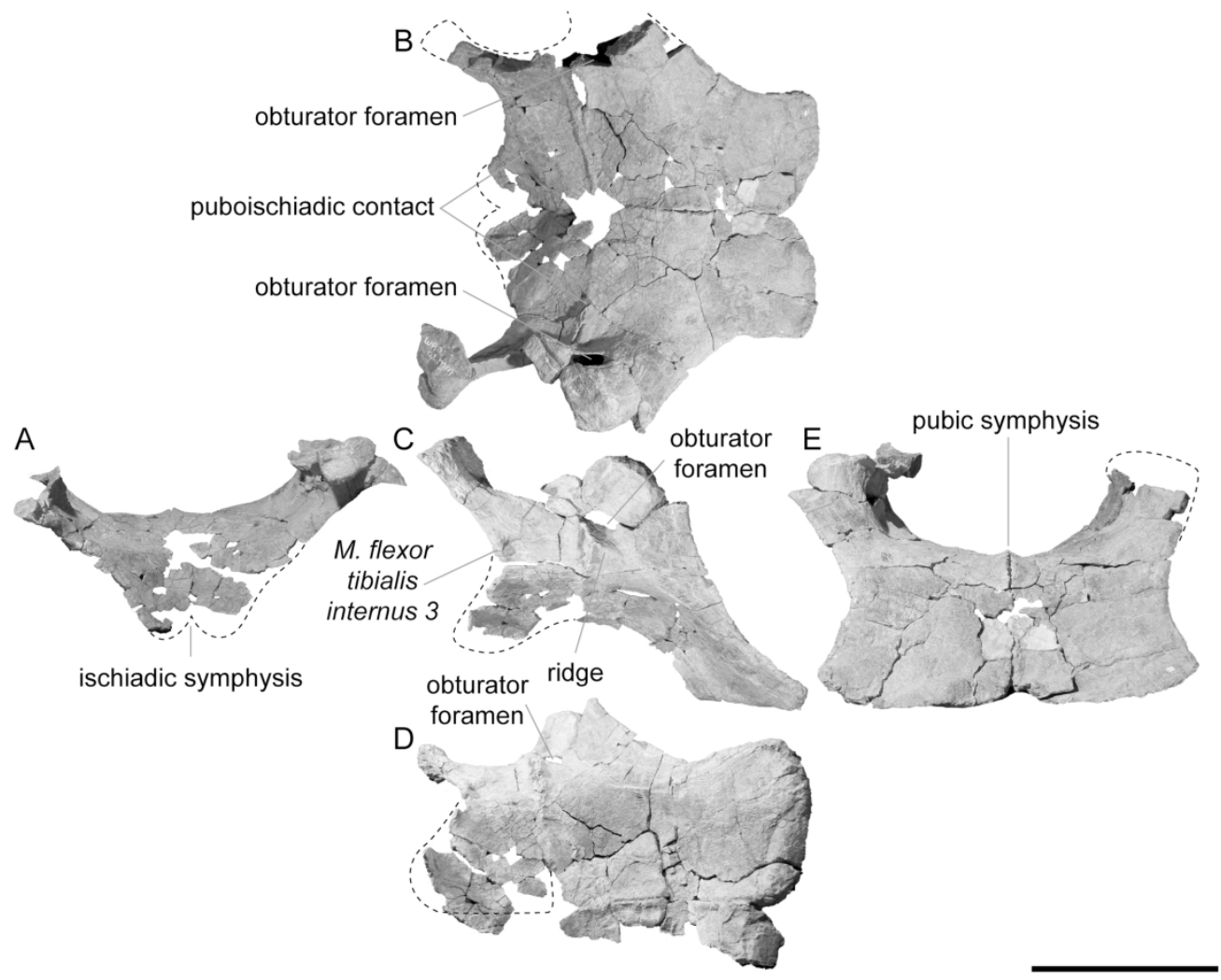

FIGURE 21. Savannasaurus elliottorum co-ossified left and right pubes and ischia in A, posterior, B, dorsal, C, right lateral, D, ventral (right pubis and ischium not included in this photograph), and $\mathbf{E}$, anterior views. Scale bar equals $500 \mathrm{~mm}$.

$182 \times 145 \mathrm{~mm}(300 \times 300 \mathrm{DPI})$ 

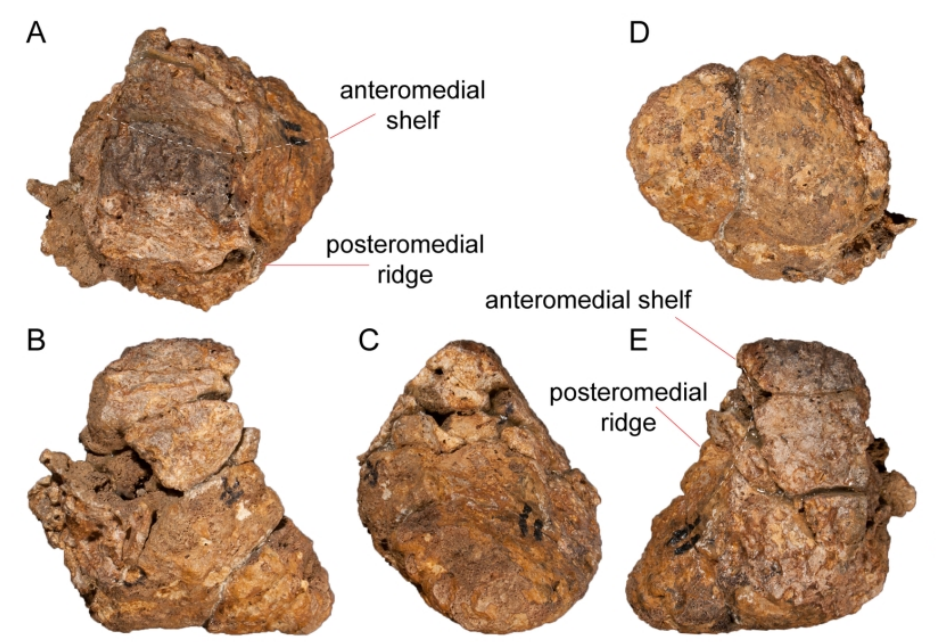

fibular articular facet
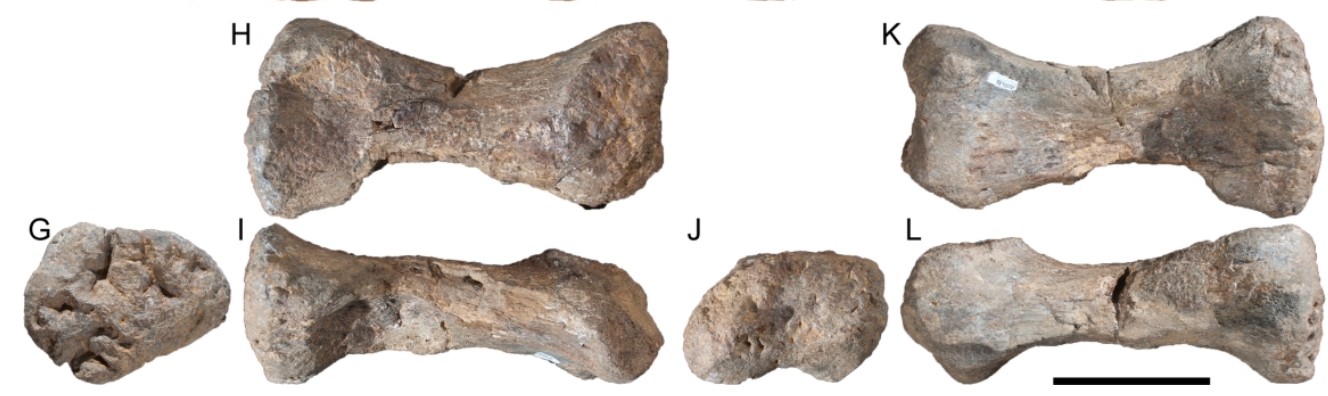

FIGURE 22. Savannasaurus elliottorum tarsus and metatarsus. Left astragalus in A, proximal, B, posterior, C, medial, D, distal, E, anterior, and F, lateral views. Right metatarsal III in G, proximal, H, dorsal, I, lateral, J, distal, K, ventral, and L, medial views. Scale bar equals $100 \mathrm{~mm}$.

$$
182 \times 141 \mathrm{~mm}(300 \times 300 \mathrm{DPI})
$$



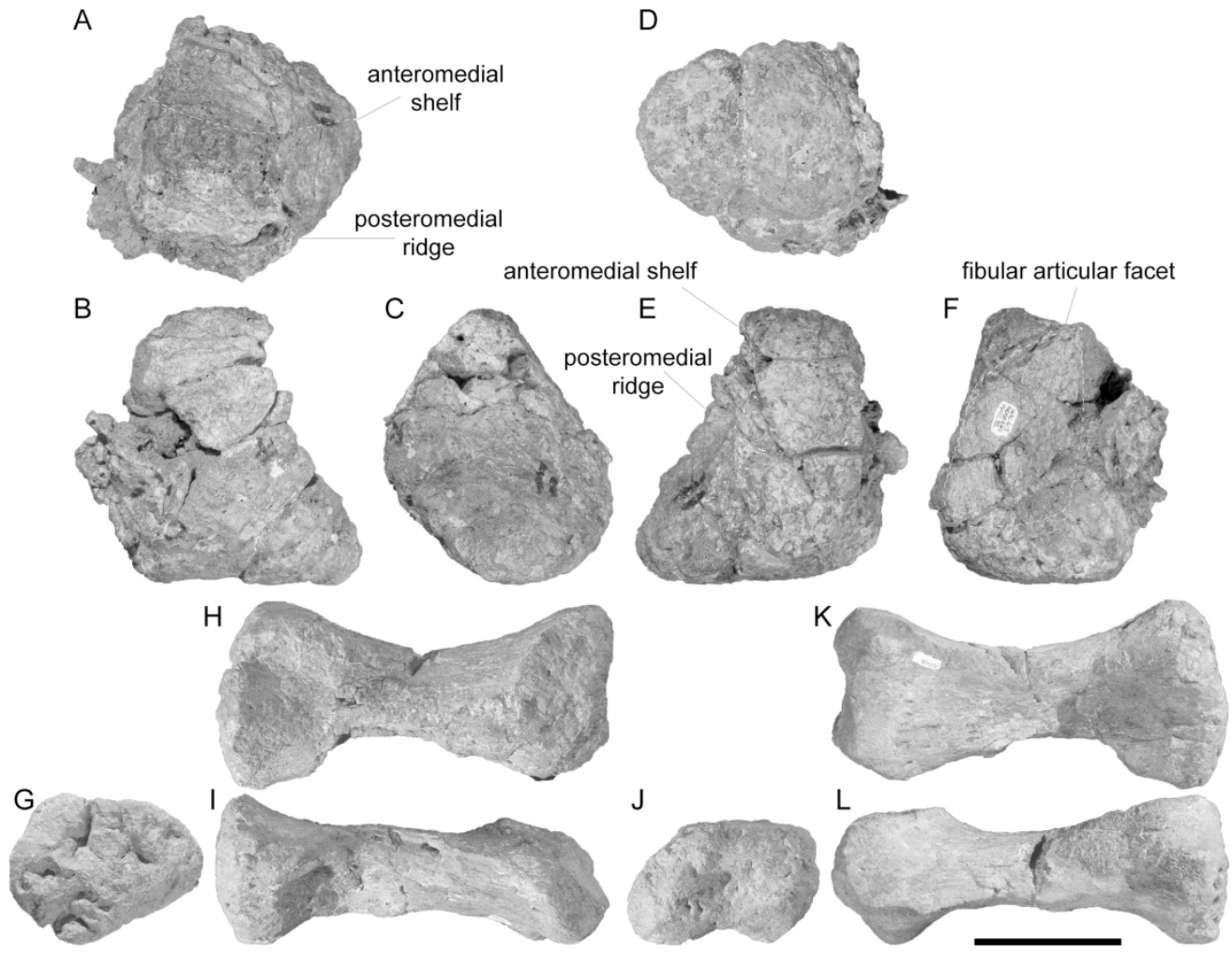

FIGURE 22. Savannasaurus elliottorum tarsus and metatarsus. Left astragalus in A, proximal, B, posterior, C, medial, D, distal, E, anterior, and $\mathbf{F}$, lateral views. Right metatarsal III in G, proximal, $\mathbf{H}$, dorsal, I, lateral, J, distal, $\mathbf{K}$, ventral, and $\mathbf{L}$, medial views. Scale bar equals $100 \mathrm{~mm}$.

$$
182 \times 141 \mathrm{~mm} \text { ( } 300 \times 300 \text { DPI) }
$$




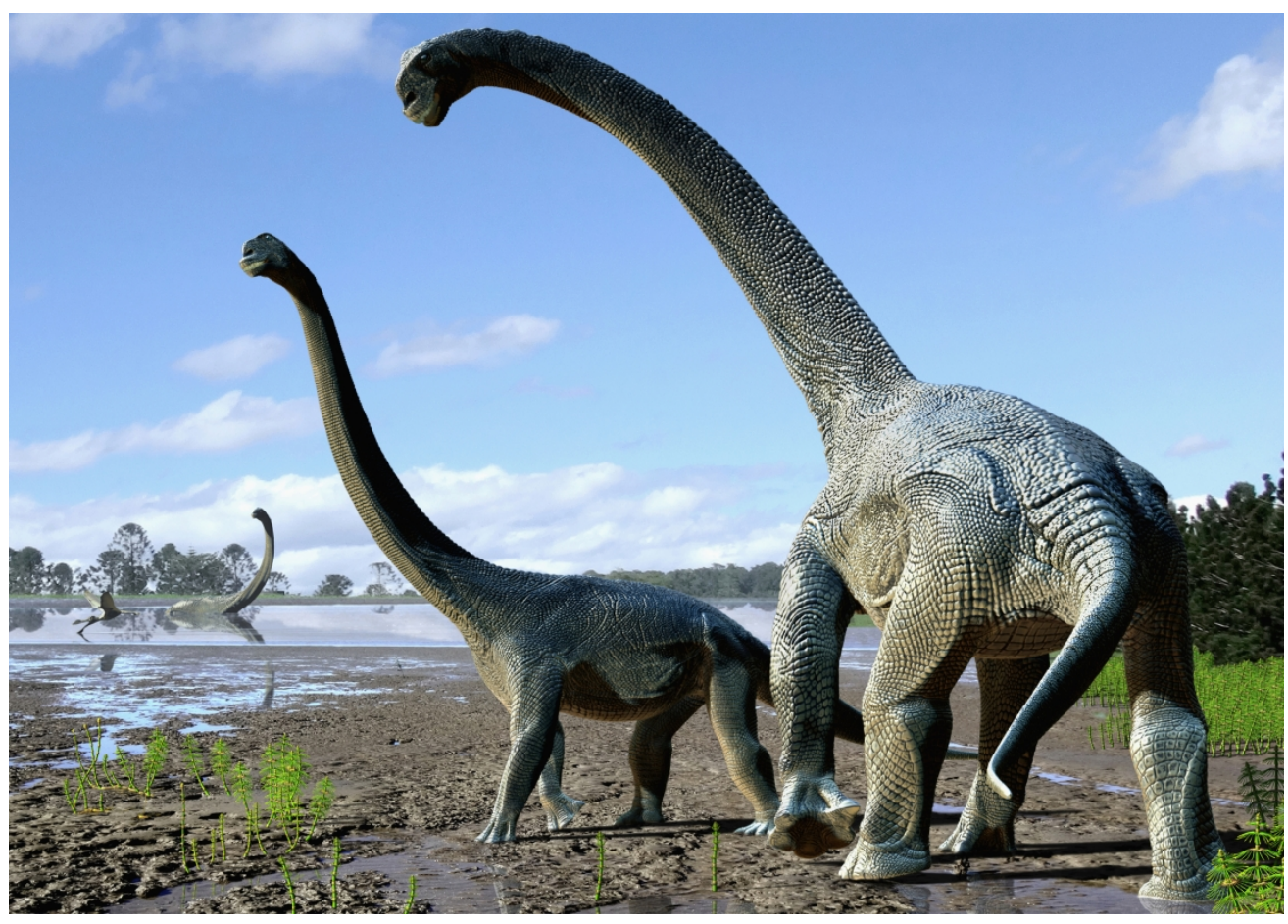

FIGURE 23. Savannasaurus elliottorum life restoration by Travis R. Tischler. $182 \times 129 \mathrm{~mm}(300 \times 300$ DPI $)$ 


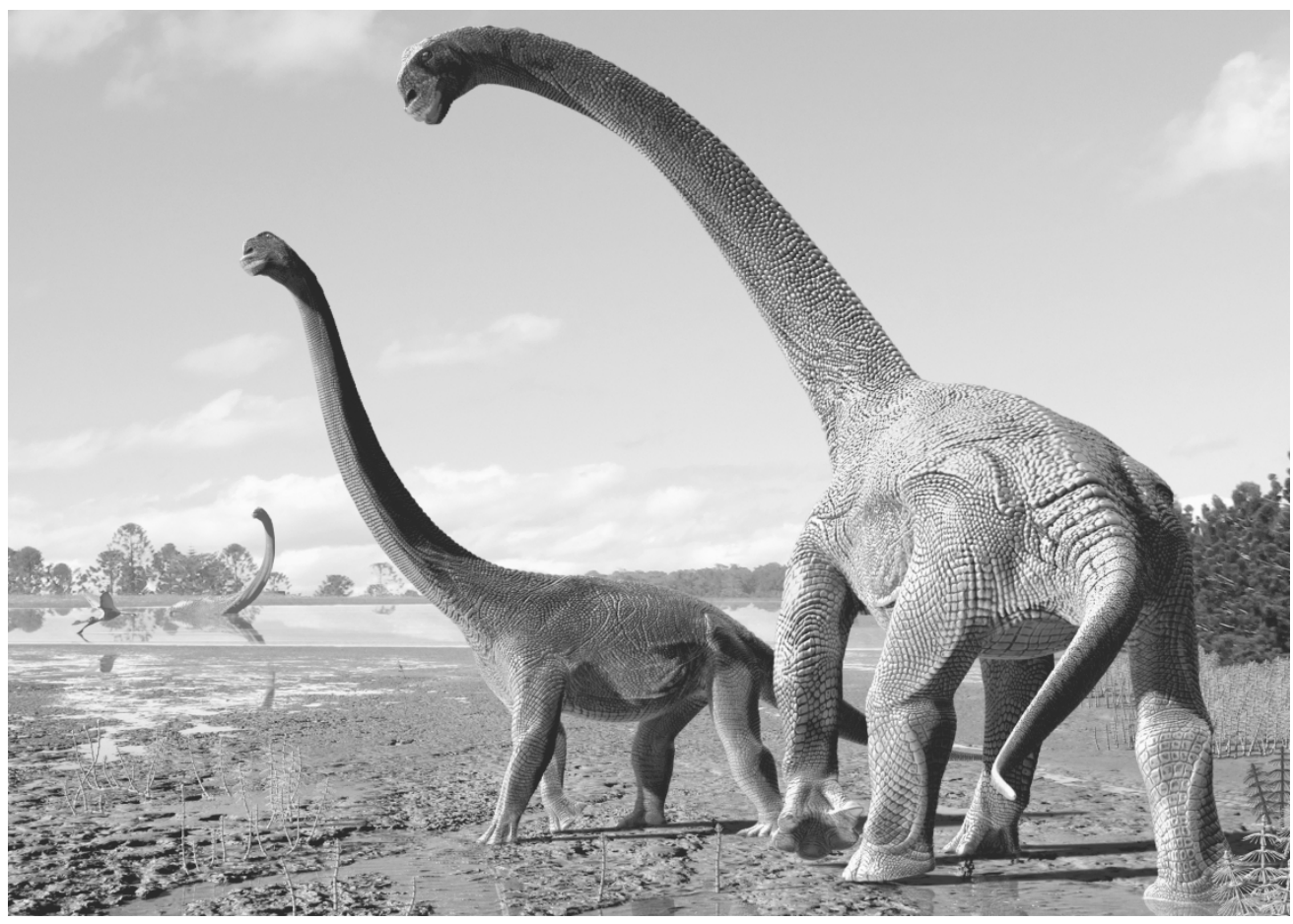

FIGURE 23. Savannasaurus elliottorum life restoration by Travis R. Tischler.

$182 \times 129 \mathrm{~mm}(300 \times 300 \mathrm{DPI})$ 